Cornell Law Library

Scholarship@Cornell Law: A Digital Repository

Cornell Law Faculty Publications

4-1-2008

\title{
Reflective Intensions: Two Foundational Decision- Points in Mathematics, Law, and Economics
}

Robert C. Hockett

Cornell_Law School, rch37@cornell.edu

Follow this and additional works at: http://scholarship.law.cornell.edu/lsrp_papers

Part of the Economics Commons, and the Law and Economics Commons

\section{Recommended Citation}

Hockett, Robert C., "Reflective Intensions: Two Foundational Decision-Points in Mathematics, Law, and Economics" (2008). Cornell Law Faculty Publications. Paper 112.

http://scholarship.law.cornell.edu/lsrp_papers/112

This Article is brought to you for free and open access by Scholarship@Cornell Law: A Digital Repository. It has been accepted for inclusion in Cornell Law Faculty Publications by an authorized administrator of Scholarship@Cornell Law: A Digital Repository. For more information, please contact jmp8@cornell.edu. 


\title{
REFLECTIVE INTENSIONS: TWO FOUNDATIONAL DECISION-POINTS IN MATHEMATICS, LAW, AND ECONOMICS*
}

\author{
Robert Hockett ${ }^{* *}$ \\ The essence of mathematics lies precisely in its freedom \\ -Georg Cantor ${ }^{1}$ \\ Only laws reach to infinity \\ -Ludwig Wittgenstein ${ }^{2}$
}

" Use of the word "intensions," with an "s," is intentional. By "reflective" I allude to selfreference, also known as "reflectivity." Intensions and reflectivity figure centrally in the arguments offered below, and are accordingly defined in due course.

** Associate Professor of Law, Cornell University Law School. This Article is the edited transcription of a talk given at the "Law and Event" conference held at the Benjamin N. Cardozo School of Law, Yeshiva University, in November 2007: Apologies, then, for the consequently conversational tone occasionally struck in what follows.

Many thanks to Matt Adler, Kaushik Basu, Brian Bix, Robin Boadway, Gerry Cohen, Marc Fleurbaey, Bob Frank, Douglas Kysar, Alistair McCleod, John Roemer, Richard Tuck, and Bradley Wendel for consistently helpful discussion of the second two of the three principal subjects of this Article. Counterpart thanks in connection with the other principal subject go to Matti Eklund and, from an earlier time, M. A. E. Dummett, Dan Isaacson, and the late Gordon Baker. Thanks to David Carlson, William Ewald, Saul Kripke, Graham Priest, and especially Talia Morag for illuminating discussion of all of the subjects here treated.

More particularized thanks go to the faculty and student organizers of, as well as participants in, the aforementioned conference, especially David Carlson, Carrie Maylor, Mary Cate Ryan, and of course Alain Badiou. The effort made by all at this remarkable gathering to understand one another notwithstanding their many stark disciplinary and idiomatic differences was profoundly affecting. I also cannot thank Timothy Yip enough for his simply superb editing of this piece in its printed form.

Finally, longstanding and loving thanks to Robert Coles, Daniela Cammack, David Grewal, Raymond Howze, Jan McKenna, Nina and Robert Irwin, Scott and Julie Von, Liz Cole, Lydia Tomitova, and Talia Morag-deep wells of enduring inspiration not only at conference time but also at many times before and since. Bless you, dear friends.

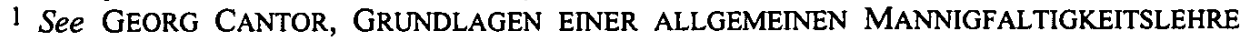
182 (1883), translated in JOSEPH WARRAN DAUBEN, GEORG CANTOR: HIS MATHEMATICS AND PHILSOPHY OF THE INFINITE 132 (1979). I feel vaguely as though I should apologize for employing this much over-used quote. It seems particularly apt here, however, in giving expression to what I shall be characterizing as the "extensionalist" point of view.

2 See LUDWIG WITTGENSTEIN, PHILOSOPHICAL REMARKS $\S 181$ (1975); see also LUDWIG WITTGENSTEIN, WITTGENSTEIN'S LECTURES, CAMBRIDGE 1930-1932, at 13 (1980) ("Infinity is the property of a law, not of its extension."). A fine articulation, this one, of what I'll be characterizing as the "intensionalist" point of view, in respect of which Wittgenstein was as characteristically thoroughgoing as was Cantor in respect of the extensionalist point of view. 


\section{Finding The Founding DeCisions}

\subsection{Extensional Choice, Intensional Criteria, and Reflectivity}

It is a distinct pleasure to have been invited to contribute to a symposium that not only features contributors from so broad an array of disciplinary backgrounds as we find represented here, but also is inspired by the work of a philosopher who takes as his point of departure the work of Paul Cohen, Kurt Gödel and, before them, Georg Cantor. It often has seemed to me that, commencing with the pioneering work of Fourier, Dirichlet, Riemann, and Weierstrass, then culminating in the monumental work of Cantor, Gödel, Cohen, and a few of their rough contemporaries-Dedekind, Frege, Russell, Skolem, Tarski, Wittgenstein, and Zermelo perhaps best known among themcertain foundational decision points that tend to recur across fields of theoretic endeavor are sharpened to a point of near optimal clarity. That is to say: to a point at which (a) their conceptual and, indeed, cognitive fundamentality itself, and thus (b) why they should tend to recur across disciplines, in but minimally varying guises, can be starkly appreciated.

In light of this mentioned impression, I also have found myself wondering at times why these same thinkers, along with their queries, should so often tend to be bracketed-off as obscure fare for mathematicians, logicians, and a comparatively small number of philosophers alone. ${ }^{3}$ For it actually amounts to a missed opportunity, I shall argue, to treat these thinkers and thoughts more as curios than as precedents. Perhaps with this conference, then, we might contribute to a broader a departure from this form of bracketing, as well as more general tendencies glibly to marginalize. That would amount to a change which might even be analogized to the one Mr. Badiou himself appears to have initiated in some precincts where mathematical and logical developments seem for much of the past hundred years or so not to have figured with prominence.

Now I am of course merely one of a good many people who have been invited here today. And I have been invited as a legal academic with some modest background and continuing interest in mathematical logic and set theory. So what I would like to do here is limit myself to discussion of two of the "foundational decision points" to which I referred just a moment ago. And in particular, I'd like to treat of what seems to me their place in two cognate disciplines that lie close to the heart of modern law and legal scholarship.

3 Of course this characterization is not true of the less mathematically oriented work of Russell or Wittgenstein. But it seems to be true of those portions of their work-viz. the portions concerned with mathematical foundations - that most directly treat of the matters which I shall be talking about here. 
I shall identify the decision points as those concerning what I call "intensional," or "criterial" choice (as distinguished from "random," "arbitrary," or "extensional" selection) in the one case, and "selfreference" (also known as "reflectivity," "reflexivity," and some forms of "recursion") in the other. Both of these junctures or "crossroads," we'll see, lie at the heart of our efforts to make sense of - or find sense in-(a) our manifest cognitive, hence normative freedom, (b) our equally manifest normative, hence cognitive boundedness, and thus ultimately (c) in an important sense, our very selves, which seem ineluctably to be both blessed and cursed with a capacity and indeed penchant for self-examination. (The reason for "hence" here will emerge below.) The two fields in which I shall consider the more freedom-appreciative and boundedness-appreciative options apparently available at these junctures, in turn, are those I shall label, following convention, (a) "general" (or "theoretical") jurisprudence on the one hand, and (b) "welfare" (or "social-choice-theoretic") economics on the other.

Limiting myself in this way, I shall hope, might render me less out of place-or at any rate less out of school-than I might otherwise have been. And, I'll hope further, it might even enable me to contribute a half helpful thought or two to normative legal theory none too broadly construed. For there are, as it seems to me, important aspects of two venerable and seemingly interminable disputes in general jurisprudence and welfare economic theory that are illumined from a helpful new angle, when we call attention to some of their deep-rooted affinities to the theoretical options that Cantor and his interlocutors long ago sharpened not only for mathematicians, but, as I'll argue, for all of us.

\section{2 ... In Foundational Mathematics}

Here, then, is how I'll proceed: In Part 2 I shall lay the critical mathematical groundwork for my subsequent, more properly legaltheoretic discussion. I'll do so by attempting historically and philosophically both to situate and to characterize the two decision points that seem to me to have been so well sharpened and forthrightly confronted in Cantor's foundational work. First I'll describe what brought Cantor to these junctures. Then I'll describe (a) what he decided to do when he got there, and (b) what considerations appear to have informed and then prompted his choices.

I shall also endeavor to throw Cantor's decisions into relief in this Part. I'll do so by discussing how other influential figures working in the since-named subfield of mathematical "foundations" have addressed the same questions. Particularly prominent here will be Wittgenstein, 
whose elaboration of what at first blush seems the counter-Cantorian view strikes me as that which, characteristically of its author, is the most thorough-going and fully thought-through. ${ }^{4}$

A brief word of warning here: Because (a) the material in this Part is apt to be less familiar to non-specialists, and because (b) some of it is not always easy to explicate pithily without a good bit of technical apparatus, and finally because (c) the discussion here is foundational to subsequent discussion, the story in Part 2 is a bit longer than that of the subsequent Parts. I hope then that you will indulge or forgive me on this score. Alternatively, particularly if the material here already is familiar to you, I hope you will feel at liberty to skim over such of it as you prefer not to tarry with.

Perhaps this will aid you in deciding whether to skim or to tarry: What emerges from Part 2 is that each of the two decision points seems at least initially to carry a "menu" of choice options that vary between polar extremes. In the case of the criterial choice juncture, the two extrema are those of putatively unfettered-"arbitrary"-selection on the one hand, principle- or rule-generated-"lawlike"-selection on the other, in conceiving and characterizing classes hence sequences, numbers, and indeed functions. ${ }^{5}$ This divide can accordingly be usefully described as that between an "intensional" (or "intelligibilist") construal of classes, sequences, numbers, and functions on the one hand, and an "extensional" (or "combinatorial") such construal on the other. This rubric proves helpful in drawing out what's at stake here. For it ties the essential divide quite explicitly to some of the most venerable debates over how best to describe and account for certain forms of rationation, cognition, and linguistic behavior themselves. In effect, the concern is with meaning-with sense-and with what sorts or degrees of cognitive freedom, indefiniteness, or "infinitude," are compatible with what sorts or degrees of intelligibility, definiteness, or "finitude."6

The upshot in this case turns out to be that the Wittgensteinian

4 I say "at first blush" here because, as we'll see, I ultimately find what seem to me to be several striking-and ultimately helpful-parallels in Cantor's particular rendition of extensionalism and Wittgenstein's rendition of intensionalism. More on that infra.

5 I say "hence" these other items because, on the extensionalist understanding of these objects that has since come to dominate, all of them are treated as classes of one sort or other. But more on this presently.

6 Please note the shared root-"fin"- at the outset, the same "fin" that figures into such words as "finish." This is no accident, nor is it mere punning. The inquiry is ultimately about the relations between, and the implications for cognizability of, finitude, infinitude, definiteness, and indefiniteness. We seem to have a sense of unboundedness, of infinite or indefinite iterability and extensibility. Yet it also seems that meaningfulness and cognizability involve or require or presuppose boundedness-completedness-of some sort, as reflection upon such words as "definition" itself brings immediately to light. At its most general, our inquiry throughout this Article will be concerned with this puzzle. 
intensionalist and Cantorian extensionalist positions are in a sense reconcilable "at the limit," as it were, of our rationative capacities, albeit in what I shall call a quite "thin" sense. This proves less recondite a matter than might first appear: For as I shall indicate, there are close analogues to this thin form of intensionalism in the other two disciplines l'll be discussing. And these serve as bases for reconciling some hitherto seemingly irreconcilable positions in those disciplines just as surely as the thin intensionalism that I draw out in Part 2 serves (thinly) to reconcile the Cantorian and Wittgensteinian positions.

The key to this broad reconciliation that I try to work in Part 2, I shall emphasize, is to notice that Cantor himself is intensionalist in respect of defining his domains of quantification, per what has come to be called his "Domain Principle;" while Wittgenstein for his part was effectively extensionalist in his truth-functional account of the logical operations in terms of which he first developed his algorithmic (i.e., intensionalist) account of number and arithmetic. There turns out to be a trade-off, I'll argue, between the intensional and the extensional positions in one's logic and one's mathematics. That is to say that the price, on pain of debilitating antinomy and indeterminacy, of a more extensional mathematics is a more intensional logic, and vice versa. ${ }^{7}$ But, crucially, this is a truth we appreciate fully only upon carefully confronting the second Cantorian decision point-that concerning selfreference. And that fact-the fact that the two points are best viewed together-proves helpful in other foundational disciplines in which they are implicated, including foundational law and welfare economics as we'll see.

The second decision point in respect of which Cantor and his successors had to stake out positions, as just noted, is that concerning the phenomenon of self-reference (also called "reflectivity," "reflexivity," and sundry forms of what is nowadays called "selfapplication" or "recursion"). Here the question is what role to permit reflectivity, in view of (a) its immediate implication by some seemingly plausible positions taken at the first-criterial choice-decision point on the one hand, ${ }^{8}$ and (b) the paradoxes and indeterminacies to which

7 Note that for "indeterminacy" I could have employed "anomie." ("Antinomy" of course connotes law-violation, "anomie" lawlessness.) I use "indeterminacy" simply because it is more customary in the present context. Please bear in mind in what follows, however, that the link between law-"nomos"- and determinacy, determinedness, or definiteness is no accident, any more than is that between lawlessness, unboundedness, indeterminacy, indefiniteness, infinitude, and so forth. This theme, like the related theme of meaning's and cognizability's relations to law, determinedness and boundedness mentioned above, will never be far from the surface of our discussion.

8 Complete freedom/arbitrariness in the defining or constructing of properties or classes, for example, immediately opens the prospect of self-ascriptive properties or self-membered classesformal analogues to reflexive self-consciousness itself. 
free reflectivity quickly gives rise on the other hand. ${ }^{9}$ Once again here, as in the case of criterial choice, we find a menu of options that can instructively be viewed as occupying a continuum between poles.

At one end of the continuum are those who seek to head-off the apparent pathologies to which self-reference can give rise simply by fiat. That is to say, by simply proscribing self-reference-or such variations upon it as what Poincaré and Russell would have called "impredicativity"-altogether. The strategy typically is to do so through "grounding" or stratification or "limitation of size" axioms of a more or less arbitrary, ad hoc disposition. (The strategy is in that sense itself strikingly arbitrary/extensionalist in spirit in most cases.)

At the other end of the continuum are those who face up to selfreference by recognizing, tagging, and accommodating it in some such manner as can render its seemingly more problematical consequences at least tractable and, ultimately, instructive or even illuminating. In such case, the strategy is generally to reexamine the foundations of something perceivedly more fundamental-one's logic-instead of one's set-theory. One then concludes that a correct logic must (a) allow for truth-value "gaps" and hence semantic indeterminacy in some meaningful formulae; (b) allow for truth-value "gluts" and hence "paraconsistency" in some meaningful formulae; (c) allow for "third" or yet more semantic values' being assigned to some meaningful formulae; (d) systematically deny tertium non datur, i.e., the "rule" that for every meaningful formula, either it or its negation is correctly assertible; or (e) in some cognate manner afford principled, independently plausible means of simultaneously tracing and quarantining the potentially most cognitively jamming consequences of reflexivity.

Means of the latter sort are not generally accounted or experienced as "costs" by proponents, but rather as quite independently attractive. For in effect they just re-intensionalize certain logical operators-in most cases negation or implication or both - that for decades were quite simply taken for granted as extensional, under the rubric of "truthfunctionality," notwithstanding the apparently intensional nature of those mental or speech acts - e.g., denial, inference, or conclusion-that they purported to model. The logic-reformers accordingly view their reforms as well warranted even apart from the matter of self-reference, and then view the reforms' taming of self-referential paradox as no more than an unsurprising side benefit. (They take the paradoxes, accordingly, to be simply the most dramatic "symptoms" or indicators that purely extensional logic is wrong-headed au fond.)

As with the discussion of criterial versus arbitrary choice, so here in the case of self-reference the point is not to be recherché or

9 For example, the Epimenides (a.k.a. "the Liar"), the Truth-Teller, the Russell class, the Burali-Forti "largest ordinal," and others. See infra Part 2.5. 
gratuitously recondite. It is, first, to draw out the fact that a reconciliation between apparently counterpoised positions in foundational mathematics, each again most thoroughly thought-through and exposited in the work of Cantor and Wittgenstein, can be worked by attending to both of the decision points simultaneously. By attending carefully to what the anomies and antinomies generated by intuitively intelligible and unobjectionable self-reference-the second decision point - seem to show us about ourselves and the nature of cognition, we arrive at what seems the most plausible settlement of the intensionalist versus extensionalist divide in respect of decision and choice-the first decision point. And precisely this strategy of attending to both the decision points at once is what I believe now can assist us in settling quite cognate disputes that bedevil foundational law and foundational economics. ${ }^{10}$

\section{3 . . . In Foundational Law}

In Part 3 I turn to what strike me as more or less straightforward analogues to our Part 2 Cantorian decision points in general jurisprudence. The most salient criterial choice divide here, unsurprisingly, is that between so-called "natural law"-what I'll call "naturalist"- understandings of law's salient features on the one hand, and "positivist" such understandings on the other. I say "unsurprisingly" in this case because I suspect that most legal academics, and many lawyers more generally who might be at least passingly familiar with this venerable divide, will quickly spot at least surface analogies between that divide on the one hand, the intensionalist versus extensionalist divide in respect of classes, functions and other mathematical objects on the other.

What I hope to show here, however, is that the mentioned analogy is both (a) philosophically deep, not merely topical; and (b) historically speaking, no accident. For it turns out that the earliest exponents of naturalist and positivist positions in respect of law also were exponents, respectively, of intensionalist and extensionalist positions in respect of what pre-Fregean logicians called "universals." (Universals, also known to the Medievals as "comprehensios," along with what the same scholars called their "suppositios," were the abstract antecedents of what today we call concepts and classes, or intensions and extensions respectively. ${ }^{11}$ )

10 That is precisely why 1 said in my opening sentences that Cantor and his interlocutors effectively sharpen what is ultumately at stake in a number of theoretical disciplines, not merely mathematics, to a point of "near optimal clarity."

11 See William Kneale \& Mary Kneale, The Development of Logic 308, 61 1, passim 
I do not think it an accident that those so-called "nominalists" who sought to reduce universals-concepts, intensions - to the objects of which they were predicable-their extensions-were the same who took voluntarist and then positivist positions in respect first of God's, then of the sovereign's, will. Nor does it seem to be accidental that their universalist opponents held that extensions, God's will, and sovereign law could only be recognized ("re-cognized") as such under conceptually and then ethically intelligible, intensional descriptions accessible to practical reason, hence took naturalist positions in respect of law and theology. Those who demand, and insist they can find, sense or intelligibility seem to do so in multiple precincts. And those who purport to find arbitrariness sensible or acceptable likewise appear to accept it in multiple venues.

I said I anticipate that many will see obvious analogies between intensionalist and extensionalist understandings of mathematical objects on the one hand, naturalist and positivist understandings of legal phenomena on the other-hence that the first Cantorian decision point makes a showing in both disciplines. What I think might be less obvious is that legal naturalists and positivists also appear in effect to commit themselves to positions in respect of the second Cantorian decision point - the self-reference divide. And just as we find in foundational mathematics over the course of Part 2, drawing out and investigating this less obvious point in foundational law through Part 3 ends up positioning us better to understand two things: First, why the seemingly stalemated, oft-declared "moribund" debate between naturalists and positivists nevertheless continues; and relatedly second, that this dispute amounts, in a sense, to a perennial "tragedy" apt to afflict any more or less "liberal" or "pluralist" polity. ${ }^{12}$ This tragedy indeed can instructively be viewed as a rough counterpart, I argue, to the anomies and antinomies that self-reference occasions in foundational mathematics, as well as to counterpart anomies and antinomies in foundational economics that I shall discuss in Part $4 . .^{13}$ And so consideration of the means by which such pathologies can be and have been addressed in the former discipline, I argue, proves helpful in this one as well.

(1962).

12 I am accordingly of course using "tragedy" in its classical- damned either way-sense, not the more trivialized contemporary sense yielding synonymy with "undesired event." (Would that more would use "calamity" or suchlike for the latter, and reserve "tragedy" for the former.)

13 Indeed, as we'll see in Part 4, there are some straightforward parallels between many wellknown and even lesser known paradoxes and impossibility results in foundational economics on the one hand, and the Russell paradox, Gödel's self-reference-involving "incompleteness results," and cognate puzzles in foundational mathematics discussed in Part 2 on the other. In this connection, I shall suggest, it would not seem to be without significance that the originator of the best known impossibility result in foundational economics, Kenneth Arrow, was a student of Gödel's great logician colleague, Alfred Tarski. But more of this below. 
The naturalists, I believe-for the most part unconsciously, but on reflection quite understandably - wish to be able to interpret the law not only as intelligible in respect of its propositional/cognitive content, but, also and relatedly, in respect of what we might call its "pragmatic" content-i.e., as giving expression to ethically intelligible collective intentions that can readily be experienced or interpreted as both (a) emergent from practical reasoning, and relatedly (b) linked in some way to what we might call the legal documents' prescriptive intensions (their full "meanings," the so-called "spirit" of the laws). ${ }^{14}$ This insistence

14 Hence, incidentally, the rise of Scalian style dictionary jurisprudence, where word meanings are offered as stand-ins or substitutes for receded intentions or "spirits," in jurisdictions where positivist understandings of law become influential. (I hasten to add here once more, in order to head off any possible confusion, that intentions, as I have mentioned and shall take further pains to explain, are not to be confused with intensions. But there also are clear linkages. More on this below. A helpful discussion of the links and distinctions, by the way, is JOHN SEARLE, INTENTIONALITY 22-26, 180-96 (1983).)

I place the word "pragmatic" here in scare-quotes because I am alluding to the distinction commonly drawn by many theoretical linguists between linguistic "semantics"-i.e., cognitive content, or "meaning" - on the one hand, and linguistic "pragmatics"-i.e., performative matters - on the other. This distinction is, not surprisingly, controversial, and has come to be increasingly debated in recent years within linguistics itself. See, e.g., the collection of entries in HANDBOOK OF PRAgMATICS 405-741 (Laurence R. Horn \& Gregory Ward eds., 2006). Intriguingly, the movement pursuant to which modern semantics came to be abstracted from pragmatics in the early-to-mid twentieth century took its cue from those, such as Frege, Russell, and the early Wittgenstein as mentioned above, who first extensionalized logic in the hope of constructing what came to be called an "ideal," or "logically perfect," language. The movement was accordingly associated with yet another movement that viewed Frege, Russell, and the early Wittgenstein as progenitors--viz., the so-called "logical [ready?...] positivists" of the early to mid twentieth century. The separation of semantics from pragmatics also corresponds to a tendency, characteristic of the "modern" era in philosophy, to privilege so-called "pure, theoretical" over so-called "mere practical" reason. And it is no accident that logical positivist philosophers and those inspired by them have tended to construe ethical language as lacking in cognitive content, amounting to little more than ejaculative expressions of "subjective" approval or disapproval. Against that backdrop, it is not surprising that the revival of interest in and careful attention paid practical reason discernible in philosophy since later in the twentieth century appears to have been inaugurated by philosophers, many of them inspired in significant part by the "later" Wittgenstein, who were critical of logical positivism and the notion of a radical semantics/pragmatics distinction in theoretical linguistics. (A hint as to why this would be the geneology is immediate upon recalling the later Wittgenstein's association with the slogan, "if you want to know the meaning, look to the use.") The turning point here would seem to be INTENTION, by the later Wittgenstein's student Elizabeth Anscombe, and SPEECH ACTS, by John Searle, probably the most distinguished student of that other mid-twentieth century philosopher who was attentive to "ordinary language," J. L. Austin. But more of this below.

There is a very clear link here, by the way, to the manner in which I have said we shall find the paradoxes of self-reference in foundational mathematics and set theory to be best managed. For recall that, as I noted above and shall elaborate further in Part 2, the best means available are means that "reintensionalize" certain of the logical operators. That is no more and no less than both (a) to repudiate the extensionalist truth-functionality of those operators worked by Frege, Russell, and the early Wittgenstein; and (b) to do so by rendering those operators more accountable to the actual linguistic practices-i.e., the "pragmatics" - of assertion, denial, and inference themselves. In effect, we are regrounding theoretical reason in practical reason, reversing the praxis-indifferent process of cognitive "purification" or "idealization" that selfreference-rooted anomie and antinomy appear to have brought acropper. But again, more of this 
upon intelligible intention accessible to practical reason hence prescriptive intension-either or both on the part of God and of the law-runs consistently through naturalist theorizing, from Plato, Aristotle, the Stoics, and Cicero, through Aquinas, Suarez and Grotius, on down to such latterday naturalists as Finnis and George. ${ }^{15}$ But intentions, as I'll take pains to draw out, whether individual or collective, always bear an essential self-referential component: the intention is always to act, among other things, upon the intention itself. And this second decision point matter turns out to be something that we can exploit in endeavoring to find common ground at the first decision point, just as we find in Part 2 with respect to Cantorian and Wittgensteinian positions. For we find in intentional self-reference both the kernels of truth in, and the limits of, both the naturalist and positivist positions.

As compared to the naturalists, the positivists for their part, also unconsciously and quite understandably, tend to downplay the role of the law as a body of full-blooded ("thick") intensions grounded in collective intentions. And there is of course very good ethical-indeed, naturalist - reason to do so. At least that is so in a latterday, culturally pluralist, liberal polity wherein law's task in part is to settle or "split differences" between unavoidably differing and even conflicting intentions that are ultimately rooted in differing views of the good toward which actions are directed. Laws in such polities therefore cannot themselves generally embody intelligibly content-wise singular, collectively willed intentions - at any rate not "thick" ones. They must accordingly, if they are to be characterized intensionally, be characterized pursuant to a form of "thin" intensionalism. And so as in Part 2, so here these words "thick" and "thin" hint at the situs where reconciliation is best sought.

The insistence upon law as an arbitration (the word's etymology is suggestive) or "settlement" of potentially or actually conflicting intentions, we'll see, runs consistently through much of theological voluntarist and then legal positivist writing. This is so from Plato's Thrasymachus and the Sophists on down through Ockham and Scotus, then effectively from Hobbes ${ }^{16}$ through such latterday positivists as Austin and Bentham, Kelsen, Hart, and Raz-just as the anti-arbitral view, as I noted, can be seen running through millennia of naturalist

below.

15 In connection with the observations just made in the previous footnote, it is not surprising that among these personages, several-in particular, Aristotle, Aquinas, and Finnis-ground their naturalist accounts of ethics and law in robust and sophisticated accounts of practical reason. More on this below in Part 3.

16 Hobbes appears to have held certain convictions of a more naturalist persuasion, but thought nature itself so brutal as to require the rule of an unquestioned autocrat. That is positivist enough to count as positivist for present purposes. More on this infra Part 3. 
writing. ${ }^{17}$ The voluntarists and positivists, it seems, just are more attentive than naturalists to the degree to which arbitrariness sometimes can and even must figure into decision-making, and in consequence can necessitate some coercive arbitration and singular rather than collective, intention - be it that of the Deity or the sovereign.

Nevertheless, I shall argue, the disagreement view to which I allude must itself still accommodate at least certain "thin" collective intentions-at the very least one such "meta-intention," which is quite naturalist/intensionalist in spirit. This intention finds modern expression in that somewhat diffuse ideal known variously as "constitutionalism," "rights-constrained democracy," and "the rule of law"-an ideal which all citizens of a polity are presumed to share. And it is, not surprisingly I'll argue, an ideal to which our best known "middling" or "third way" naturalists-cum-positivists, Dworkin and Habermas perhaps best known among them, appear increasingly to have appealed in their writings.

This "thinned" collective "meta-intention" to constitute a lawgoverned polity, I'll argue, constitutes a rough jurisprudential analogue to Part 2's "thinned" Cantorian intension expressed in the "Domain Principle"-the very intension we find to be the situs at which Wittgensteinian and Cantorian positions in respect of foundational mathematics are appreciably reconciled. For it amounts, in the end, to a fallback position found at the outer reaches of legal cognizability ("legitimacy") and the concept of truly normatively binding or obligatory, as distinguished from merely arbitrarily or positively coerced, law. It amounts to that just as the Domain Principle amounts to a fallback intensionalism at the outer reaches of mathematical cognition (constructibility) and the concept of a class. It is accordingly a fallback to that minimal degree of legal intensionalism which even legal extensionalists must acknowledge-even as intensionalists acknowledge that the data which we there intensionalize is for its part extensional (tradition-posited) too. ${ }^{18}$ And as in the case of Part 2, so here we find this "thin" form of reconciliation between positions around the first decision point-criterial versus arbitrary choice-once again most readily only upon carefully considering conundrums that crop up

17 It is no accident, 1 believe, that among these writers, in contrast to the case of the naturalists mentioned in note 15 , only one-Raz-has devoted much attention to practical reason as a subject in its own right.

18 Here the "posit" in question is the polity's legal tradition, as embodied in documents and decisions - the data to which Dworkin, for example, holds subsequent decisions accountable in integrity. The "nature"- - the ethical intelligibility and collective intention-in question, for its part, is what a Dworkinian might call the morally "best," normatively coherent interpretation of that tradition. More in Part 3. We'll find a similar dynamic, incidentally, at work in the other non-purely-mathematical discipline where Cantor's decision points find themselves implicatedwelfare economics. More in Part 4. 
at the second decision point--that involving self-reference.

\section{$1.4 \quad$... In Foundational Economics}

In Part 4, I turn to analogues of the two Cantorian decision points in welfare economic-or "social choice"-theory. Because (a) welfare economists typically act as policy analysts inquiring into what policies might best ensure a political society's faring well, while (b) policy in turn generally finds formulation in a society's laws, the discussion here straightforwardly tracks that of general jurisprudence in Part 3.19 Not surprisingly, in consequence, the Cantorian decision points turn up in the one discipline much in the same guises as they do in the other, even offering similar options, similar divides, and, in the end, opportunities for a similar mode of reconciling long-running disputes. That is especially so in light of the "pluralism" noted in Part 3 to be so characteristic of most modern polities.

The first, criterial choice question's welfare theoretic guise is the question of how individual and social well-faring-"welfare," "wellbeing," "utility," or somesuch - are to be understood or construed. The arbitrary choice-i.e., "extensionalist"-option in this case is that pursuant to which welfare is characterized in putatively unbounded, normatively unadjudged preference-satisfactionist terms. In the case of individuals, then, welfare is characterized without reference to the contents or sources of, or any boundaries that might delimit the social or ethical cognizability of, individuals' preferences themselves. Individuals, we might then say, are viewed "extensionally" as voluntarist deities or positivist sovereigns where "welfare" is concerned.

Social welfare, for its part, is construed by extensionalists in rough aggregationist-"summing"-terms, without either reference to or apparent awareness of any sense in which societies and their well-faring might have to be understood in "internally" structuring (citizeninterrelating), rather than merely in what I'll call "heaping" or "arbitrarily aggregating," terms. ${ }^{20}$ If an individual's welfare is her preference-satisfactions, the underlying intuition here seems to run, then

19 Rather in the way that Austin and Bentham were fonts of modern positivism and welfarism alike.

20 Note that the heap versus structure opposition is yet another rendition of the extension versus intension opposition. The extensionalist view of a class, as we'll see in Part 2, is that view pursuant to which the class just is its members. It is in that sense a "heap." The intensionalist view, by contrast, views the class as no more than the output of an algorithm, a law, a method of generation. The class's members are accordingly "internally related," to use the Wittgensteinian jargon: They bear a common genetic imprint, as it were, in the algorithm that successively generates them. (Note, incidentally, the common root-"gen"-shared by "genetic" and "generate" here.) 
a (heap-like) society's welfare is simply its members' satisfactions "added up" in some sense. This is of course Hobbes, in effect-and other voluntarists and premodern positivists as well-save without the arbitrator. That in turn gives rise to well-known impossibility results perceived as "crises" in the discipline. Such results-indeed, I shall show, many more than have thus far been actually derived-prove quite readily derivable, at least in the absence of interpersonally comparable Benthamite utility such as can raise up a magnitude-a "greatest good"--to arbitrate when sought by the Austinian sovereign. Such crises can even be usefully analogized to those we shall see to have struck foundational mathematics early in the twentieth century; they prove to be structurally similar, counterpart anomies and antinomies rooted in unbounded arbitrariness - sheer extensionality-itself.

The "intensionalist" side of the divide over welfare in foundational economics, for its part, is that whose adherents reckon that some preferences-at any rate, some increments of possible preference satisfaction-are always potentially excludable, if not indeed inevitably excluded as a matter of conceptual entailment, when resources are scarce and choices between satisfactions accordingly have to be made. This position seizes upon a construal of society as something more than an unstructured heap or, as it were, "arbitrary set" of persons. In effect it attends to what might be called the "internal" structures of societies as relations - including normative relations of justice-between persons with preferences, hence persons whose always potentially conflicting preference-satisfactions must be adjusted relative to one another and in that sense adjudicated. The attention to internal structure amounts, of course, to a straightforward analogue of mathematical intensionalists' attention to the "internal logic" or "generative law" of an algorithmic function over and above the extension of ordered pairs which that law generates. And it amounts to an analogue of legal intensionalists' attention to the internal structure of practical reasoning and intention over and above the "extensional" physical motion or behavior in which practical reasoning and intending ultimately issue.

This view accordingly views bona fide "welfare" as precisely those satisfactions which survive or result from the aforementioned "adjudication"-and hence ultimately those satisfactions that are bounded by the ethically intelligible normative principles (intensions again) by reference to which the adjudications are reasoned, justified, and legitimated. (Lawyers know such principles as ratio decidiendi.) It views preferences for satisfaction in excess of such adjudications, in turn, as just that-mere positive preferences, not normative welfare. It accordingly observes a distinction between extensional fact-positive preferences-and intensional value-normative welfare-that the contrary view tends to conflate or elide. 
Like the divide between mere arbitrary will of the sovereign on the one hand, and "only ethically intelligible, moral law is binding law" on the other in the case of general jurisprudence, then, that between unbounded positive preference-satisfaction and principle-contoured normative welfare in social choice theory is readily viewed as a straightforward analogue of the intensionalist/extensionalist divide in foundational mathematics. Also as in jurisprudence, however, what is apparently less apt to be appreciated prior to reflection is how consideration of puzzles that arise at the other decision point-again, that concerning self-reference-can throw light on this, again rather more stalemated debate.

Careful consideration of the self-reference decision point in this case, as in that of jurisprudence, once again reveals quite quickly that there has to be at least some, even if "thin" and but minimal, bounding of potentially conflicting positive preferences by normative principle if the social welfare function (SWF) that takes preferences as arguments is to be intelligible as indeed being a welfare, and indeed social welfare, function at all. ${ }^{21}$ For as we shall see, first, in the absence of such bounding, SWFs are vulnerable to self-subversive antinomies and indeterminacies, rooted in self-reference, quite analogous to those that Part 2 shows to crop up in foundational mathematics-a vulnerability that few economists appear as of yet to have noticed. ${ }^{22}$ And, second, a veritably prescriptive SWF, like a legal prescription or any other normative, would-be plural-action-guiding object, must give expression to something very like a collective intention-even if so "thin" an intention as that to formulate and act as to maximize a veritable social welfare function, rather than simply an analyst's individual preference function, itself. The point is made plain to us the moment we attend to the ineluctable self-referential component of any intention, and indeed any normative judgment whatever, of the sort to which any would-be complete SWF is meant to give expression. Attending carefully again to the concerns that come up at the site of the second Cantorian decision point, then, again offers means of resolving hitherto stalemated dispute at the first such decision point.

In the case of SWFs as these currently are constructed-viz., as maximizing formulae-attending to self-reference assists, more

21 Another analogue here, then, to the "thinned" form of thick Wittgensteinian intensionalism to which the otherwise extensionalist Cantor himself had in effect to resort in articulating the Domain Principle by reference to which he defended the otherwise unintelligible notion of completed infinities.

22 Thank you especially to Kaushik Basu and Robin Boadway for their kind assurances on this score. Both have consistently encouraged me in my pursuit of this line of thought, on grounds both of the appositeness of the formal results I've been deriving, and of the apparent want of appreciation in the discipline more generally that it is, as presently practiced in most quarters, prey to such results. 
precisely, in this way: We note that in order truly to give "complete" expression to a set of normative commitments per the original Bergsonian program, ${ }^{23}$ an SWF must value what I call the "incumbency"- that is, the effectiveness in actually forming intentions (be these those of the citizenry, of government functionaries, or simply of the social welfare "analyst" or "planner" herself)-of the values pursuant to which the SWF itself has been formulated. That includes most conspicuously the values that determine the SWF's domain of arguments and its aggregation rule, we'll see.

Absent this valuing of incumbency, I'll show, the SWF simply will not be interpretable as giving expression to any intelligible value judgment or prescription at all, notwithstanding the fact that giving such expression is precisely what SWFs are for. It will be no more, actionguidance-wise, than an ethical analogue to the arbitrary Dirichletian functions that turn up in Part 2: It will be but a formula which describes ethically arbitrary, de facto allocations (in effect, extensions), rather than one which prescribes ethically intelligible, de dicto distributions (in effect, intensions) pursuant to the value commitments which determined the SWF's construction in the first place (the intension and intention codified in any bona fide prescriptive SWF). It will accordingly not be intelligible as "social," or as having to do with "welfare" in any antecedently recognizable sense, at all. It will do no more than positively describe arbitrarily heaped preference-satisfactions rather than normatively prescribing structured distributions deemed "right" per some principle. And so it will be quite as normatively arbitrary and inert as the merely positive demands of a voluntarist deity, a Hobbesian despot, or the unbounded individual preference-schedules that constitute its argument domain.

The upshot here, then, will be that attending to the role of selfreference in any recognizably prescriptive, veritably social, welfare function reveals how individual preference satisfactions, as a matter of sheer analytic entailment, have to be principle-bounded (and in that sense structured rather than merely "heaped") in at least one, "thin" sense if they are to be intelligible as normatively compelling welfare as distinguished from mere positively present preferring at all. That thin form of contouring and structuring amounts, in the final analysis, to a conception of distributive justice. As in the case of general jurisprudence, then, so in the case of welfare economic inquiry: A bit of attention paid the second Cantorian decision point yields a "thin" form of intensionalism that even hardcore extensionalists must acknowledge, while offering intensionalists means of affirming so-called

23 More on this program and the ambitions of its principal architects-Abram Bergson, Paul Samuelson, and Kenneth Arrow-in designıng it below, in Part 4. 
"individualism" and even (non-strict) 24 "welfarism" of the preferencesatisfactionist sort in the construction of SWFs. Work at the second decision point accordingly proves salutary yet again in breaking apparent impasse at the first decision point.

\section{$1.5 \quad$... And Beyond}

On that note I shall conclude my contribution with a few brief general remarks about some of the farther reaches of the intensionalist/extensionalist problematic in matters of fundamental individual-a.k.a. "existential"-and social-broadly "political"import.

Let me add one brief disclaimer of sorts, and an associated request, before we proceed. As might be evident already, I find the questions that surround what I'm calling the Cantorian "decision-points" most engaging, indeed quite seductively fascinating. I accordingly recognize a disquieting prospect that lurks here: Perhaps I am wrong in believing that Cantor's concerns are indeed literally all of our concerns, and that close attention paid the debates that surrounded his decisions can shed light upon what I assert to be cognate debates in fields other than mathematics. Perhaps, in a word, I am merely "projecting" my own, idiosyncratic interests more profligately than the subjects themselves in fact warrant.

Of course I don't think this is so, else I wouldn't try making the case I'll now put to you. But I humbly request that you tell me if you find things otherwise. Thanks in advance, and now on to the argument.

\section{Foundational Mathematics}

\subsection{Rules, Sequences, and "So On"-A Preliminary Gedankenexperiment}

As indicated in the Introduction, I'd like to begin my discussion of what I am calling the founding "decision points" by characterizing their form in that field where they appear in their boldest relief. That is in what used to be called mathematical "foundations," and what I shall be calling "foundational mathematics." 25 Let us begin, then, as

24 "Strict" welfarism is what $I$ call the view pursuant to which possible worlds are ranked solely by reference to individuals' first-order preference schedules. Strict welfarism, which proponents imprecisely label "welfarism" in some cases, "individualism" in other cases, proves to be incoherent. That is one upshot of Part 4's discussion.

25 I shall generally employ the phrase "foundational mathematics" to refer to what used to be 
mathematicians themselves perhaps sometimes still do, at the chalkboard. I'd like first to write down a few formal expressions, or "signs," which at first glance at least look like bona fide symbols, signs in use-in this case numerals. ${ }^{26}$ (Whether all of them are in fact numerals is something we'll have to interrogate. ${ }^{27}$ ) Posing a few questions to ourselves about these signs will then help to draw out what is at stake in the foundational debates. I'll group the signs into four classes for expository purposes:

Class A: $\quad 3.11$

Class B: $\quad 3.1111111 \ldots$ $3.1414141 \ldots$ Class C: $\quad 3.1415926 \ldots$ $1.4142135 \ldots$

Class D: $\quad 3.7621598 .$. $1.4196231 \ldots$

All right, now let us consider the signs in Class A. I take it that no one finds anything particularly interesting or puzzling about these. Right? Good. These seem to be garden variety numerals. The first will be taken in most contexts of use to designate the number three-andeleven-hundredths. The second one typically designates the number three-and-fourteen-hundredths. Strike the last two digits of either, in turn, and you've got the numeral generally employed to refer to the number three. And so on.

There seems little more to be said here, agreed? The signs' meanings are not generally thought to be vexing, at least no more so than the question of what numbers in general are. And that question in turn has not seemed particularly perplexing since Frege's explication of the natural numbers ${ }^{28}$ (zero, one, two, and so on) as second-order

meant by the "foundations of mathematics." Because the discipline I have in mind has by and large been incorporated now, as subdiscipline, into the discipline of mathematics itself, I think the alternative term warranted.

26 By a "sign" I shall mean simply the recognizable mark. By a "symbol" I'll mean the sign in intelligible use. More on this distinction presently.

27 To head-off any possible confusion, by "numeral" I shall mean a written symbol employed to designate a number. The numeral " 3 " is used to designate the number three, etc. (In this sense, the word "three" could also be called a numeral; but the convention is to restrict the word "numeral" to the so-called "Hindu-Arabic" numerals-those formed of the ordered set of symbols "0," "1," "2," up through "9.")

28 In number theory, the naturals $\mathrm{N}$ are generally defined as to exclude zero. In mathematical logic and set theory, zero is included among the naturals. The integers $Z$, for their part, include 
("quantifier") concepts-extensionally speaking, as classes of equipollent classes-late in the 19th century. ${ }^{29}$

Definitions alternative to Frege's have of course been proposed since the time of his pioneering work-most notably perhaps by Dedekind, whose roughly contemporaneous effort has been favored by many acute mathematical thinkers. But Frege's general take on the question has proved quite influential. And more importantly for present purposes, since Frege and Dedekind no one appears to be in doubt that at least the familiar "counting" numbers can be satisfactorily defined, while the other number-types in their turn can be explicated by reference to these..$^{30}$ So again, Class A's signs seem in good order, and I shall not quibble with the apparent consensus to the effect that they are.

Now for Class B. The signs in this Class might initially seem more problematic than those of Class A. But only a little, I take it. On the one hand, we have these ellipses. And some might wonder what on earth it could mean for decimal expansions to go on "forever"-or, as might be a somewhat less controversial way of putting the point, "indefinitely" - which is of course how the ellipses are conventionally interpreted. The question of what to make of, or how best to understand, such indefinite extensibility — or of "infinity," as some are more apt to put it-can certainly occasion perplexity. ${ }^{31}$

On the other hand, however, the infinity with which we deal in the decimal expansions of Class B seems to be a tractable, intelligible sort of infinity, does it not? For while the expansions might be accurately said in some sense to go on, whether in Aristotelian potential or in Platonic actuality, ${ }^{32}$ indefinitely "without end," we seem nevertheless to have determined-perhaps even to have predetermined, "stipulated,"

not only zero, but the negative numbers as well. The words "integer" and "natural," I suspect you'll agree on reflection, are quite suggestive. The naturals are "natural" in the sense that they are the most familiar, and quite commonly employed, "counting numbers." The integers are integral in the sense that they include no nontrivial fractional parts. They are "whole" and "complete" as they are.

29 See Gottlob Frege, Grundlagen DER ARITHMETIK [THE Foundations OF ARITHMETIC] (J. L. Austin trans., 1964) (1884).

30 That is precisely what Principia showed, in fact. See Alfred NORTH WhiteHEAd \& Bertrand Russell, Principla Mathematica (2d ed. 1925-1927). And subsequent repudiation of Principia has not been repudiation of the general idea referenced here.

31 There are many interesting articles and monographs on this subject, so I shall simply cite one I have found particularly pleasant and instructive in the reading: Please see A.W. MOORE, THE INFINITE (1990). Moore discusses much other work of which I am aware, in addition to a fair bit of which $\mathrm{I}$ had not been aware before happening upon his own.

32 The venerable division in views concerning the infinite has traditionally been tied back to views associated with Plato and Aristotle, the former said to have treated of an "actual" infinite, the latter of a "merely potential" infinite. While it is an oversimplification, it is not altogether without merit. Likewise the tendency to label Cantor, Frege and Gödel "Platonists," and "intuitionists" like Brouwer, Heyting and Weyl "Aristotelians." Full clarity on these linkages would require rather more space than we have at our disposal. 
"legislated," "laid down," etc.--in the case of these numerals what the series expansions can or will look like and include. No surprises appear to be in the offing here, that's to say. There is a finitely and indeed very simply specifiable pattern to which each of the "infinite" expansions in this case will conform.

The expansion is, in short, what we call "eventually periodic." And that periodicity - the repetition of pattern-affords us a form of intelligibility, an assurance against cognitive distress or disruption. ${ }^{33}$ (They're cognizable, in part, precisely because their patterns are readily re-cognizable.) You randomly select a decimal place-“"pick a card, any card"- -and I'll tell you precisely what sign will occur in the decimal expansion at that place. And I'll do so without having to resort to any particularly sophisticated method of calculation to boot; it's merely a matter of grammar school algebra. There is, then, no "devil we don't know" here, no theoretic or even practical "unknown" up ahead to be troubled or anxious about.

For reasons connected with this point-in particular, the fact that repeating decimals can be proved to name geometrically realizable Euclidian ratios-we say that these patterned numerals name "rational" numbers. ${ }^{34}$ I doubt it's mere accident that we use the same adjective"rational"- to describe recognizable, intelligible, "reasonable" discourse and action. Nor, relatedly, can it be accident that we translate the Latin "ratio" into English as "reason," while a court's rationale in deciding a case is called its ratio decidiendi. It's all about tractability, interpretability, understandability.

Note also, by the way, that in respect of intelligibility and indeed rationality, Class $B$ can be viewed a straightforward extension from Class A. For all of A's terms could be immediately transformed into terms looking rather like those of Class B, simply by appending decimal points followed by indefinitely extended strings of zeroes to each. And any integer can of course be treated as a so-called "vulgar ratio" simply by assigning the unit segment-the number one-to it as fractional denominator. For reasons connected with such facts as these, the natural numbers as well as those named by the numerals in Class A typically are treated as constituting a proper subclass of the same set of

33 I find it at least passingly intriguing, in this connection, that both Kierkegaard and modern information-theorists have rooted significance itself in the idea of repetition, while Neitzsche, for his part, at least for a time was attracted by the cognate idea that each moment of a life would be weightier and more significant-indeed "infinitely" significant-were that life to be repeated again and again into the future pursuant to a dynamic of "Eternal Return." Yet by the same token, repetitiveness often is likewise associated with "the merely mundane or quotidian," hence with boredom, with triviality or futility or pointlessness, hence with "meaninglessness." Go figure.

34 More on this matter of ratios, along with the cognate matter of commensurability, immediately below. Not surprisingly, the field of rationals is generally designated "Q," as in "quotient." 
"rational" numbers that the numerals in Class B belong to and invite us to consider.

Now let us turn to Class C. Here things grow still a bit more complicated, though again, as we'll see, hardly intractable. Does anyone recognize these expressions? Does anyone know what comes next—or how to find out what comes next-if we expand the series pursuant to the ellipses? Good! I was certain at least somebody would. The first symbol in Class $C$ yields the first several components of that decimal expansion conventionally employed to name pi (Greek " $\pi$ "), the numeric relation-I don't quite say "ratio"- subsisting between the circumference and diameter of any circle. The second symbol similarly yields the first several elements of that decimal expansion conventionally employed to name the numeric relation-again I don't quite say "ratio"- - subsisting between the diagonal and the length of any side of a square, also known as "the square root of two," or " $\sqrt{2} . " 35$

Now, as at least some of you might know, we tend to shy away from calling the two mentioned relations "ratios" in the strict sense, hence from calling the "numbers" that their decimal expansions designate "rational" numbers. We do so precisely because there is no integral fraction or repeating pattern, respectively, that precisely represents these numbers or characterizes their decimal expansions. The expansions, indeed, go on indefinitely just like those encountered in Class B. But in their case it is well established that, no matter how far you take them, you'll never find any sub-expansion within the expansion that immediately follows itself thenceforth forever and ever. There is no periodicity. And this amounts to another way of saying that there is no finite numerical characterization of the relations in question: The relations subsist between magnitudes known to be what we call Euclidianly "incommensurable." The numeric expressions that correspond to those relations, in turn, we call "irrational," precisely because they do not correspond to relations that might properly be called "ratios."

35 Those who know Pythagorus's theorem will of course know immediately why the relation between the diagonal and side of the square is root two. (Hint: Sides $\mathbf{a}$ and $\mathbf{b}$ in this case, whose squares when added are equal to c's square, are of the same length.)

36 Here, in case you are interested, is a typical proof that $\sqrt{2}$ is irrational, i.e., cannot be represented by any familiar fractional ratio $x$ : Let $x=m / n$ for integers $m$ and $n$, with $n>0$ and $\mathrm{m} / \mathrm{n}$ reduced such that there is no common divisor shared by both $\mathrm{m}$ and $\mathrm{n}$. Now assume, arguendo, that $x=\sqrt{2}$. Now if it does, then of course $x^{2}=2$, meaning that $(m / n)^{2}=2$, meaning $\left(\mathrm{m}^{2}\right) /\left(\mathrm{n}^{2}\right)=2$. But this means that $\mathrm{m}^{2}=2 \mathrm{n}^{2}$. And that means that $\mathrm{m}^{2}$ is even. But this means in turn that $m$ itself is even, since the squares of odd numbers are odd. It also means, in turn, that $\mathrm{m}^{2}$, and hence the $2 \mathrm{n}^{2}$ which $\mathrm{m}^{2}$ equals, are divisible by four, since the squares of even numbers are divisible by four. And since $2 n^{2}$ is divisible by four, $n^{2}$ in turn also is even, as therefore is $n$ itself. But then, if $m$ and $n$ are both even, then $m / n$ is not fully reduced after all, since numerator and denominator share a common divisor (viz., 2), a conclusion which is contrary to one of our opening assumptions. Hence we reach contradiction in supposing that there is some ratio $\mathrm{m} / \mathrm{n}$ which, squared, yields 2 . There is accordingly no such ratio. 
Now lest it be thought that irrational numbers of this Class $C$ type are cognitively-jamming or unintelligible rather than merely geometrically challenging, note this: There actually exists a determinate procedure or "recipe," in each case, by which determinately to generate new terms in these decimal expansions. ${ }^{37}$ Each such procedure, moreover, determines the (unique) value of each decimal place quite determinately. You name the place, and I-or some supercomputercan generate precisely the numeral that fills it; and anyone who repeats the process will arrive at the same result. Matters are accordingly not all that unlike the case of Class B expressions. The "recipes" sometimes can grow quite complex, and often take years to discover. But they'll remain finitely specifiable once found.

We have, then, determinate and feasibly specifiable rules by which to calculate irrationals of this sort-irrationals of the pi and root-two, "Class C" variety. For this reason, these magnitudes and the sequences which name them, while "irrational," are nevertheless recognized to be tractable, "lawlike," and in this sense intelligible. Indeed we even have yet another quite helpfully suggestive name for them: They're called "computable." 38 In the case of these numbers, then, a determinate method of generation - "recipe," "law"-amounts in effect to a workable substitute for actual enumeration, notwithstanding that the latter is inherently incompletable. Fair enough? And this is so even though pi, for its part, is one of the so-called "transcendental," non"algebraic" reals about which I'll say more in a moment in connection with Class D. (Root-two, for its part, is a tame algebraic, rather than full transcendental, irrational. $)^{39}$

All right, now let us turn to Class D. Does anyone recognize these "numerals"? Really? No one? Well, that's actually good news! For these formal expressions have no significance at all, at least none of which I'm aware. I simply threw them up randomly. But then if that be the case, what can these ellipses mean? Am I not pulling your leg in writing them, if I've quite literally nothing in mind as to what might come next? Aren't the ellipses, in effect, a sort of grammatical joke in this case? As if I had spoken of "Todd M.," say, without actually

\footnotetext{
37 In fact there are multiple such recipes, some of which have been with us for millennia.

38 Computable numbers also are called, sometimes, "recursive numbers," or "computable reals." The idea is that there is a finite algorithm for each of them that can be used to compute them within any desired degree of precision. Much of real analysis can be replicated through use of computable reals alone, but, as we shall see, not all of it can.

39 Roughly speaking, algebraic numbers are those among the reals that are roots of non-zero polynomials with rational coefficients. They represent what might be called a particularly "tame" portion of the reals, precisely because they are computable and, more over, denumerable. (They can be put into one-one correspondence with the naturals.) All reals that are not algebraic are, as we shall note presently, so-called "transcendental" numbers, which turn out to be incomparably more numerous than the naturals or rationals or algebraics. The wonder is that some of them nevertheless are computable-as is pi.
} 
having anyone in mind whose forename I believe to be "Todd" and whose surname I believe to begin with the letter " $\mathrm{M}$ "?

Put another way, does "and so on" have any purchase or mean anything at all in connection with these marks on the chalkboard, in the case of Class D? What would be the content of the word "so" here? "So" what? To what "thus" or "this way" have I gestured with this word? Isn't it rather as if I have said, "now, shuck the corn this way," thereupon opening a book and beginning to whistle? In the absence of any named "law" or procedure for "computing" or "generating" further values in these putative sequences, it seems a bit much to be calling them "sequences" at all-or, therefore, to call these expressions "numerals" at all. They don't seem to name anything. At least not as yet.

Now, as I'll explain shortly, there are various attitudes that we might take to these puzzling Class D expressions. And it is the felt necessity to adopt some such attitude, I believe-a necessity rooted in the centrality of such expressions, or at least of the prospect that they are meaningful, to much of modern mathematics-which gives rise to the first of the Cantorian "decision points" to which I've alluded since the Introduction. I'll come to that in a moment, but first I shall close our preliminary discussion of these Class $D$ expressions with the following two observations, which I think will prove helpful below.

The first remark is that one might, presumably, decide to treat the signs in Class $D$ as the shared beginnings of an infinite-indeed, as we'll see, transfinite-number of finite and infinite decimal expansions. Somewhat in the way that "To..." might be viewed as the shared beginning of such names as "Todd," "Tom," "Tomas," "Tony," "Torre," and so forth. In so doing, we might say that we would be taking preliminary steps toward assigning meanings to these signs, preparatory to rendering them bona fide symbols. Indeed, this seems in effect to be the way Cantor regarded them, as I'll argue. And by far and away most of the remarkable (indeed, transfinite) number of such sequences that could "in principle" be "generated"-or at any rate "randomly named" - in this manner will then be said to name what is called ... ready? ... "transcendental" numbers: The transcendentals are, with but comparatively few exceptions, precisely those irrational numbers that are not "lawlike" in the way that those algorithmically generated series designated in Class $\mathrm{C}$ are..$^{40}$ And I trust that we all can appreciate just how apt this term-"transcendental"-might be in the present context. In effect, the numbers here countenanced "transcend" our capacities even so much as to individuate them. ${ }^{41}$

40 The exceptions are those transcendentals that are at any rate "computable"approximable-in the manner described above in connection with pi.

41 And as we'll see shortly, some consider a putative object's not being individuable as 
The final remark to make here is best made in connection with a little game I would like us to play for a moment, if you'll indulge me.42 Let us, then, return to the chalkboard for a moment. Now would somebody please name a single-digit numeral for me to add to the first sequence in Class D? Anything from zero to nine. Ah, good, thank you! Ok, how about another one? Perfect. And another? Very good, thanks.

Now, I'll bet you can see where this is going: Isn't there a sense here in which we have settled upon a procedure for "generating"-or at any rate "choosing" or "designating"-further terms in this sequence? Perhaps it isn't "lawlike" in any algorithmic or otherwise determinately predictive sense of the term. And admittedly as well it would be odd to say that our procedure is capable of generating an infinite sequence even "in principle," let alone in practice. ${ }^{43}$ At least it would seem odd to say so without recourse to some claim concerning the metaphysical status of counterfactual specifications-for example, "the sequence we 'would' generate were we to live and continue this game forever"-which would be hardly less puzzling than those Class D strings of signs we were trying to explicate in the first place. And I think it would be odd even apart from that, absent some means of calculating or predicting the $n$th term in advance for any $n$, in the way that we might do with computable expressions of the Class $\mathrm{C}$ variety.

Nevertheless, though, at least there was something a bit like a procedure in our game, even if it be a procedure for choosing rather than for calculating. And this procedure was even a bit cozy, familial and fun, not to mention "democratic," was it not? We began freely, and communally, to create something together. We were creating a name, pursuant to familiar name-forming rules ("place-value" rules), which bears a standard interpretation at each step of our creation. What we did, in short, was to begin cooperatively to construct something a bit like what mathematical "intuitionists" call "choice sequences." 44 Usually that's done in private. But no one ever said it couldn't be

tantamount to its not existing. If you can't provide a criterion of identity, you can't be said to have singled anything out, such challengers will hold. What might it be, they will ask, for something you can't individuate nevertheless to exist "transcendentally?" Well, we'll come back to that.

42 An old friend of mine long held a fantasy about being a gameshow host, while I for my part was content to settle for that second-best option known as "law professor." At birthday parties for my friend, we invented gameshows that we all would play and he then would host. Since today is his birthday, I hope you'll indulge him vicariously by humoring me here for a moment and playing along.

43 The impossibility here is not merely "medical," to use Russell's seemingly mischosen term. See Bertrand Russell, The Limits of Empiricism, 36 PROC. ARISTOTELIAN SOC'Y 131, 143 (1936).

44 On choice sequences, their development by Brouwer (under the term "spreads"), and their subsequent role in intuitionist mathematics, see generally ANNE TROELSTRA, CHOICE SEQUENCES: A CHAPTER IN INTUITIONIST MATHEMATICS (1977). 
enjoyed by multiple consenting adults. I'll come back to these observations and their import a bit later.

\subsection{A Menu of Apparent Options}

Now, one can typically get at least a feel for the general thrust of most proposed accounts of mathematical foundations, I suggest, through comparison of what they have to say about expressions of the kind we have just been considering in connection with Class D. And the kinds of consideration that the proponents of these accounts adduce in arriving at their own and rejecting one another's positions, I believe, are precisely the "data" in response to which foundationalists have made their decisions at what I am calling the Cantorian "decision points."

I think I can best flesh this out by briefly characterizing some of the principal decisions that actually have been made, historically speaking, in respect of what to make of or conclude about expressions like those in Class D. I'll focus principally upon what appear at first glance to be polar endpoints that bound a continuum of available positions. (Later we'll query whether, upon closer inspection, they are really so different. $)^{45}$

\subsubsection{Wittgensteinian Intensionalism}

At one apparent polar end of the menu of options available to those inclined to form opinions about Class D expressions is what I shall call "Wittgensteinian intensionalism," for reasons that will emerge presently. I shall devote most of my attention to Wittgenstein at this end of the scale because his views on the matters at stake seem to me to be, characteristically, the most searching and integrated of the many views expressed. ${ }^{46}$ But there are of course family resemblances

45 This little continuum hypothesis I assume proves heuristically convenient, though I'll later suggest that the endpoints converge. We've ultimately a circle here, I have come to believe.

46 As we'll see, there are many points of contact between those of sundry "constructivists," "finitists," "intuitionists" and so-called "French semi-intuitionists." But Wittgenstein's views here, as I say, are much more thoroughly thought-through, integrated and far-reaching than those of the others, so his views are best suited to my heuristic task of drawing out what's at stake here by reference to the most starkly counterpoised positions-the "poles" of the continuum of options, as I am provisionally calling them. If I were pressed to distinguish Wittgenstein from the others I mention here in a "soundbite," I would say that he is the only one fully to draw out the consequences of viewing mathematics as essentially calculative, hence not really "about objects" at all. The others I mention share much of Wittgenstein's epistemic orientations, I think, but nevertheless view mathematics as treating of objects. Their difference from Cantor, Dedekind and other extensionalists is simply in respect of the criteria they impose upon object-existence or -identification. More on this below as we proceed. 
between various of Wittgenstein's views and some of those of sundry "intuitionists" and "finitists" whom I shall note from time to time. We might also have labeled the position that I shall be attempting to explicate here a sort of "latterday Thomist" account. For a good bit of the spirit of Wittgenstein's take on our Class D expressions appears to be anticipated to at least some degree in St. Thomas Aquinas's arguments for the Aristotelian "potential infinite," as distinguished from the Platonistic "actual infinite." 47 This linkage, I think, will prove of some interest below in connection with our discussion of the Cantorian decisions points' analogues in general jurisprudence. ${ }^{48}$

Now the Wittgensteinian position, as I understand it - and this appears to be a position that Wittgenstein maintained, more or less, throughout his philosophical life-is that our Class D expressions are not symbols, as distinguished from signs, at all. That is to say, the recognizable numeric expressions in Class $D$ are indeed of the kind standardly employed to designate numbers-hence are "signs"- -but are not actually being employed to name numbers in this case-hence are not "symbols"--at all.49 Any more than a particular utterance of the familiar phoneme "Tom" amounts to the use of a name when one does not actually intend to refer to anyone.

Now, why might one say this? Well, there are multiple variants of what I think to be the principal argument that presses itself upon us here. Indeed the observation just made in connection with "Tom" amounts, in a way, to just such an argument. For one might say to anyone writing down one of the expressions in Class D, "what number are you trying to name here?," just as one might ask the vain employer of the sign "Tom" who or what actual person or thing he or she means to designate. If no further criterion of identity or mode of individuation

47 Yes, the same St. Thomas who is associated with the naturalist position in general jurisprudence, as we'll note in Part 3 below. As we shall also note nearer below, Cantor-the fellow whose views I'll initially contrast with Wittgenstein's-considered Aquinas to be one of his principal interlocutors. This is perhaps less surprising than it might initially be, once one recalls that Cantor considered himself to be as much theologian as mathematician (indeed even to have received transfinite set theory directly from God), and that he carried on lively correspondences with a number of Roman Catholic theologians. He apparently even rejoiced when his doctrines came to be accepted by the Roman Hierarchy. On these matters, see, for example DAUBEN, supra note 1 at 120-48. And see further below.

48 A further link in this latter connection, we'll see, is traced in Anscombe's seminal work in the philosophy of action, Intention. G. E. M. ANSCOMBE, INTENTION (1957); see infra, Part 4. The extensionalists, incidentally, for their part are anticipated in some ways by the nominalism of Ockham and Scotus, who intriguingly also prefigure the voluntarist/positivist position in jurisprudential theory as we'll observe below. But matters are more complicated as well, in that Ockham and Scotus also were finitists, in contrast to latterday extensionalists like Cantor and his many "closet Platonist" followers.

49 This is the standard Wittgensteinian terminology. The symbol is the sign in use. See, e.g., LUDWIG WITTGENSTEN, TRACTATUS LOGICO-PHILOSOPHICUS proposition 3.32 passim (1922) [hereinafter TRACTATUS]. 
is forthcoming, one grows suspicious that the string of numerals and ellipsis, or the phoneme, is being no more than scrawled down or uttered in vain, as a sign, rather than actually employed as a symbol..$^{50}$ You can always challenge, that is to say, the person who speaks or writes to provide further means of singling out whom or what is being referred to, if anyone or anything actually is. And then an answer or two typically will be forthcoming. ${ }^{51}$ In the case of our Class D expressions, by contrast, no such answer appears to be on the cards.

Now a somewhat more technical way of putting what I believe is the same point here is this: A number, on the Wittgensteinian view, is not an extension, but an intension. Yes, that's "intension" with an "s," not to be confused with the cognate but nevertheless distinct "intention" with a "t." 52 What do I mean here? Well, this is a familiar distinction oft-encountered in logic and, in earlier times, function- and set theory as well..$^{53}$ In essence, the idea is this: Suppose I inquire, upon glancing at a cover of the National Enquirer, whether there might really be a threeheaded man. You can understand what I am asking, even if in fact there is no three-headed man. The "concept" of a three-headed man, that's to say, is coherent enough and intelligible. You know what to look for if I set you to searching, even if you never have seen such a man and even if there never has been such a man to be found.

We call the concept, in this case, the "intension" of the phrase. It is that cognitive content, or "meaning" of which you take hold in understanding the phrase and thus in determining what (or who?) to look for. We call the class of entities fitting the description that is the phrase, in turn, the concept's "extension." It is the class of three-headed

50 Intriguingly, Cantor himself, whose point of view I shall shortly be contrasting with Wittgenstein's, conceded a similar point, saying, in response to a very Wittgensteinian argument made centuries earlier by Aquinas, that it was "right and correct to oppose actually infinite numbers, so long as a principle of individuation, specification, and ordination of that actual infinite which I call the transfinite had not been found." Georg Cantor, NACHLASS VI 110 (letter book used by Cantor between 1884 and 1888), translated in MiCHAEL HALLET, CANTORIAN SET THEORY AND LIMITATION OF SIZE 22 (1984). I'll quote the relevant passage from Aquinas presently.

51 Here is Aquinas on the matter: "[E]very kind of multitude must belong to a species of multitude... Furthermore, multitude in the world is created, and everything created is comprehended under some definite intention of the Creator; for no agent acts aimlessly." 1 Thomas AQUinas, Summa THeOlogica, q. 7, art. 4 (Fathers of the English Dominican Province trans., 1947)(c. 1267-1273). As we'll see below, Thomas's "species" and "intention" here appear rather closely to track what is nowadays meant, in mathematical-logical parlance, by "concept" and "intension," respectively.

52 There are of course conceptual linkages between intensions and intentions, some of which I shall draw out. But the concepts remain analytically distinct.

53 As we'll see below, Cantor himself was partly responsible for its ultimate elimination from set and function theory, which grew steadily more combinatoric in orientation from the mid to late nineteenth century onward. The ultimate triumph of this mode of treating mathematical activity is found in modern category theory, in effect the present day successor of abstract Cantorian set theory, as we'll see below. 
men. Now as it happens, this class appears to be empty. But that is precisely one of the reasons why we distinguish between intensions and extensions. It is that one can use and understand symbols-words, phrases, names, numerals, etc.- - even when they fail actually to single out or denote anything. Just as we can look for things that we might never find-unicorns or El Dorado, for example. We can elaborate criteria of identity even where there turns out to be no entity that happens to satisfy them. The expressions pursuant to which we formulate or communicate aims can connote even when it turns out that they do not happen to denote. ${ }^{54}$

So how does this connect to the matter of Class D expressions? Well, in this way: One way of regarding the phrase "three-headed man" is as something akin to a sort of instruction to somebody to whom you are speaking, an instruction that assists in communicating the full thought that you wish to communicate: You are instructing your interlocutor, in effect, how to go about determining or identifying who or what you are speaking about, with a view ultimately to understanding what proposition you are asserting or what command you are issuing or what question you are posing, etc., in connection with that person or thing: "Consider all men," you instruct in effect, "then the one or more among them with three heads. It is of him or them that I speak." 55

Likewise and of course less fancifully, I can instruct you to seek out or draw part of the graph specified by some such expression as " $\{y \mid$ $x=3 y$ \}" - that is, the $y$ 's that are quotients of $x$ 's over three, in some specified domain-say the reals, $\mathbb{R}-$ over which the expression in brackets is intended to quantify. When I thus instruct you, I supply you with a simple means of determining the full class of $y$ 's in question, such that you never need inspect that class itself-or its individual members - in order to get a "grip" on it, so to speak. The formula, the algorithm, suffices. And indeed, you can understand many such formulae for which there might not even be any easily drawn or

54 The "connote" versus "denote" distinction figures in Mill's Logic. It corresponds, by and large though not fully, to the now perhaps more familiar Fregean distinction between "Sinn" (generally translated into English as "sense") and "Bedeutung" (generally translated into English as "reference" or "referent"). See GOTTLOB FREGE, Uber Sinn und Bedeutung [On Sense and Reference], in TRANSLATIONS FROM THE PHILOSOPHICAL WRITINGS OF GOTTLOB FREGE 56 (Max Black \& Peter Geach eds., 1952).

55 This matter of "aboutness" affords a link, incidentally, between intension with an "s" and intention with a " $t$." Intentionality is often described as that aspect of consciousness having to do with its "directedness"--its always being consciousness of or about something, its being "directed" to things. In some cases, the things do not happen to exist, but that does not appear to keep them from being "objects of consciousness," so to speak. (Consider Santa Claus, for example, or perhaps even numbers, for that matter.) And typically what it is that one is thinking about per her intentionality is best ascertained by the intension-the cognitive content, connotation, or meaning-of her report in naming or describing that thing. See generally Graham Priest, Towards Non-BeING: The Logic and Metaphysics of INTENTIONALity (2006). 
visualized graph. ${ }^{56}$

Now the Wittgensteinian position on putatively infinite classes like our Class B, C, and D sequences, I think, is in effect the position that the algorithm not only is sufficient, but is in fact necessary as well, at least in this sense: If you have no algorithm to offer-no rule, "law," "generative principle," "recipe," Fregean sense ("Sinn"), procedure, concept, connotation, or intension - then you really have no class, set, thing, denotation, or extension in mind either. And if you've not got it in mind, so to speak, there is no reason to think it is there. The burden is on you to explain what you purport to be talking about. If you don't meet that burden, then we presume that there just isn't anything there, as of yet, to be had. Your cognitive clutch has not yet engaged.

"No intension, no intention," we might say here. You have not yet succeeded in actually thinking of anything, hence of indicating anything; you have "nothing in mind" (at least yet). ${ }^{57}$ You have, at best, simply begun to call something to mind. You have "cleared your cognitive throat," so to speak, in a manner that's preparatory to thinking or saying something. Somewhat in the way that choosing a sign is preparatory to deploying a symbol-since choosing it precedes using it. To hold otherwise, I think Wittgenstein would have said, is effectively to fetishize - or as he might have put it, "to sublime"-the sign. It is to treat the sign as if it were magically possessed of an "essence" or meaning even prior to anyone's using or conceiving a use for it, such that it might even have possessed its particular meaning had nobody ever come along to utter or write it. . $^{58}$

In this sense, then, I think we can see why Wittgenstein would be happy enough with the decimal expansions of Class $C$, and would be perfectly willing to say that they are numerals which name numbers. At

\footnotetext{
56 As in the case of many "arbitrary functions," in fact. But more on this below.

57 Note in this connection that a Fregean "Sinn" is a "mode of presenting" an object-a "Bedeutung" or referent. There must at least be some "intentional" object, even if it is not actually instantiated, for there to be an intension at all. We might say, one must be aiming if there is to be anything to hit, even should it turn out that we were mistaken as to whether there really was something there to be hit once we've aimed and fired. I am of course now beginning to take us in the direction of Brentano and the so-called "Austrian school" of intentionality prominent in the earlier twentieth century. Alas, we must now pass, rather than further pursue, this interesting detour.

58 I've often thought there to be a parallel here, by the way, with the old Marxian idea of "commodity-fetishism" (a variant on Hegelian "alienation," of course) in "bourgeois political economy." I refer to the idea that what is in fact the upshot of a set of productive relations between interacting human persons-in this case, the produced item, with its "embodied labor power" and so forth-is misleadingly viewed as possessing exchange value quite independently of the sundry inter-related human "inputs" that have gone into producing it ("putting it out" into the world). Wittgenstein appears to have viewed word-, phrase-, and sentence-meanings as the products of communicative relations between acting persons rather as Marx viewed products' exchange-values as the products of productive relations between acting persons. But I'll have to leave this interesting parallel to one side for present purposes, mentioning it only in honor of some of those present at our conference.
} 
least that would be so provided we bore in mind that the number was, strictly speaking, the "rule" rather than the set of digits constituting the decimal expansion. ${ }^{59}$ But I think Wittgenstein would say of the signs of Class D that they are signs that as yet haven't been made symbols denoting or connoting or, therefore, denoting anything at all. They are made symbols only once a method of generating further terms in each non-terminating series has been specified. Until that happens, there just "is no "there' there," for there is as yet no "so" for "and so on" to engage. This is the thrust, I believe, of the Wittgensteinian quote that I've used as an epigram above, to the effect that "only a law reaches to infinity."

It might come as no surprise in this connection, then, that several of the principal developers of what ultimately came to be called "algorithmic" or "recursive" function theory-which figures prominently as an intensional alternative to full-blown extensional, combinatorial Cantorian set theory-were students of Wittgenstein's. ${ }^{60}$ It is somewhat surprising, I think, that this is not rather more often remarked.61

\subsubsection{Cantorian Extensionalism}

All right, now let us turn to what can readily be viewed, at least initially, as the extremum opposite Wittgensteinian intensionalismwhat I'll call "Cantorian extensionalism."62 How best to elaborate this

59 In this connection, note TRACTATUS, supra note 49, proposition 6.021 ("A number is the exponent of an operation.").

60 The Tractarian conception of a number as exponent of an operation in fact prefigures Skolem's "primitive recursive arithmetic" and Church's celebrated "lambda calculus" also. The students to whom I allude are Goodstein and Kreisel. See Thoralf Skolem, The Foundations of Elementary Arithmetic Established by Means of the Recursive Mode of Thought, Without Use of Apparent Variables Ranging over Infinite Domains, in JAN VAN HEIJENOORT, FROM FREGE TO GÖDEL: A SOURCEBOOK IN MATHEMATICAL LOGIC, 1879-1931 at 303 (1967); Alonzo Church, $A$ Set of Postulates for the Foundation of Logic, 33 ANNALS MATHEMATICS 346 (1932) (First Paper), 34 ANNALs MATHEMATICS 839 (Second Paper); R. L. GoodsteIN, Constructive FORMALISM 10 (1951); George Kreisel, Critical Notice: Lectures on the Foundations of Mathematics, in 3 LUDWIG WITTGENSTEIN: CRITICAL ASSESSMENTS 110 (Stuart Shanker ed., 1986); George Kreisel \& George Takeuti, Formally Self-Referential Propositions for Cut Free Classical Analysis and Related Systems, 118 DISSERTATIONES MATHEMATICAE 1 (1974).

61 Note in this connection that the mathematical logician George Kreisel, himself once a student of Wittgenstein's and Gödel's (could one be more fortune-favored than that?!), came later to revise his once unfavorable opinion of Wittgenstein's attitudes toward foundational mathematics and set theory on the basis of considerations such as these. See Kreisel, supra note 60. See generally PAUlo FraCOLLA, WitTGENSTEIN'S PhILOSOPHY OF MATHEMATICS (1994); MATHIEU MARION, WITTGENSTEIN, FINITISM, AND THE FOUNDATIONS OF MATHEMATICS (1998); STUART G. SHANKER, WITTGENSTEIN AND THE TURNING POINT IN THE PHILOSOPHY OF MATHEMATICS (1987).

62 I'll subsequently say a bit about several middling options between the extremes- e.g., so- 
one? Well, let's try this avenue (or set of converging avenues): If you take any of the expressions in Class $\mathrm{D}$, and begin at the ellipses, note that there are ten possible choices for selecting a next step in the expansion. One may choose any of the numerals "0" through "9." Suppose you select one. Well, then you may choose from the same menu again in filling the next decimal place. And so on.

Now note that, while that is occurring, you can (say via a "parallel process" conducted with simultaneously operating computers) also go back to the first place you filled, and fill it differently than you did the first time. And then you can choose from among the ten numerals " 0 " through "9" again in filling the next place, and so on. Then you can go back to the first digit you filled yet again, and fill it differently than you have done already, ten options in all at each decimal place. And so on.

Well you see at least roughly where this is going, I trust. And if you do, that is precisely the point! There is a sense in which it does seem to be going somewhere. Right? There is an intelligible "so" here, it would seem. In effect, we are beating round a real bush here, or perhaps a "tree," to be more precise-a "decision tree!" Ten branches proceed from the last place we filled at any stage. Then ten branches from each of those branches. And so on. Indeed, we began specifying one such path in our gameshow simulation earlier.

And don't, by the way, let the number ten hang you up here. That is simply an accident of our system of numeral-construction, which is of course a "base ten" system. The essential point would hold true of what ever familiar such "place value" system we chose, even a binary "base two" system of zeros and ones: The point is that there is a sense in which the possibilities of decimal expansion, although indeed "endless" and as inclusive of nonperiodic as of periodic and finite expansions, are nevertheless tractable. Their tracks are quite simply the branches of the tree. And in that sense, these possibilities are "there," so to speak. For any particular expansion to be actualized, we might say, all such expansions-even those that we never happen to actualize-must be possible. The sum total of possibilities, in turn, at least at first glance, ${ }^{63}$ is captured by the full tree, infinitely branching as that tree may be. It is some such picture as this, I believe, that lies at the heart of the Cantorian (and for that matter Dedekindian) conception of numbernaming, hence numeric series and, ultimately, number itself. ${ }^{64}$

Now, just as we noted that there is a more technical way of

called "strict" finitism, and intuitionism - the capacity of which not to collapse into one of the extrema sometimes is questioned. I'll also suggest that the continuum of positions that I describe might circle back on itself, such that the extrema in effect come to converge.

63 I'll explain shortly that things actually are a little more complicated than this.

64 Indeed, this seems to be more or less just what Cantor meant in writing what I quote him in note 50 above as having said. More on the Cantorian/Dedekindian number-existence criteria below. 
characterizing the Wittgensteinian intensionalist position than the folksy way in which we began, so too there is a more technical way of characterizing the Cantorian extensionalist position. It is this: It might be that, what ever the merit of Wittgenstein's tendency to view extensions as intelligible only by reference to intensions, intensions nevertheless "presuppose" extensions in a certain sense. ${ }^{65}$ The view that they do, which Cantor certainly seems to have held, is sometimes now called, following Hallett, "the Domain Principle."66 (The view appears first to have been suggested by Pascal. ${ }^{67}$ ) Here is how Cantor articulates it:

In order for there to be a variable quantity in some mathematical study, the "domain" of its variability must strictly speaking be known beforehand through a definition. However, this domain cannot itself be something variable, since otherwise each fixed support for the study would collapse. ${ }^{68}$ Thus, this "domain" is a definite, actually infinite set of values. ... [E] ach potential infinite, if it is rigorously applicable mathematically, presupposes an actual infinite. ${ }^{69}$

Make sense? The basic idea, I take it, is that in order for the terms that we employ in specifying a rule or law or recipe or algorithm-an intension-actually to be possessed of determinate meaning, there must in a certain sense already be a determinate domain - a totality, an extension - of objects with which the rule or law or recipe or algorithm

65 Note that, as observed, supra note 55, Fregean "Sinn" presuppose "Bedeutungen" as well. There must at least be the idea-the Sinn?-of Bedeutung itself, in order that there be any conception of "aiming" under a description. We might say that intension requires intention, which latter requires intentionality, which latter requires "aboutness" or "aiming," which latter finally requires the notion of an object-a referent, hence an extension.

66 See, e.g., HALLETT, supra note 50, at 7. Cartwright rather disparagingly calls it "the all in one principle." See R. L. Cartwright, Speaking of Everything, 28 Noûs 1 (1994).

67 See, e.g., BlAISE PASCAL, OEVRES COMPLÈTES 199-221 (Louis LaFuma ed., 1963).

68 Incidentally, a cognate point (if not indeed the same point) seems to be that which is made in TRACTATUS, supra note 49, propositions 2.021 ("Objects form the substance of the world."); 2.0211 " "If the world had no substance, then whether a proposition had sense would depend on whether another proposition was true."); and 2.026 ("Only if there are objects can there be a fixed form of the world."). A nice parallelism here, I think, since, as you'll recall, I quoted Cantor, supra note 50, as agreeing with a position that I was attributing to Wittgenstein. This might all seem odd, given that Wittgc 1 stein notoriously referred to set theory as "a disease." But note that Wittgenstein seems to have diagnosed himself very often as suffering from something very much like "the disease," and recommended not only his later philosophy, but the Tractatus itself, as a manner of therapy. See, e.g., TRACTATUS, supra note 49 propositions 6.521 " "The solution of the problem of life is seen in the vanishing of this problem."); and 6.54 ("My propositions are elucidatory in this way: he who understands me finally recognizes them as senseless, when he has climbed out through them, on them, over them. . . . He must surmount these propositions; then he sees the world rightly."). I'll suggest later that this disease is perhaps nothing other than selfconsciousness itself - a disease that I think we ought in fact celebrate.

69 GEORG CANTOR, Über die verschiedenen Ansichten in Bezug auf die actualunendlichen Zahlen, in BIHAN TILl Koniglen SVENSKa VeTENSKaPS AKAdEMIENS HaNdLIGAR 11 (19), 1 (1886), translated in, HALLETT, supra note 50, at 25. 
correlates the objects that it does. Otherwise we don't know what we're talking about in articulating the algorithm, any more than, as Wittgenstein had it, we knew what extension we might be referring to before formulating an intelligible intension. ${ }^{70}$ For the algorithm is understood by reference to the notion of a "variable," and the notion of a variable is understood, in turn, by reference to a determinate domain over which it quantifies. ${ }^{71}$

Per the Cantorian view, then, in employing concepts in statements that quantify over domains of objects at all-that is, in countenancing the possibility that various objects fall under the concepts we use-we involve ourselves in what a follower of Quine might call "ontic commitment" of a sort. ${ }^{72}$ We assume the existence of those things that one might in principle "feed into" our rules, concepts, algorithms, or decision procedures as well as those things that will be "put out" by the same-at least if the algorithms or procedures be well formed-when we do so. To reject the assumption-to decline the ontic commitment-is accordingly to reject the intelligibility of the rule or algorithm itself, since the algorithm makes sense only as a rule applied to objects falling within its specified domain of application. To reject the extension as being in a certain sense present even prior to the intension-to deny that it is "available to the intension," we might say-is then effectively to reject the intension itself on this view..$^{73}$

Now I think, on reflection, that there is a nice symmetry between this idea and that which we saw in connection with the Wittgensteinian rejection of expressions like those in Class D, don't you? Just as Wittgenstein might say that those expressions are ill-defined and nonmeaningful until we view them as proceeding from some calculative procedure - some intension-so might Cantor say that the procedure in

70 One natural follow-on speculation, that both Wittgenstein and Cantor are right and that intensions and extensions in a certain sense might presuppose one another, is a prospect that I shall consider below.

71 To put the point first in a somewhat more technical, then in a folksier, way: An algorithm or other formula is understood by reference to the notion of quantification over its bound variable(s)-i.e., by reference to the employment of "all," "some," or "how many" concepts in connection with a domain of objects in respect of which those concepts have application. For the formula to be of determinate meaning, then, the mentioned domain must be, in a certain sense, itself considered determinate, and in that sense "completed." More colloquially now, note that the number zero-along with the class of dogs, cans, rocket ships, spools of dental floss, etc.-is excluded from the domain over which possible denominators of fractions is defined. " $2 / 0$," " $2 / \mathrm{dog}$," and so on have not assigned meanings. If you don't have a determinate domain specified, I think Cantor would say, the operation or algorithm-the intension-that you intend to employ is itself indeterminate. It is as ill specified as are any of the expressions above in Class D absent some mode of generation.

72 See W. V. O. Quine, On What There Is, 2 REV. METAPHYSICS 21 (1948).

73 This is, perhaps, just another way of saying that for something to be actual, it must in a certain sense "first" be possible. Scarce wonder, then, perhaps, that some philosophers of mathematics, seeking to avoid apparent commitments to Platonic metaphysics, recast mathematics in modal terms as a language of possibilities, "possible objects," or "structures." 
question, in turn, is itself ill-defined until we have specified some domain - some extension - over which it is operative. ${ }^{74}$

Now note one final point of interest in connection with what I am calling the Cantorian position: Note that, if we accept the Cantorian view as I've thus far elaborated it, then we appear to accept even more than I have specified so far. We accept also that there is a sense in which there might be extensions in respect of which nobody ever happens to come along to form or articulate an intension. ("Potential intensions," we might call these extensions, i.e., these available but never actualized intensions. $)^{75}$ Indeed, if we carry the logic of Cantor's position to its outer reaches as Cantor himself did, we find that there must in a certain sense - a sense we'll come back to- be uncountably many more extensions than any intension ever could finitely define.

This is indeed one upshot of the celebrated Cantorian mode of argument known as "diagonalization," a simple instance of which I shall elaborate briefly below. ${ }^{76}$ And if we accept an analogy between extensions and possibilities on the one hand, intensions and actualities on the other as proposed in several footnotes above, then this even makes a certain sort of intuitive sense, I submit: For surely all of us possess at least some feeling that possibilities always exceed actualities, that things "might have been different." That, I suppose, metaphorically speaking, is an appreciation that a healthy tree's totality of branches will typically exceed any one squirrel's path from ground to branchtip.

Extensions, then, quite inevitably outrun intensions on the Cantorian view; their doing so is written into the structure of conceiving and thinking themselves. ${ }^{77}$ But they are also, pursuant to the selfsame structure, nevertheless presupposed by intensions themselves. Sum up the argument thusly: By the Domain Principle, all actual correlations or selections of objects presuppose possible such correlations or selections. And by the diagonal principle upon which Cantorian diagonal argumentation is founded, one can never actually have made all possible such correlations or selections. (Such selecting is, in the

74 As in the case of the "Cantor as Wittgenstein all the way out" observation made above, I shall return to this just-mentioned symmetry below, in attempting to work a reconciliation between views that at first strike us as polar extremes.

75 The idea would then be that, for there to be intensions, there must be possible intensionsintensions that might have been well-formed per the syntactic structure of or logic embedded in what ever language we use. And it should not be surprising that we never would formulate all intensions that might be formulated. Voilà, incompleteness of a sort even before incompleteness theorems.

76 See infra Part 2.4.

77 Intriguingly, some intensions seem to outrun extensions as well, as witness the case of some "arbitrary functions"- cases in which coherent formulae actually can possess no graphswe shall encounter shortly, below; and as witness some of the self-referential paradoxes that stem in part from so-called "comprehension" axioms-i.e., axioms asserting the existence of a class (an extension) for every stipulated criterion of membership (i.e., intension)-as discussed further below. 
contemporary idiom, "incompletable."78) Thus the possibilities-i.e., the "possible intensions," which are precisely the extensions-outrun the actualities-i.e., the actually formulated intensions.

Note finally that this all amounts to a sense in which possibilities "transcend" actualities. (Precisely what sense is a point that is effectively at issue between Cantor and Wittgenstein, a matter to which we'll return shortly.) And some such intuition as this doubtless accounts for many people's considering the expressions in Class D above to be partial characterizations of what I noted before often are called "transcendental numbers." We don't know which number in either of the two sample cases that I supplied above in Class D, but we can certainly assume that it might be some "one of them" in each case; and there are vastly "more" of them than ever could be fully described. ${ }^{79}$

This surely is at least part of what accounts for the most quoted remark once made by Cantor, which I've also conscripted above as an epigram, that "the essence of mathematics lies in its freedom." He has to have had this matter of sheer mind-boggling possibility, of incompletability, at least partly in mind-a vast field of possibility to which the practice of mathematical analysis as it had by his time developed had to have unrestriced recourse. ${ }^{80}$ For Cantor could not have meant that mathematical development is "free" in the sense of not being in any way bound by a logic or thinking-structure which contours and guides the development. Why? Because it is this logic itself that Cantor purported to have found and to which he then appealed in arguing his positions. Indeed, that sense of inevitability is what seems to have underwritten Cantor's perhaps second most oft-quoted remark, made in a letter to Dedekind in connection with his proof, which at first he had trouble believing could be valid: the proof that any $n$ dimensional $\mathbb{R}$-space could be mapped onto the unidimensional linei.e., $\mathbb{R}$ alone. ${ }^{81}$ Cantor said, in immediate reaction to this, his own proof, "I see it, but I don't believe it!" So he was apparently not as "free" to see what he expected to see as he was, for a time, to believe what he expected to believe.

78 There is not only an obvious link between the incompletability that diagonalization makes manifest and the incompletability that figures into Gödel's celebrated Second Incompleteness Theorem, but also a link between it and the Wittgensteinian point made, supra note 43 and associated text, that, pace Russell, the impossibility of completing one of the Class D expressions is not simply a "medical" one.

79 More on "more" shortly.

80 We'll see why shortly, as we turn to the "extensionalization" of function theory to accommodate "arbitrary" functions, below.

81 Intuitively, the idea would be that one can one-one correspond the points in a volume of any number of real-valued dimensions with the points on the real line itself, or indeed even a segment thereof. It is as if one could put all of the points constituting a cube into one-one correspondence with the points along one corner-edge of that cube. 


\subsubsection{Sharpening the Differences}

Now, if I have interpreted them aright, then we have at least initially a stark contrast between the Wittgensteinian and Cantorian positions. The Wittgensteinian view is that the existence of certain objects can intelligibly be countenanced only where there is some criterion of identity for-interpreted as some workable means of identifying - those objects. If you don't specify something, we might say, then there is no reason to think as of yet that there's anything there to be specified. You might almost call this a species of "humanist"even, ironically, Protagoran ("man is the measure of all things") position. The onus is on the claimant of existence to specify what it is that she claims to exist. Successful selection, and hence the existence, of actually selected objects depend on selection criteria. Intelligible extensions in that sense then presuppose articulable intensions. We might even find here, in this connection, a link to a well known remark in the Tractatus, to the effect that "It used to be said that God could create everything, except what was contrary to logic. The truth is, we could not say of an 'unlogical' world how it would look." 82 The burden in this case is on you, not on God.

Now the Cantorian view, we might say at first, is that the burden is in a certain sense still "on God" here. For even if it be true, per the Wittgensteinian view, that it takes an intension to single out any particular extension (any particular object or group of objects), it must nevertheless first be possible-logically possible, coherent, etc.-to articulate an intension before such intension can be articulated. That is just trivially true, of course; but some upshots of the trivial truth apparently sometimes escape notice. For another way of putting the same thought would seem to be that the articulation presupposes that the terms in which the intension is articulated possess a determinate sense. And that determinacy of sense presupposes an extension- an abstract one, to be sure, but an extension all the same: In this case, the extension of all objects of the kind being discussed-e.g., decimal expansions naming numbers-which might be singled out. ${ }^{83}$ And there seems no reason to suppose that all possible intensions are ever actually articulated, any more than one has to have heard a particular sentencea particular combination of words-before in order to understand that sentence now. ${ }^{84}$

82 TRACTATUS, supra note 49, proposition 3.031 .

83 Recall that the Tractatus itself seems to say something quite similar in justifying the claimed existence of featureless "objects." See TRACTATUS proposition 2.021 , supra note 68 , on equating objects with substance, which in turn is required for determinacy of sense. On the featurelessness of objects, see, for example, TRACTATUS, supra note 49, proposition 2.0232 .

84 This is of course the standard example given by theoretical linguists for why theories of 
So of course extensions are more numerous than intensions, we might say on Cantor's behalf, just as possible combinations-like sentences, for example, which are combinations of words-are more numerous than actually encountered combinations. And for this reason there seems no reason to think that one cannot as it were "inadvertently" hit upon or stumble across some extensions - including abstract oneseven without an intension. ${ }^{85}$ Nor, all the more then, does there seem any reason to think there is nothing there to be singled out in such case: That would amount to a mere question-begging ontic assumption (of nonexistence in this case) just as surely as is the assumption of preintensional extension existence. Indeed it would seem in a way more assuming, since per the Domain Principle it appears that we must assume such existence: Again, our meaningful talk seems to presupposes it.

Finally, there would seem to be no reason why we cannot explore this Domain Principle's "domain" further, determining what its more general structural features must be, what it might and what it cannot include, and so forth. So then perhaps not every choice or selection of a particular object need be criterial. We might well randomly discover things - like what Cantor saw but at first couldn't believe - even while of course not exploring just aimlessly, but nonetheless "openmindedly," inquiringly. ${ }^{86}$ And if we seek understanding of our domain of inquiry in full generality, it would seem to make sense, would it not, to think as much in terms of "possible"-and in that sense "arbitrary"choices as in terms of "actual," criterial choices. That's Cantor, I think, interpreted charitably and interpreted in light of how set theory, and subsequently category theory, ultimately came to be viewed by

meaning are necessary. How are we able to understand an infinity of possible sentences, it is queried. The reply then takes the form of some theory of compositionality, whereby a large finite number of words can placed into no end of possible meaningful combinations. If I recall correctly, the philosopher-linguist Wilhelm von Humboldt colorfully observed that "language makes infinite use of finite means," a quote of which Chomsky appears to be fond. It is tempting to "one-up" this observation and say that, in light of the apparently indefinite extensibility of word- and phrase-meanings over time, the "means" might be other than "finite" as well. For more on these matters, see generally, GORDON BAKER \& P. M. S. HACKER, LANGUAGE, SENSE, AND NONSENSE (1984) (critiquing the significance that theoretical linguists attach to compositionality). The matter of indefinitely extensibile word-meanings figures prominently in the emerging field of "cognitive linguistics," more on which in Robert Hockett, Taking Distribution Seriously (Cornell Legal Studies Research Paper No. 08-004, 2008), available at http://ssm.com/abstract $=1108217$.

85 After all, when you hit upon a particularly nice way of wording something-a way that is still grammatically correct in the way that a decimal expansion is mathematico-syntactically correct-have you not in a sense stumbled upon an extension? Would we not be launched upon an infinite regress were we to say otherwise-i.e., were we to insist that the extension is not there until there's an articulated intension to single it out?

86 Practitioners of algorithmic information theory-that discipline stemming from the work of Kolomogorov and, later, Chaitin-often indeed invoke locutions very much like this. See, e.g., GREGORY J. CHAITIN, EXPLORING RANDOMNESS (2001). 
practitioners-viz. as the study of possible structures.

\subsubsection{Softening the Differences}

Now note, in this connection and in anticipation of a reconciliation I shall try to work below, that we can view Cantor's insistence upon determinacy of domain as an insistence that the domain itself beready?-intensionally well understood! It is an insistence, is it not, that that over which we are quantifying be well defined-i.e., that $i t$ be the extension of a well-formed, fully formulated, hence determinate intension. The concept of a "real number," for example, can be seen to be well understood by somebody not only by dint of her being able to individuate some particular such number, necessarily, but also by dint of her being able to determine, of some given object, whether it does or does not count as such a number when it is presented to her. The criterion of applicability of the concept "real number," that is to say, is not the same thing as the criterion of identity-of individuation-for some particular such number. These are distinct criteria, and one's capacity to employ either of them, I think a defender of Cantor might say, is sufficient to show her understanding of the concept "real number." But one of them-the first one-is what the Domain Principle fixes upon as necessary-as necessarily entailing the existence of certain totalities that might exceed our capacities to individuate certain members of, and as necessarily entailed by our meaningful discourse itself.

For consider again, if the words "real number" are to bear a determinate sense at all-as they certainly seem to do when we use them - there must be such criteria of applicability. And where we have such criteria, again, there we have, in a sense, the totality of objects-be it an indefinitely extensible ("infinite") such totality or otherwise-that meet those criteria. So a Cantorian, I think, can admit Wittgenstein to be perfectly correct in saying that "only a law reaches to infinity," but can then go on to add that there remains still the question of which law. And Cantor's Domain Principle appears to be to the effect that the law in question can be a criterion of concept-applicability as readily as it can be a criterion of particular object-individuation. Indeed it would seem even more readily to be that, if such criteria are indeed entailed by the determinacy of sense of our vocabularies as the Domain Principle would have it. Perhaps, then, we might view Cantor as a sort of Wittgenstein "all the way out," so to speak-carrying the intensionalist position out to its true principled outer limit. ${ }^{87}$ We'll come back to this

87 This is not, I think, merely a gimmicky remark. Note, for example, that Wittgenstein in the 
below. The idea of a prínciple's being carried "all the way out" will recur throughout our inquiry.

Finally in this connection it also seems worthy of notice, if you ask me, that there is actually a striking resemblance between the Domain Principle and Cantor's justification thereof on the one hand, and Wittgenstein's own (compressed) argument for the existence of what he calls "objects" in the Tractatus, his first and indeed only preposthumously published book: Objects form the fixed and unchanging "substance" of the world, which must be present if propositions - all of which in effect "picture" configurations of objects - are to bear determinate sense. ${ }^{88}$ The idea that determinate sense prerequires a determinate domain of namable objects, then, which is set forth by both Cantor and Wittgenstein in the form of a Kantian-style "transcendental argument" proceeding from apparent fact (in this case, determinacy of sense) to apparent prerequisite (in this case, determinate domain), might serve to point us in the direction of a zone of reconciliation between the intensionalist and extensionalist positions. This too we'll come back to below.

\subsection{Deciding Whether-And if So, How-to Decide}

All right, now at least initially we seem to have a problem. We have these two apparently contrary views about limitless possibility in naming, inquiring, and investigating within a domain; and each of them seems in certain respects to be plausible, even compelling. One view emphasizes the need of definite criteria to be actually naming hence

Tractatus singles out a special class of concepts which he calls "formal," concepts which include among them that of an "object." And pursuant to the conception of meaning advanced in the Tractatus, it is, strictly speaking, nonsensical to speak of "objects" simpliciter (the formal concept "object" accordingly amounting to a sort of pseudo-concept). And this in turn entails, as the Tractatus itself admits, that the propositions of the Tractatus are themselves nonsensical. The Tractatus is, in short, self-referentially antinomial, as the work itself forthrightly admits and as Wittgenstein appears to have intended, as one means of "showing" us the sense in which, at the limits of our understanding - that is, at the point where we seek to understand understanding itself - we inevitably cross over into ineffable nonsense, "higher nonsense," we might say. There's a striking parallel between this antinomy, I think, and that which we shall shortly find to afflict Cantorian set theory itself. Finally, note one other thing: As noted earlier, supra note 50, Cantor was sympathetic to Aquinas's own arguments against the actual infinite, and a fortiori would then have been sympathetic to the Wittgensteinian position too. But his answer to Aquinas-that the argument against the actual infinite loses traction once a structure or order has been found in the actual infinite that is presupposed, per the Domain Principle, by the potential infinite-also would seem available as a reply to Wittgenstein. And this reply, again, amounts in effect to the claim that the "actually" infinite extension that is the domain of quantification presupposed by the potential infinite is itself intensionally defined. So, again, I think that we can view Cantor as in effect takıng the Aquinas, Frege, Wittgenstein insistence upon intensional construal "all the way out," to the "limits of understanding" (of quantification), as it were.

88 See TRACTATUS, supra note 49, propositions 2.021 et seq. 
speaking of any particular thing at all. The other view emphasizes the need first of possible such naming-hence the existence of particular nameables-before there can be naming at all, and suggests that such possible naming is itself entailed by the determinate senses of certain general terms that select the domains in which such naming might be possible. This latter view also suggests that certain structural features of this field or domain of possibility might themselves be explored even in the absence of names for each one of its occupants, and even if the entities occupying this field indeed can be shown to outstrip-to outnumber, and in that sense "transcend"-our merely finite capacities to name.

Proponents of the first view, we'll see, then go on to disparage the second as "theology." Proponents of the second view-at any rate Cantor-we'll see in turn, happily admit to that characterization. And it also is open to them, as too we'll see, to point out that the first view itself is in its own way "pietist"-as pietist as we'll find Wittgenstein himself often to have been. And finally, in this latter connection, again, both views appear upon closer examination to share more in common than first meets the eye, or that either set of early proponents seem even to have noticed.

How, then, should we choose? On what grounds would one choose? And why, for that matter, might one feel compelled to choose at all? Is anything actually at stake here, need one choose? If so, is the choice "tragic," in the classical sense in which both options are equally dictated and yet incompatible? Or might they, as I have suggested above, be ultimately reducible to the same, single option-even if, perhaps unavoidably, a somewhat paradoxical option? ${ }^{89}$

Well, in respect of the first of these questions I am nearly inclined to conscript Professor Badiou's delightful reply to my somewhat lengthily elaborated question posed yesterday morning, and say that at certain points one must "simply decide." (I could not have asked for a more perfect entrée into my discussion of Cantorian "decision points," incidentally - but I promise that I did not plan things that way, nor did Professor Badiou collude with me!) But it is by reference to the subsequent questions I just posed, I believe, that one best addresses the matter of identifying such points-again, those "decision points," as I have been calling them-as in respect of which one might actually have to decide.

So let me first say a bit about what seems to have prompted Cantor and other "extensionalists"-who include most, though not all, mathematicians since Cantor-to have decided as they did. Along the way I shall also say a bit about what seems to have prompted

89 I think we shall find that the latter is the answer-but that the one same reduction is itself unit-wise incompatable, i.e., internally paradoxical! 
Wittgenstein and other "intensionalists" to have decided as they did (assuming that Wittgenstein for his part ever in fact finally "decided" at all). ${ }^{90}$ Then we shall be well poised to draw out such lessons as we might here for general jurisprudence and welfare economics. For I think, first, as mentioned in introducing my talk that the intensionalist versus extensionalist dispute in mathematical foundations boils down to a well sharpened criterial versus arbitrary choice dispute that we shall find running through general jurisprudence and welfare economics as well. And I think, second, both as suggested above and to anticipate, that there is ultimately a rather satisfying sense in which the Wittgensteinian and Cantorian positions can be, to non-trivial degree, actually reconciled once we reflect upon the second Cantorian decision point-that concerning what to do about self-reference.

The reconciliation that I shall attempt, moreover, seems to me to offer means of resolving — dissolving, in fact-some hitherto seemingly intractable disputes in the other two disciplines I have indicated. As just suggested, however, I shall have to resort to the other "decision point" in working the reconciliation. Please bear with me a little longer, then, as I first attempt to explicate (a) why extensionalists and intensionalists chose as they did in respect of criterial choice, then (b) how both choices end up implicating self-reference, and finally (c) how adequately confronting the indeterminacies and antinomies to which self-reference gives rise yields what appears to be the only satisfactory way possible both to handle indeterminacy and antinomy and to reconcile criterial with arbitrary choice. It is a way to which I believe both Cantorians and Wittgensteinians, and in a certain sense therefore all of us, are ultimately committed.

\subsubsection{Charting the Continuum}

The reason that Cantor decided as he did-and, for that matter, the reason that despite fierce initial opposition, his view ultimately triumphed among mathematicians-is simpler at bottom than first might appear. It was essentially a matter of (a) carrying forward a logic by then well embedded in the discipline as theretofore developed, and relatedly (b) an apparent theoretic necessity rooted in by then current and quickly developing mathematical practice. We'll also do well to

90 What Wittgenstein actually decided, in the end-and whether he ever came to some decided set of beliefs - is a matter of some controversy. Witness the great variety of conflicting interpretations, and of course the inimitable questioning style of virtually everything we have from his pen written after the Tractatus. One suspects that the relentless questioning is in a sense of a piece with this fellow's fascination for so many. In a way, he seems to be locked into what all of us are locked into, "only more so." To watch him think is to watch our own drama enacted with more passion and clarity than many of us manage (or bother?) to muster. 
remember that all here occurred against the backdrop of simultaneous movement on the parts of the physical sciences, geometry, and mathematics more broadly, from the late sixteenth or early seventeenth century onwards, in the directions of greater abstraction, conceptual unification, and "rigor" of a sort. Now this is potentially a very long, complex tale-much longer than we have time for today. But I've worked out a short-playing version that I think won't mislead us. Here goes.

Commencing at about the time that Descartes and Fermat began developing algebraic means of systematically conducting geometric inquiry, geometers and physicists began gradually to depart from their previous reliance upon spatial intuition and visualizable figures. They moved steadily thereafter toward regular employment of abstract symbolic word- and sentence-like expressions comprising numerals, letters, and signs for arithmetic operations- - +,", "c," " "," and the like-in representing the relations of which they treated. Spatial and temporal magnitudes, relations among which to that point in the main had been explored visual-intuitively with straight-edge and compass came increasingly to be explored via more logico-combinatoric, symbolmanipulative methods.

Why did this happen? Presumably part of the answer lies with one of those who appears to have initiated the movement in the first place: Descartes, you'll remember, is the fellow who famously doubted. How might we be certain, he had inquired, that our experiences were not all illusory-the product, perhaps, of a "malign genie?" It is perhaps not surprising that such a fellow should have mistrusted exclusive reliance upon spatio-temporal intuition and figural drawings in geometricomathematical inquiry. ${ }^{91}$ An additional and indeed related impetus probably would have been this: Geometry since the time of the Greeks had been flummoxed by apparently "incommensurable" magnitudes such as circumferences and diameters, or the sides and diagonals of squares-relations corresponding to our "Class C" expressions above. Perhaps, then, Descartes and successors would have reasoned, we might draw a better bead on these puzzles by more sharply defining and rigorizing the magnitudes in question with the then-freshly developing logico-combinatorial methods of algebra.

Now as geometry was thus "algebraized" and transformed into what ultimately came to be called "analytic" geometry, it was in a sense

91 I run some risk here, again, of overstatement. There are actually some startling anticipations of Descartes' algebraization of geometry in Archimedes and, subsequently, the Renaissance Italian, Vieta. Moreover, Fermat seems to have anticipated Descartes' own method by ten years, but did not publish until after Descartes. I must then importune that we not elide from the convenience of singling out particularly significant contributors to the false belief that all developments spring fully formed from the minds of certain singular "geniuses." 
only natural that the physical sciences should begin to be algebraized too. For as we noted above, these sciences themselves as then practiced already were heavily geometrized: Natural scientists at the time were exploring the motions of bodies on earth and beyond, and motion was a matter of changing spatial positions through time. It was quite understandable, then, that motion would come to be represented on the newly developed metrical Cartesian plane-mapping changes in spatial position on one axis, corresponding changes in temporal position on the other. Such correspondences were of course, abstractly speaking, precisely what motion was, after all-changes in spatial position corresponding to varying temporal instants.

Now in view of motion's being a relation between one set of changes (spatial) and another (temporal), the notion of a "function"--an algebraic representation of the relations between varying $x$ and $y$ values in the Cartesian coordinate plane-naturally enough came to figure with increasing prominence in the work of such figures as Leibniz and Newton. To the graphic representation of change corresponded a new and yet more abstract formulaic representation of change: We moved, in effect, toward conceiving discrete "correspondence" relations between members of what effectively amounted to one class (e.g., a class of spatial points) and members of another class (e.g., of temporal instants). Physical instants, durations, positions, motions, and paths just like geometrical points, lines, curves, and planes, then, came increasingly to be thought of in equational and cognate abstract formulaic terms rather than merely as graphic visual images or otherwise intuited temporal processes.

Now as might be apparent already from what I have just said, one particularly poignant challenge to which the movement from images to formulae-from continuous "graphs" to discrete correlational "functions"-gives rise is that of first "punctualizing" the continuum (the continuous line segment or curve), then "numerating" the points. This is quite simply the problem of representing the lines, planes and volumes of geometry (and ultimately topology) as sets of points representable by numbers or ordered sets of numbers. ${ }^{92}$ For one identifies places or positions along or within or without such forms, recall, by numeric coordinates-Cartesian $x$ and $y$ values. And these latter, again, stand-in for discrete and extensionless points. In order for spatial or temporal intuition to be fully proxied by formulaic expression per the Cartesian desideratum, then, it grew increasingly obvious that mathematicians would have to determine whether and how every point

92 Think of the ordered sets of numbers here as the familiar " $n$-tuples" of numbers that name coordinates in $n$-dimensional spaces. Where $n=2$, a point is represented by an ordered pair $(x, y)$, the first term in the pair naming the horizontal coordinate, the y term the vertical one. Nothing more complicated than this need be countenanced here. 
on a line segment or curve, or within a volume more generally, might be indexed by numbers.

Now, there are three things to note here that bear straightaway on the intensional criteria versus extensional selection question with which we are ultimately concerned. These are matters that come up the moment we embark upon treating continuua as aggregates of points and then indexing points with numbers or ordered sets of numbers. The first is that, since we are now viewing points as being, in a certain sense, "there" even before assigning them numbers, ${ }^{93}$ it now becomes in a sense "natural" to postulate that, if the points can all be assigned numbers, then in a sense the numbers too all are "there," even before we define them. The numbers are there to be found and then designated precisely because they correspond to points that are there to be found and then designated. It is for precisely this reason, I think, that Wittgenstein came to deny this very premise, a point to which we shall return. He understood very well that the premise itself, if granted, would tend to the Cantorian position-and in that sense he understood that mathematics itself had been tending toward the Cantorian position at least since the time of Descartes.

The second thing to note is that, for reasons tied to such incommensurabilities as those we observed in connection with our Class $\mathrm{C}$ expressions above, punctualizing the continuum and then enumerating the points proves to be a bit difficult! You might have thought it was all just a matter of ongoing "infinite" division: Keep dividing a line segment, the thought would run, and you'll assymptotically approach the set of all points on that line. Indeed this is precisely what the earlier, Greek conception of points, lines, and (hyper)planes as mere "breaks," respectively, in lines, planes and volumes suggests. But if this were in fact fully satisfactory, and if the points (as breaks) all in turn were indeed indexed by numbers, then all numbers would be rational - they would be ratios, divisions.

The fact that not all relations between geometric magnitudes are representable by such fractions-hence by rational numbers-is effectively the fact that the geometric continuum is in some sense (what sense is what ultimately proves to be at issue) far richer than can be replicated in acts of division, even "infinite," "indefinitely continuing,"

93 The significance of this shift is often missed. In the prior, essentially Greek conception, a point tended to be viewed more as a gap or a "break" in a line- "the point at which" one line broke another one, for example-than as a constitutive "part" or "member" of a line. A shadow of that conception is of course found in the locutions "dimensionless point," and "extensionless point." The point was the donut hole, not the donut. Likewise for line-segments, of course, and planes, etc. The line segment was no more than the locus over which one plane cut another; the hyperplane no more that an analogue in the case of volumes, and so forth. The shift to viewing these entities as constitutive of, rather than opened by, continuous magnitudes was subtle but critical, as we are about to see. 
or "unendingly iterated" such acts. It exceeds the capacity of our Class B expressions, above, to represent. This turns out to be just another way of saying that we must employ at least some such expressions as those hinted at by the expressions of Class C and even of Class D, if we are indeed completely to enumerate a fully punctualized continuumi.e., a continuum now viewed as "made up of," rather than merely "divvyed up by" points. ${ }^{94}$ And just as the question of what it could be for literally extensionless (unextended) points actually to "add up" to extended line segments or curves is exceedingly puzzling to say the least (as if there were some number large enough that that many zeros would be larger than zero), so do the "numbers" purportedly indexing such points prove to be puzzling, as we'll presently see.

The third and final thing to note here is that, once we decide that the continuum perhaps can indeed be punctualized and then arithmetized, we shall immediately have positioned ourselves, ipso actu, to countenance some previously uncountenanced prospects: First, we shall now naturally come to conjecture that there might be some, indeed many "functions," conceived now as graphs (in effect, what we shall soon begin calling "point sets," or in a word mentioned earlier, "extensions") that can be traced on the plane "prior" to being formalized arithmetically - and whose formulaic expression might then turn out to be difficult to write out compactly. If the points are all there, after all, so will there be all manner of possible aggregates of such points - even "randomly selectable" ones, and even selectable ones that never happen to come to be selected. Mathematics might then come to be seen as the study of such selection-possibilities themselves.

Second, we might conjecture that there might likewise be some, indeed many "functions," conceived now as formulae (what we shall soon be calling "laws," "recipes," or, in the other word mentioned earlier "intensions") that can be formulated "prior" to being graphed and whose graphs might then turn out to be, shall we say, a bit difficult to trace or even visualize. They might indeed be so difficult to imagine that we'll be tempted to label them "pathological!" (Note the resonance between "patho's" relation to "logical" on the one hand and "ir's" relation to "rational" on the other.) Enter here the so-called "arbitrary function" problem-a problem quite intimately associated with this course of punctualization and arithmetization as I have been briefly (I hope not too briefly) describing. It is also a problem quite intimately connected to Cantor's work and the first Cantorian decision point, which you'll recall we've been calling the "criterial" versus "arbitrary" (or "random") choice point. No random accident, this.

94 We'll see presently why the Class C expressions are not enough - that is, why not all of the points on the line can be put into relation with computable numbers. 


\subsection{2 “Arbitrary" Functions}

One way of viewing the gradual algebraization and arithmetization of geometry and the physical sciences that we've been describing is as a gradual movement toward greater conceptual unity and generality across previously distinct mathematical domains. The punctualization and arithmetization of the continuum of course worked in this way in their own rights. But they also set the stage for yet further movement in this direction.

One way in which they did so was that of enabling mathematicians quite readily to view functions from either of two "sides," so to speak, both of which sides are implicit in some of what I have said just above: One could view functions as mere correlations-indeed any such correlation-between Cartesian $x$ values and $y$ values on the plane, and in that sense as no more than the graphs of selected $x, y$ coordinates themselves. Or she could view functions as the formulae which stated those relations and thus "generated" those graphs. The former view would be what I've been calling "extensional." It would be a view of functions simply as sets of points, hence effectively as sets of ordered $x$, $y$ numerical pairs-sets of (two-membered) sets. The other view would be what I have been calling "intensional"-a view of functions as the "laws" that pick out the aforementioned points and/or numerical pairs.

Now initially in the era that we are considering, emphasis tended to be placed on the intensional aspect of a function. The function was viewed more as the "law" to which the graph served as little more than a heuristic aid. This was consistent, of course, with the Cartesian privileging of algebra in the first place, prompted by distrust of sole reliance upon sensory experience or intuition. But as progress was made in punctualizing the continuum and then arithmetizing the resultant points, mathematicians found it increasingly tempting to explore both sides of the divide, so to speak, in their own rights. In consequence, previously observed restrictions-"prior restraints," as we lawyers might call them-steadily came to be lifted in the activities of conceiving, formulating, and investigating functional relations.

Probably the best known early figures in this movement in the direction of "liberalizing" function theory were Euler, Fourier, and Lejeune-Dirichlet, nowadays better known as "Dirichlet." Dirichlet, most significantly for our purposes, seems to have been the most thorough in investigating "from both sides" a prospect first famously raised and preliminarily explored by Euler and Fourier-that of first drawing a graph (indeed any graph), then calling a "formula" yielding that graph a "function" even if the "formula" had to be formulated differently over different intervals of the graph. It would count as a "function" defined over the interval $x_{q}$ to $x_{z}$, for example, even if one 
algebraic formula characterized the $x$ and $y$ relation from $x_{q}$ to $x_{r}$, then another such formula did the trick from $x_{r}$ to $x_{s}$, and so on all the way to $x_{z}$. A functional formula, in short, could be what we now call "piecewise" constructed. Dirichlet investigated the implications of such prospects as these, eventually developing a significant number of truly strange-in some cases notoriously so-"pathological" functions. Indeed he developed formulations that appeared to be well-enough formed and thus surely to describe possible graphs, but whose graphs were entirely imagination-defying.

Dirichlet's movement forward along these lines could readily be viewed, as I have suggested, as simply pushing mathematics further along "on a roll" that it had by now long been on. This "roll," again, was simply the full algebraization of the continuum begun by Descartes and Fermat. Dirichlet was investigating possibilities opened up by that process, exploring relations between possible formulae and possible graphical representations in full generality, that is all. It turned out, however, that his steady self-emancipation from formulaic restrictions in conceiving functions yielded side benefits which grew increasingly appreciated by mathematicians..$^{95}$ Nothing previously present seemed to be lost, while much more now was gained. Such gains came particularly in the shape of ever-augmented generality and conceptual unification, desiderata earlier mentioned to have been attractive to Descartes and his followers as well. Particularly attractive, in this connection, was the ease with which Dirichlet's fully liberalized conception of functions - as effectively randomized correlationspermitted analysis as developed by the likes of Newton and Leibniz (as earlier mentioned, itself enabled by the Cartesian innovations), to be fully generalized to functional spaces beyond those that modeled mere physical motion.

It is surely for reasons such as these that the Dirichletian conception of functions came ultimately to prevail. It is now customary among mainstream mathematicians to consider functions extensionally-as sets of ordered $n$-tuples, hence sets of sets. ${ }^{96}$ It is also of considerable relevance to our story that among those who followed Dirichlet's lead was another of the more influential mathematicians of the ninteenth century, Bernard Riemann. For Riemann, we shall soon see, was a teacher to both Dedekind and Cantor, and made extensive use, in his own investigations, of correlations between points

95 It seems often to be thus in mathematics. The logic that's latent in some movement carries forward to "beautiful" newly discovered possible operations and constructions. Later, applications are found for these things-applications within other mathematical subdisciplines, and applications in other less mathematical disciplines.

96 Those who do not treat them this way are the algorithmically-oriented folk whom we above saw to stem from the Wittgensteinian tradition. See supra note 60. 
constituting what he called "manifolds" ("Manfaltigheiten")-direct ancestors of the "sets" of which Cantor and Dedekind ultimately came to make much. It also bears noting, in this connection, that Cantor first developed what came later to be his transfinite ordinal numbers while working on a problem first posed by Dirichlet. This stemmed from the so-called "representation problem" opened up by the liberalization of function theory in the first place. It was the question whether every arbitrary function can be uniquely represented by some "Fourier series" of trigonometric formulae. ${ }^{97}$ Cantor's first celebrated result was that the answer was "yes," but what proved more important were the means he developed to reach that result. More of that presently.

\subsubsection{Early Intensionalist Backlash}

Now, before moving on to Cantor's role in all of this, and in anticipation of the specific Wittgensteinian response to Cantor himself that we shall find to have been to intensions much what Cantor's was to extensions, I should note that this movement in the direction of fully punctualizing the continuum, numbering the points, and then accepting arbitrary functions was initially a departure from prevailing opinion. And not surprisingly, therefore, it was not without critics-indeed even vehement critics for a time. Probably most vocal among them was Leopold Kronecker, who not surprisingly later came to figure prominently as a vigorous opponent of Cantor and Cantorian set theory themselves. Kronecker held a number of connected methodological commitments that can readily be viewed as adumbrating later positions taken by mathematicians of finitist, constructivist, and indeed Wittgensteinian persuasion. ${ }^{98}$

The best known - or at any rate most nauseatingly oft-quotedsuch commitment probably was Kronecker's claim ("legislation," as Hilbert amusingly put it) that only the natural numbers could be legitimately taken as primitives, the existence of any others then being subject to their being definable in terms of the naturals. ${ }^{99}$ Another characteristically Kroneckerian position was that infinite totalities such as numeric series could be construed only in Aristotelian "potentialist" terms, never as "completed" totalities. (Cantor's "Domain Principle"

97 See, e.g., DAUBEN, supra note 1, at 30-46.

98 It is also well documented, incidentally, that Wittgenstein cited work of Kronecker's in conversation. See generally FREIDRICH WAISMANN, WITTGENSTEIN AND THE VIENNA CIRCLE: CONVERSATIONS (Brian McGuinness ed., Joachim Schulte \& Brian McGuinness trans., 1979).

99 This view found canonical expression in the above mentioned, somewhat annoyıngly oftquoted Kronecker soundbite that I just cannot bring myself to quote here, the one concerning God's having fashioned the integers, all else being the work of "man." It wasn't merely Cantorian extensionalists who were mathematical theologians, as I indeed intimated above. 
directly targeted this position: If we can speak of "the" natural numbers, and there is no end to them, then there is an infinite totality of natural numbers of which we speak.)

Finally and relatedly, Kronecker held that we could not make sense of definititions or proofs that cannot be formulated or carried out in a finite number of steps. A sort of corollary to this position is the admonition often attributed to Kronecker that no infinite series should be viewed as legitimately designating anything absent a rule for generating or calculating each term in it. In effect, of course, this means that Kronecker would have approved our "Class C" expressions above, but not those of Class D. In this latter connection, it is significant for purposes of some questions that arise below in connection with Cantor's "diagonal argument" that one of Kronecker's students, Julius Molk, objected to Dirichlet's extensionalist conception of ("arbitrary") functions precisely on grounds that this conception treated as intelligible, "on faith" as it were, even such functions as could be characterized by an "ideal table." $\mathrm{He}$ is worth quoting here if for no other reason than that we shall soon find the Cantorian diagonal argument itself, and Cantor's subsequent effort to order the continuum, to implicate precisely such ideal tables:

In order to bring to the fore the arithmetical dependence of a (real) variable $x$ and a function $y$ of this variable $x$ in a domain $(x)$, in the general sense of the word given by [Dirichlet], one would have to draw a kind of "ideal table" in which each value of $y$ is facing the corresponding value of $x \ldots$... [But] one cannot see how [this] could be effectively realized. [Morover,] there is no need for [such a table] since, in order to study in a precise manner the arithmetical dependence of $y$ and of $x$, it is not necessary to encompass it all in one look; it suffices to obtain at any moment, in a rigorous fashion, those of the elements which are needed... This is the case when the ideal table is, so to speak, condensed in a computational procedure from which one obtains effectively the value of $y$ corresponding to each value of $x$ in the domain $(x) .{ }^{100}$

I trust it has not escaped notice how much this passage anticipates the Wittgensteinian position I described earlier. Indeed, there is even evidence that Wittgenstein had read much of the literature on all sides of the debate over arbitrary functions. ${ }^{101}$ It also, we'll see presently,

100 Julius Molk, Principes fondamentaux de la théorie des fonctions, in ENCYLOPÉDIE DES SCIENCES MATHÉMATIQUES PURES ET APPLIQUÉES 20 (Molk ed., 1909), translated in MATHIEU MARION, WITTGENSTEIN, FINITISM, AND THE FOUNDATIONS OF MATHEMATICS 9 (1989) (lightly modified by myself). Wittgenstein too, incidentally, had something to say about "ideal tables": "It seems to me to be nonsense." See WAISMANN, supra note 98, at 47.

101 See, e.g., MARION, supra note 100, at 74 passim, 94 passim. There once was a regrettable tendency among some mathematically informed philosophers to speak dismissively of Wittgenstein's mathematical writings, as if this had been an area in which the fellow simply had not been well versed. Further study has put the lie to that notion-one that ought perhaps have 
anticipates views held by many who have been called "intuitionists"whose views often strike one as "middling" positions between full Wittgensteinian and Cantorian views. ${ }^{102}$

It is also not without significance that a substantial number of subsequently influential French mathematicians who studied under Kronecker came to put forward similar views. Best known among them probably were Baire, Borel, Drach, Lebesque, and ultimately the quite influential Poincaré-sometimes labeled "the French semiintuitionists." Much of these gents' later insistence that mathematical objects be effectively definable by finitary means, along with Wittgenstein's consistent insistence upon the algorithmic, calculative, and indeed even applicable nature of mathematics, proved influential in the later development of computability theory, recursive function theory, and the lambda calculus, as mentioned earlier. These are the heirs of the intensionalist tradition as surely as latter day set theory and indeed category theory can be viewed as the heirs of the extensionalist tradition.

What we see here, then, is that it is precisely the notion of an arbitrary function, which seems to have developed straightforwardly out of the cognate projects of arithmetizing the continuum and generalizing mathematics, that split those with opinions on mathematics into what I have been suggesting amount roughly to Wittgensteinian and Cantorian camps. Crudely speaking, those of the Cantorian persuasion ultimately made themselves comfortable with fully extensionalizing mathematics and in that act taking mathematics to be, in effect, "about" somethingabout points, numbers, sets, and ultimately other abstract objects of a more or less Platonic nature including, as we shall see, actually "completed infinities."103

appeared immediately as implausible as it surely was, given Wittgenstein's background as an engineer. In all events, the shift is nicely evident in the contrasting "before" and "after" assessments of George Kreisel. See supra note 61 .

102 There is accordingly an analogy one might draw between these positions and Dworkinian views discussed in Part 3, infra. Intuitionists, in Dummett's words, aim "to reform mathematics, not to prune it." See M. A. E. DUMMETT, ELEMENTS OF INTUITIONISM 45 (2d ed. 2000). In effect, then, they attempt to reinterpret it in its most plausible possible light, rather as Dworkin aims to interpret the law-the given, "posited" law-in its "best" light. But more on this below.

103 Strictly speaking, of course, one need not be Platonist to accept this "aboutness" idea. One might be some manner of Brentanian, Meinongian, or even Husserlian "intentionalist""intentional" with a " $t$ " now, not an "s." The phenomenological tradition that grew out of the thought of these thinkers would hold that it is simply an ineluctable attribute of human consciousness itself to "objectify"-to posit objects "toward" which our thoughts and our consciousness are "directed." The same phenomenon is at work in the writing of fiction, they might say. See generally PRIEST, supra note 55. An influential Anglophone philosopher of mathematics-Quine's successor to the Peirce Chair at Harvard, no less-who plies this tradition to a considerable extent is Charles Parsons. See, for example, CHARLES PARSONS, MATHEMATICS IN PHILOSOPHY (1980), a collection of some of Parsons's more influential early papers. 
Those of the more Wittgensteinian persuasion never have accepted this, insisting instead that mathematics remains in its essence an assortment of variously related calculative methods-even if often very sophisticated such methods-which therefore should not, strictly speaking, be viewed as being "about something" but rather simply applied to various things. ${ }^{104}$ That view in turn construes "totalities"sets, aggregates, etc.- - as no more than ever-finite outputs, of various lengths, generated by pre-formulated algorithms-intensions. It accordingly eschews the picture-if "picture" there even is here (can you picture this?) - of completed infinities as a misconceived extrapolation from the case of finite series or lists, a misconception effectively grounded in misunderstanding of the "grammar" of such phrases as "and so on." Where the "so" bears a content, the only "infinity" in play is the indefinite iterability of what ever rule it is to which the "so" refers back as a manner of pronoun. Again as Wittgenstein himself put it, "only laws reach to infinity."105

\subsubsection{Enter Cantor, with Some Help from a Friend}

All right, so now we are positioned more fully to appreciate the significance of, and impulses behind, Cantor's going fully extensional. ${ }^{106}$ Cantor began, in effect, along with his occasional friend and mentor Dedekind, as more or less just another contributor to the aforementioned then-ongoing mathematical course of arithmetizing the continuum that we saw Descartes and Fermat in effect to have

104 See, e.g., Ludwig WitTgenstein, Philosophical REMarks 157 (Rush Rhees ed., Raymond Hargreaves \& Roger White trans., 1975) ("the signs . . do mathematics, they don't describe it"); id. at 159 ("We can't describe mathematics, we can only do it. (And that of itself abolishes every 'set theory.')"). Relatedly, Wittgenstein eschewed prose glosses on mathematical results, which he viewed as getting in the way and propagating misleading pictures. See, e.g., WAISMANN, supra note 98, at 137 ("The proof lets us see something. What it shows, however, cannot be expressed by means of a proposition."). "Less talk," we might view him as saying, "more rock."

105 See supra note 2. Incidentally, I think we can see here what marks Wittgenstein off from the "intuitionists." The latter agree with Wittgenstein about rules and infinity, more or less, and this accounts for their firm insistence upon "constructability" as a criterion of mathematical existence. But they remain attached, nonetheless, as the notion of "construction" itself here attests, to the picture of mathematics as being about something, about objects. It is just that their objects are "mental constructions" rather than Platonic ideals. The thoroughgoing Wittgensteinian rejects the "object" picture itself, hewing firmly to the view of mathematics as what even the Tractatus called "a logical method"-i.e., a sort of "toolbag" of calculii.

106 Cantor did so, in a sense, notwithstanding a mathematical consensus before him. For, although we shall see that pressures toward extensionalism were mounting in consequence of the very history that $I$ have just very briefly elaborated, all influential mathematicians who spoke in respect of the matter at all spoke an intensionalist party line. The line took the form of a conventional wisdom that functions could not be arbitrary; that all were "lawlike." More on this presently. 
initiated. ${ }^{107}$ That meant, among other things, providing some numeric account of the "gaps" between rational numbers $\mathbb{Q}$. Those were the gaps corresponding, most immediately for puntualization of space, algebraization of geometry, and arithmetization of analysis purposes, to such relations as those between "incommensurables" of the square's side and diagonal, or the circle's circumfrence and diameter. These, then, were gaps calling for numbers of what we earlier called the "Class C" variety. So among the earliest contributions made by Cantor and Dedekind were two of the first complete and consistent definitions of the real numbers-the "gaps" present between even infinitely compact rational numbers.

Dedekind's approach was the simplest and most elegant, though for precisely this reason suspicious to some. I am alluding to the familiar "Dedekind cut," defined simply as the gap itself between distinct sequences of rational numbers between which some such irrational relation as pi, or root-two, or even an as yet undesignated such relation might fall. ${ }^{108}$ If the gap falls just where you require a number, Dedkind in effect said, and if one can consistently apply familiar arithmetic operations-addition, subtraction, multiplication and so onor analogues thereto to these gaps, just say the gaps themselves are the numbers. It might not be surprising that Russell lauded this solution as enjoying "all of the benefits of theft over honest toil." 109 This isn't quite fair to Dedekind, but fully to spell out precisely why would amount, I'm afraid, to a distraction in the present context.

Suffice it for present purposes, then, to note that at the heart of the matter is the question of what precisely it is for mathematical objects to "exist." Are there such objects at all, and if so, are they in some sense independent and self-standing in the way Pythagorus and his followers Socrates and Plato appear to have thought? Or were they in some sense "constructed" by "intuition" or intellect? If the latter, in what did such

107 This is greatly to simplify, to be sure. More specifically, for example, Cantor began as a contributor to the study of Fourier series, while it is Dedekind who was more immediately actuated by the wish to afford conceptual unity and rigor to the whole of mathematics by, among other things, grounding all in a completed number system. (Dedekind seems to have been of a particularly "systematic" disposition, even having recorded his body temperature each day in his diary.) But that level of detail, much as someone like Dedekind himself might have preferred it, would amount to distraction here. And the study of Fourier series is of course, in any event, precisely the study of relations between certain algebraically representable functions and their graphs-hence, between certain algebraic formulae and geometric figures. So let us stick with our algebra-geometry story at the present level of generality. It also bears noting that both Cantor and Dedekind, in contrast to Weierstrass and others of their immediate contemporaries, were quite explicit about connecting their numerical work-in particular, their work on defining the irrationals, more on which presently - with the points on and geometry of the Euclidian line.

108 See RICHARD DEDEKIND, ESSAYS ON THE THEORY OF NUMBERS (Wooster Woodruff Beman trans., 1901).

109 See Bertrand Russell, introduction to Mathematical Philosophy 71 (1919). But Russell of course harbored ontological ambitions quite distinct from Dedekind's. 
"construction" consist? What could it be, apart from metaphorical, for the intellect to engage in "construction" of such kind?

Dedekind's answer to such questions was, in effect, that any object which can be defined without logical contradiction and then integrated into a system of already familiar calculative operations like arithmetic "exists" in the only sense that matters for mathematical purposes. ${ }^{110}$ In effect, then, Dedekind's criterion is reminiscent of a celebrated Fregean, and later Wittgensteinian, maxim about word- and symbol-meanings. I am alluding to the so-called "context principle," pursuant to which "it is only in the context of a sentence that a word bears a meaning." 111 For Dedekind, I think it fair to say, the relevant context was, not simply a sentence, but a full calculus-an arithmetic. Carry that idea out further, to full "theories," "languages," "language-games," "forms of life," and so forth, and you arrive at a manner of "meaning wholism," complete with attendant metaphysic or ontology (hence Wittgenstein's "metaphysics as the shadow of grammar" and Quine's "ontological relativity") familiar to mid-twentieth century philosophy decades later and indeed even to "pragmatist" philosophers of earlier times. ${ }^{112}$

Dedekind's existence criteria were a bit cavalier for many of his time, including the aformentioned Russell, whose ontic ambitions were rather more traditional than Dedekind's. ${ }^{113}$ Most in the late nineteenth and early twentieth centuries wished to be able to view new kinds of number as independently self-standing, even apart from the operations performed on or the calculations performed with them. The numbers were meant to serve as "foundations" of such operations, and thus had to be defined as it were "prior to" such operations.

For practical purposes this meant defining new numbers in terms of old numbers-in particular, the natural numbers, which as we noted above Frege had managed quite well by reference to concept extensions. Cantor's approach to defining the irrationals, we'll see in a moment, was of this less suspect type. And probably for this reason, it has proved more enduring than Dedekind's. Nevertheless, as we'll see

110 Note that a similar approach to defining new number types is visible in such constructions or "discoveries" as "imaginary numbers"-i.e., numbers which, when sqaured, yield negative numbers. Likewise, accordingly, the case of complex numbers. All that is typically required is that such introductions fill gaps opened by existing mathematical operations, and that their introduction not introduce self-contradiction into the relevant calculus. We'll see presently that it subsequently grew doubtful whether standard arithmetic itself, once fully "founded" upon sets, could pass that test.

111 See FREGE, supra note 29. Note also that Frege and Dedekind were contemporaries, and read one another.

112 Actually Peirce, one of the founding "pragmatists," was himself of course a contemporary of Frege and Dedekind, and published views quite anticipatory of Quine and even Wittgenstein's later views. He was not widely read in his day, but certainly is now.

113 See, for example, Russell's objections in BERTRAND RuSSELl, PRINCIPLes OF MATHEMATICS 278 passim (1903). 
shortly, Dedekind's take on the matter of mathematical existence was ultimately quite influential on Cantor. For Cantor in effect fell back upon it as his work took him steadily in directions that required his defining yet more exotic numbers-_"transfinite" numbers-quite beyond the most visionary dreams of Dedekind or anyone else.

As I say, however, at least in respect of the irrationals, Cantor's approach to defining was a bit more traditional and in consequence more complicated than Dedekind's. But it also, as mentioned, has proved quite enduring. That owes in large part, one presumes, to its greater traditionality and thus familiarity itself. And it owes also, one suspects, to its reliance upon concepts familiar to analysis from Cauchy onwards, in which latter Cantor's approach is in consequence quite readily applicable. ${ }^{114}$ I allude in this case to Cantor's so-called "fundamental sequence" approach to defining the irrationals, understood by reference to Cauchy sequences. In this case real numbers are defined as sequences of rationals-hence, sets of rationals - such that, for any positive rational $\varepsilon$ there is an integer $l$ such that $\left|a_{n+m}-a_{n}\right|$ $<\varepsilon$ for any $m, n>l .{ }^{115}$

The real number as defined by Cantor, then, is treated as a "limit" toward which sequences of rationals converge but of course never quite reach, the sequences themselves being such that one is always able to bring the last term in any such sequence "as close as one likes"-i.e., within $\varepsilon$ for any "arbitrarily" selected $\varepsilon$-to the limit. Such limits, since one only approaches but never reaches them, are of course not unlike "gaps," and the similarity shows up in a particular form I'll describe in the next paragraph. But as noted before, thinking in terms of sequences and limits had become familiar by Cantor's day, and so not surprisingly

114 Cantor's approach has been viewed by many as a simplified rendition of the account given by his Berlin teacher, Weierstrass, who in turn acknowledged the influence of Bolzano. See DAUBEN, supra note 1,

115 See GEORg CANTOR, CONTRIBUtions to THE Founding OF THE THEORY OF TRANSFINITE NUMBERS (Philip E. B. Jourdain trans., 1915). Cauchy sequences, which had been pioneered decades earlier by the cloistered priest-mathematician Bolzano, were developed in order to afford consistency and rigor to the calculus-i.e., to what came to be known as mathematical "analysis"-itself. The latter had fallen into disrepute since the time of Bishop Berkeley's celebrated attacks upon the inconsistency-riddled locutions of Newton and others in respect of the "infinitessimals" upon which the calculus-in those days indeed simply a calculus, a technique, more than a rigourous "theory"-was at that point seemingly founded. See GEORGE BERKELEY, THE ANALYST, OR, A DISCOURSE ADDRESSED TO AN INFIDEL MATHEMATICIAN (1734). The new idea, in essence, was to view the calculation involved in the calculus as an iterated-ultimately, an indeed "infinitely" iterated-process of approximation. The derivative or integral of a function could then be viewed as a "limit" to which one could draw arbitrarily close without ever quite reaching. (A sort of asymptote.) To each such iteration corresponded a term in the sequence, the terms all then "converging" toward the limit. A good historic account of these developments is CARL B. BOYER, A HistORY OF THE CALCULUS AND ITS CONCEPTUAL DEVELOPMENT (1959). A helpful treatment of present day analysis in terms of the kinds of problem that prompted Bolzano, Cauchy, Weierstrass, Riemann and others to set analysis upon its present footing is Otto Toeplitz, The CALCulus: A GeneTiC APPROACH (1963). 
the mathematical community was a bit more receptive to Cantor's somewhat more opaque rendering than to Dedekind's more-dare we say?- "honest" one.116

Now it happens that Dedekind's and Cantor's systems of real numbers $\mathbb{R}$ are effectively isomorphic, and in that sense, systemically speaking, are identical. They also go a long way toward completing the arithmetization of the continuum. ${ }^{117}$ Both systems, for one thing, are respectively closed under the operations of cut-forming and sequenceconstructing: Dedekind cuts among reals are themselves reals, that is to say, and Cantorian fundamental sequences of reals are themselves reals as well. Both cuts and fundamental sequences also are closed under the familiar arithmetic operations defined over the other number domains: Operations defined over the integers $\mathbb{Z}$ and the rationals $\mathbb{Q}$, that is to say-addition, subtraction, multiplication and division-operate analogously over the reals as defined by both Cantor and Dedekind. So with Cantor and Dedekind the long course of conceptual unification and rigorization initiated by Descartes and Fermat - that of fully arithmetizing the continuum by punctualizing it and then grounding the points in a completed number system - is very nearly, though not quite yet completely, consummated. ${ }^{118}$

\subsection{Extensionalist Triumph—and "Tragedy"}

Now, I said just now that the Cartesian project of fully arithmetizing the continuum was nearly, but not quite completely, consummated in Cantor's and Dedekind's definitions of the reals. What was required to complete the mission is what ultimately accounts, I believe, for Cantor's and most of his mathematical successors' having settled upon the position that they did in respect of the criterial choice versus arbitrary selection decision point. So at last we are poised now to see what precisely is at stake in the matter of "choosing" between Wittgensteinian intensionalist and Cantorian extensionalist positions as adumbrated above. Let's draw it out by continuing the narrative we've been following.

Once it is thought or acknowledged that full rigor requires that we algebraize geometry and thus punctualize and then number-i.e., again,

116 Russell's earlier mentioned "honest toil" might well be viewed as toil on behalf of opacity. The mathematical mainstream was simply not ready at the time for Dedekind's stark honesty. Cantor, however, we'll shortly find was.

117 What is required for either to go all the way, we shall see presently, is precisely what implicates our first "decision point."

118 I say "not quite completely" because arithmetic itself eventually came to be thought in need of "foundations"-logicist, formalist, intuititionist or some other, as emerges below in connection with our discussion of the paradoxes of self-reference. 
"arithmetize"- the continuum, it not surprisingly becomes necessary to assure that the continuum's linear (or planar, etc.) order be preserved in the number system that represents it. Points to the left of other points, to put the point intuitively, no matter "which" points they might be, 119 have to be represented by smaller numbers than those other points. That is so even in the case of our earlier Class D type numbers whose decimal expansions are not only infinite, but as we saw, incomputable.

The problem, however, is that this order-isomorphism turns out not to be provably instantiated in the now-defined reals without resort to the idea of choices quite as arbitrary as the "arbitrary functions" which the arithmetization project is supposed to "found" or "ground" or show to be "secure" by reference to self-evident, indubitable "first principles." It turns out, that is to say, that we cannot find sense, or show there to be sense, in our "Class D" expressions above without resort to assumptions that seem no more intelligible than those expressions themselves!

In essence, the story runs thus: Cantor quickly came to realize, in connection with the reals $\mathbb{R}$ as he and Dedekind had defined them, that the "gaps" among rationals $\mathbb{Q}$ that he had filled-in with them were in a sense far more numerous than the rationals themselves. Rather than a case of some holes among rationals, it turned out, the continuum was more like the case of a hole - an infinitely long-extended one, in factwith a few rationals scattered in along the way! I am alluding here once more to the matter of "diagonalization" that I mentioned earlier. It is time now to confront it.

In defining the reals $\mathbb{R}$, Cantor and Dedekind-like Weierstrass and Cauchy before them in connection with distinct although cognate purposes - had found themselves regularly having to deal with infinite sequences of numbers effectively treated as well defined and in that sense "completed" domains or totalities. It was only a short step from dealing with such sequences to dealing self-consciously with completed infinite classes-aggregates, sets-of objects, such as points or numbers.

Indeed the notion of class, even infinite class, had been in use, albeit unselfconsciously, for a significant while even prior to Cantor. It seems in fact that Cantor developed the notion of a class or set out of the Riemannian notion of "manifold" (German "Mannigfaltigkeit"-a word Cantor himself used before using "set," German "Menge"). Riemannian manifolds themselves amounted to collections of pointsindeed generally infinite such collections. Moreover, Dedekind, who edited the collected work of and was quite close to Riemann, self-

119 I place "which" in scare-quotes for reasons that will momentarily be evident. Strictly speaking, prior to the arithmetization project, the notion that "each" of "all" points might possess a distinct identity and be order-related to "all of the others" would not even have been quite intelligible. One would barely, if at all, have been conceptually equipped to think such a thought. 
consciously developed a notion of set much like the modern one even prior to Cantor, himself a student of Riemann's. And there is considerable evidence that the two friends effectively developed the first rudiments of modern set theory together in their oftentimes brisk written correspondence with each other. ${ }^{120}$

What set Cantor apart, however, appears to have been this: He seems to have grasped very quickly what now in hindsight perhaps strikes us as obvious but at the time had apparently gone scarcely noticed: This was the fact that, if the rationals $\mathbb{Q}$ already are infinitely compact, as would seem to have to be the case if we can indeed go on dividing and subdividing a line segment indefinitely, then there must be some order or magnitude of infinity that is yet "higher" or "denser" even than that already infinitely dense order. How else to account for the presence of these staggeringly many "gaps" among inifinitely compact rationals $\mathbb{Q}$, and thus the equally staggeringly many reals $\mathbb{R}$ defined so as to correspond to and "fill" them?

\subsection{1 "Orders" of Infinity}

Some such observation as this is at least one of those which would first have set Cantor about exploring just what and how many "orders" of infinity there might be. ${ }^{122}$ What ultimately developed out of that exploration seems at least initially to have astounded even him, while notoriously occasioning much scandal and schism among mathematicians for a long while as well. ${ }^{123}$

Now it is at about this point in the story that the typical expositor will have to begin telling you all about Cantor's cardinals and ordinals, his transfinite arithmetic, the hierarchy of aleph-denominated infinities topped by the unthinkable "Absolute," then the Continuum Hypothesis and perhaps even how attempting to prove the latter drove both him

120 See, e.g., JOSE FERREIROS, LABYRINTH OF THOUGHT: A HISTORY OF SET THEORY AND ITS ROLE IN MODERN MATHEMATICS 172-209, and passim (1999).

121 Well, one might have objected to the entire enterprise of attempting to arithmetize the continuum, as Wittgenstein did. But more of that later.

122 Again I hope that I am not overstating this claim simply in order to lend intelligibility to my brief narrative. There is also good evidence, for example, that Cantor, who considered himself something of a theologian and had long taken great interest in religiously-oriented philosophical writing -in particular that of the medieval schoolmen and Spinoza-was interested early on in "the infinite" owing precisely to its theological resonances. See, e.g., DAUBEN, supra note 1; HALLETT, supra note 50.

123 Indeed there are some, though they're now certainly out of the mainstream, who remain in the Kronecker, Poincaré, Weyle, and Wittgenstein camp-the camp that views set theory as little but a "disease." Intuitionist, for their part-among whom there still are some-might be said more to view the matter as analogous to an overused substance; used in more moderation, it's fine. More on these matters below. 
and, later, Kurt Gödel insane, and so forth. Alas, interesting-and regrettably oft-sensationalized-as that story is, we shall have to forgo the pleasure of recounting most of it here and confine ourselves principally to one such distinction between orders: This is the one that grows straightforwardly out of the story as we've been abbreviatively recounting it. And it suffices, in any event, to ground the tale I seek to tell here-that of Cantor's first decisive confrontation with what I am calling the "criterial versus arbitrary choice decision point."

Here, in a nutshell, is how what I have been calling the first Cantorian decision point came to be presented in what I earlier called its starkly "optimal" clarity: In exploring the comparison between the rationals $\mathbb{Q}$ and the reals $\mathbb{R}$-in particular, the transcendental reals that appeared to comprise by staggering degree the greater part of themCantor initially employed the natural (or "counting") numbers $\mathbb{N}$ as a. sort of yardstick. In particular, he found that the rationals, though infinite in number, were what we now call "denumerably" infinite. That is to say, they could be put into one-one correspondence with the natural, or "counting" numbers. Hence their order of inifinity-what Cantor soon came to call their "power," or "cardinality," was no greater than that of the natural numbers themselves. (Formally, one says something like " $P(\mathbb{Q})=P(\mathbb{N})$, " $P$ " standing-in for the Cantorian notion of "power.")

Centuries earlier, Galileo had analogously observed that there were as many squares of natural numbers as natural numbers for the same reason, in essence-the possibility of one-one correspondence between each "counting" number and its square. And similar such possibilities had been explored exhaustively, not long before Cantor's day, by Bolzano, perhaps best known today for what came to be known as the Bolzano-Weierstrass Theorem but also for his catalogue of so-called "paradoxes of the infinite," many of which latter prefigure subsequently discovered paradoxes afflicting set theory and mathematical foundations. ${ }^{124}$ So familiar had the "part as large as whole" paradoxes of the denumerable infinite become by Cantor's day, in fact, that Dedekind actually employed the possibility of one-one correspondence between part and whole as definition of an infinite totality - or what we would today call, post-Cantor, a merely "denumerably" infinite totality. ${ }^{125}$

Now one of Cantor's first results in exploring the nature of that infinity which characterized the rational numbers was his celebrated "zig-zag" proof of 1874 , to the effect that these latter were fully as denumerable as had been Galileo's squares of naturals. It was in this

124 See BERNARD Bolzano, PARADOXIEN DES UNENDLICHEN [PARADOXES OF THE INFINITE] (1851).

125 See DEDEKIND, supra note 108. 
proof, too, that Cantor first employed what I think we can view as a prototype of what subsequently came to be known as his "diagonal method" of mathematical argumentation. In essence, he first developed a straightforward means of arranging (we might even say ordering) all of the rationals $\mathbb{Q}$ in an orderly and exhaustive way, then showed how the said order could be put into one-one correspondence with the naturals, hence could be shown to be denumerable. The terms "zig-zag" and "diagonalization" stem from the means by which he laid out the said "orderly" arrangement and then natural-numbered each entry. It looked, more or less, like this:

$$
\begin{aligned}
& 1 / 12 / 13 / 14 / 15 / 1 \ldots . \\
& 1 / 22 / 23 / 24 / 25 / 2 \ldots \\
& 1 / 32 / 33 / 34 / 35 / 3 \ldots \\
& 1 / 42 / 43 / 44 / 45 / 4 \ldots \\
& 1 / 52 / 53 / 54 / 55 / 5 \ldots \\
& \ldots \ldots \ldots \ldots \ldots \\
& \ldots \ldots \ldots \ldots \ldots \\
& \ldots \ldots
\end{aligned}
$$

Now, as I suspect you'll agree, the ellipses here all seem to carry a straightforward, intelligible meaning, a "so" to give content to "and so on." You can see what the next terms in all cases will be. You also can see, I suspect, that continuing onward indefinitely in the apparently prescribed way will lead you to the inclusion of every rational number-every number that can be represented as a vulgar fractional ratio. There are of course many-infinitely many-redundancies, but this does not matter for present purposes and in all events all redundancies can simply be passed over.

Now, given all this, it is also easy to see how denumerability can be established: Simply start at the upper left corner, and assign the number one. Move thence one over to the right, and assign two. Now proceed diagonally downward to the left, and assign three. Then drop down one, and assign four. Then diagonalize again upward to the right, and assign five and then six. Move over one to the right, and assign seven. Then diagonalize downward to the left again, and assign eight, nine and ten. And so on. I assume it will be clear why this method of argumentation has been callled "the zig-zag" method. But its employment of so much as a single diagonal movement is arguably what ultimately proved most fateful of all. For presumably it is what first suggested the idea of a diagonal process to Cantor, a suggestion which later resulted in another, ultimately much more interesting

126 I leave fractions involving 0 as numerator out of account for simplicity's sake; but nothing essential is lost in this way. Simply make zero the first, and we're off to the races. 


\section{Cantorian proof. ${ }^{127}$}

Now, in his exploration of what sort of comparison, precisely, might be made between the already infinitely dense rationals $\mathbb{Q}$ and the seemingly in some sense "more" densely packed reals $\mathbb{R}, 128$ it was in a sense only natural for Cantor to attempt to replicate in the latter case the proof strategy he had successfully employed in the case of the former, rational case. So he assumed, arguendo, that the reals might indeed be enumerated like the rationals, and set about trying to arrange them-or, more precisely, a portion of them-into some manner of array. Confining himself, for the sake of simplicity, to the reals between zero and one, he commenced a list of roughly the following form:

$$
\begin{aligned}
& 0.0000000000001 . . \\
& 0.0000000000010 . . \\
& 0.0000000000100 . .
\end{aligned}
$$

Now, what actually fills in for any particular set of ellipses here does not actually, in the end, matter. Nor do the particular choices of filling-in of decimal places supplied above. (Though I trust you will have noted some resemblance between what is afoot here and what we found occasion to note in connection with the Class D expressions above!) It does not matter because Cantor noticed something quite interesting almost immediately upon attempting to construct the beginnings of an intelligibly completable array that might completely and in orderly fashion include all of the reals, as the preceding "zig-zag" array did for the rationals.

What Cantor noticed was that, no matter how the digits in any array such as that above might be filled, one could, first, construct a new numeral simply by proceeding diagonally downward from the upper left to the lower right, borrowing a consecutive digit from each string thus passed; and then second, arbitrarily change (and in that sense "negate") 129 each digit in this new numeral to anything other than what it was (e.g., by simply increasing it by one), and thereby construct an

127 I find it also intriguing, incidentally, that just as a two-dimensional array set this whole process in motion, in a way-I refer now back to Descartes' and Fermat's assignment of and would-be "reduction" of geometrical forms to numbered coordinate axes-so does such an array, as we shall now see, ultimately serve to show from yet another angle that geometrical relations cannot be reduced to a denumerable infinity of number-measures.

128 The so-called "algebraic" reals, noted earlier, Cantor found to be denumerable like the rationals. Strictly speaking, therefore, one should say "transcendental reals" here. But what holds of the latter here holds, a fortiori, of the reals as a class, and it is simpler simply to speak of the full class here.

129 Note that "negating" in this case takes the form of replacing with a contrary-a new term which excludes the erstwhile term. The role of negation-particularly negation as affirmative contrariety - turns out to be of more general significance, we'll presently see. 
altogether new numeral which could not have been in the array. (It could not have been in the array because it differed from each numeral already in the array in respect of at least one decimal place. See?) This was, in a nutshell, the celebrated "diagonal argument." It showed, in a straightforward, familiarly combinatoric way, that there simply could be no complete enumeration of the reals. The reals must therefore in some sense be "non-denumerable." 130

Now it was here that Cantor took what turned out to be a critical decision. For it is one thing to say that the reals can't be counted-or, therefore, ordered through correspondence with "counting numbers"natural numbers. It might be quite another thing to say that there is nonetheless some determinate "order" or "level" of infinity, understood by strict analogy with the analogy of the naturals and rationals, that the reals possess which is "larger" or "higher" than that other. Wittgensteinians, and early critics of Cantorian set theory before him objected to the latter way of talking. And they did so essentially on intensionalist grounds, as we'll see presently. To thoroughgoing Wittgensteinian intensionalists, we might say, Cantor's diagonal argument did not reveal a new "paradise" of uncountably many new numbers waiting to be explored and found to be in order. ${ }^{131}$ It revealed, more simply, that the project of arithmetizing the continuum had been a fool's errand au fond. The difference in view will be easier to appreciate once we see what Cantor did next in response to the diagonalization that initially surprized even him.

In order better to understand what Cantor did next, note that, in a sense, we might have seen that the reals were in at least some sense quite different, counting-wise, from the rationals even before literally diagonalizing-indeed at the very beginning of the attempt to arrange them in an array. For if you go back one step, what in heaven's name are we to make of the incipient "array," above, over which we diagonalized? Was it not an "ideal table" of the sort mentioned a bit earlier-a table, moreover, of something like what we called "Class D"

130 In what sense is what came to be at issue, we'll see. Note that Cantor's proof could be called "constructive" - an attribute favored by many who have opposed Cantor's subsequently developed "transfinite arithmetic." The diagaonal argument showed a means, immediately appreciable as indefinitely repeatable, by which one might always construct a new number not on any given enumeration. The significance of this form of "constnuctivity" proves important below. In effect, even "finitists" and "intuitionists"-indeed, even Wittgenstein himself-could and did accept the diagonal argument. What they disagreed about was what the manifest possibility of diagonal construction actually showed. Does it show the existence of an unimaginably vast "paradise" of nondenumerably many real numbers? Or does it merely show that the continuum cannot be arithmetized after all? Stay tuned.

131 The "paradise" moniker stems from Hilbert, who famously stood firm against intuitionist and other assaults upon early Cantorian work by insisting that "no one shall expel us from the paradise which Cantor had discovered for us." See David Hilbert, Über das Unendliche [On the Infinite], translated in VAN HEIJENOORT, supra note 60, at 375-76. 
expressions? Can you see any way at all in which this array might have been put into some form of order analogous to that which Cantor had constructed for the rationals before? I confess that I for one cannot-or cannot quite, or quite consistently, at any rate. Indeed the prospect of such an ordering seems to me to shimmer as the sheerest mirage-at one moment seemingly as acceptable as it is desirable, at another moment fully as illusory as "and so on" seemed at first in connection with our "Class D" expressions.

For think about it: In the case of the rational array, there was an obvious rule of construction by which to extend every row or column rightward or downward in such a way as would obviously include every conceivable rational. There was, that is to say, a recipe, a straightforward (well, "zig-zagging") method, a simple algorithm-in a word, what amounts to an intension! But what such rule, recipe or method can we envisage for carrying forward the would-be "array of reals" just above? Is there any more prospect for it here than there was for a "so on" in the case of Class D expressions earlier? I just can't see it. Can you?

At most I can see what we noted above that Cantor seems effectively to have had in mind in connection with Class D expressions: Namely, that there seems to be at least some intuitive content to the suggestion that there might be some such "order"-or, less misleadingly put, ${ }^{132}$ "level" or "type" - of infinity as that of the reals, by analogy to an infinitely extended "decision tree" proceeding in branches from an origin to $0,1,2, \ldots$ through 9 , then from 0 to $01,02 \ldots .09$, from 1 to $10,11,12 \ldots 19$, and so forth. But the idea of ordering "all" of the possible paths of the "completed" tree, once "all" of the branches have been filled in, seems on reflection to be an altogether different order of business than that of ordering all of the infinitely many rationals. That seems so even granting that "all" of those sequences beginning with ".9" are "larger" than those beginning with " 8 ," etc.

For consider, each of the reals is itself unavoidably represented by an infinitely extended row each of whose digits can randomly vary between 0 and 9 . The array of rationals is, by contrast, a listing of quite readily finitely nameable individual numbers. See the difference? In the case of the rationals it is only the array that is infinite. And because it is denumerably so, it can be ordered via one-one correspondence with the "counting" numbers. In the case of the reals, it is not only the array that seems to be infinite (or even, per the diagonal argument, "more" than merely (denumerably) infinite): In addition to the array here nearly every would-be individual number in the array is itself nameable only

132 Note that "order" is ambiguous as between "kind" or "level" on the one hand (as in "that is a problem of an altogether different order"), and "arrangement" on the other (as in "you've put them into a nice, neat, orderly array"). 
by a nonperiodic, unpatterned infinite sequence.

An infinite array of infinite random sequences would seem, at least in that recursive sense, to be of an "order" of infinity quite distinct from and indeed "higher" than that of an infinite array of merely finitely nameable numbers. (Infinite array of infinite names, versus infinite array of finite or finitely specifiable names.) And whether this "higher order" can itself be ordered or in any sense considered "orderly," that is another question. ${ }^{133}$ For our intuitive conception of "ordering" seems just to be putting into one-one correspondence with the naturalscounting "first," "second," "third," and so on. What can it be, then, to "order" that which is non-denumerable, i.e., that which cannot be put into correspondence with the counting numbers?

So again while it is one thing to recognize (a) that there "ought" or "must," in some sense, be reals, and (b) that these reals in turn cannot, in some sense, be numerically managed (either counted or, as it turns out quite relatedly, ordered) in the same manner as the rationals are (or perhaps in any manner), it would seem quite another to say that we might be able to say (c) in what if any sense beyond that of the diagonal argument itself how the reals "outnumber" the rationals, ${ }^{134}$ or (d) in what if any sense they might actually be "manageable" or "orderly" if they are not denumerably so. Indeed, it might even be plausibly argued that Cantor "discovered" no more with his diagonal argument than that the line and the numbers are, after all, incommensurable: that is, not amenable to one-one correspondence between points and intelligibly orderly-"rational"-numbers. That is of course just what the Greeks long ago discovered, and simply reported in a different language, so to speak. ${ }^{135}$ In what way, then, if any, might it be said that Cantor discovered anything more than this? Well, in a way, we are going to see that he didn't. For it turned out that "legislation" was at least as decisive here as anything we'd call "discovery." 136 And this is of

133 Incidentally, as has since been brought to light in the intuitionist practice of modeling "choice sequences" as decision trees, such trees have a denumerable number of nodes, but a nondenumerable number of paths. (A bit as we anticipated above with Class D.)

134 Apposite here is Wittgenstein's remark that in mathematics the proof shows no more than what it shows, while the verbal gloss with which mathematicians often embellish their proofs often occasions mischief. On the diagonal argument in particular in this connection, he pointed out that, strictly speaking, it simply shows that the continuum cannot be squeezed, as it were, into the mold of integer arithmetic. (Note, incidentally, that as we noted earlier, this is no more than what Greek geometry already had known.) But this does not itself suffice to warrant the claim that there is a new "level" of inifinity here that is somehow "larger" than the infinity of the natural numbers, let alone that some such new "level" is arranged in some orderly fashion that can be analogized to the orderly arrangement of the naturals and rationals. Something much more is required before that extra step can be taken, as soon we shall see.

135 To wit, the language of "incommensurables," such as the earlier noted Class C relations between sides and diagonals of squares, or between circumfrences and diameters of circles.

136 There is irony here too, incidentally, in that Hilbert and others objected to Kronecker's and the intutionist's attacks upon Cantor because, as he libertarianly put it, they sought to "legislate" 
course where the story gets interesting.

Now recall that, although he found through diagonalization that the reals $\mathbb{R}$ were of a different "type" or "order" of infinite magnitude than the rationals $Q$, and though we just noted that he might have guessed this even before hitting upon the diagonal itself-simply by reflecting on what it would be (or perhaps better, not be) to catalogue any line segment's worth of reals in an orderly array-Cantor, along with Dedekind and others who now were working with the newly defined reals in arithmetically exploring the continuum, wanted some assurance that the reals and the geometric line were at least order-isomorphic. And that meant they needed, if they were to allay all possible Cartesianstyle doubt, some proof of a complete ordering. Could that be had?

Well, as it turns out, no, at least not in the absence of what I called just above "legislation"--indeed, arbitrary imposition. And there has been foundational trouble ever since. In effect, we have noted the basic problem already: The challenge of coming up with some straightforward way of arranging the array of reals, which we noted just above in connection with the diagonal argument and which we effectively noted earlier still in connection with the puzzle of our Class $\mathrm{D}$ expressions, just $i s$, in effect, the problem of the missing order. And again, if you think about it, this shouldn't be surprising. For what is it, in the end, to "order" some collection of items in the ordinary sense of the word? Is it not simply to put them into correspondence with the "counting" numbers one, two, three, etc.? When you arrange something in an order, do you not say "first," "second," "third," etc.? And if the diagonal argument shows that the reals are non-denumerable, does it not, then, say in effect precisely that they cannot be ordered, at least in any familiar sense of the term?

What, then, to do? Well, Cantor came up, in effect, with an answer-an answer that it took Zermelo, some years later (1904, precisely ${ }^{137}$, to formulate explicitly. He employed this answer not only in "establishing"- or perhaps "imposing"- the ordering of the continuum (the reals, $\mathbb{R}$ ), but also the ordering of a full "paradise" of transfinite numbers. Here, in brief, is the system he came up withwhat came to be called by many others, at the time, a "disease," but which long sense has become dominant.

In exploring the nature of the (at least) two "orders" of inifinity that the diagonal argument seemed to reveal, Cantor noticed an interesting combinatorial fact: If you take any finite set of $n$ members, the number of subsets that can be formed from that set is two raised to

what numbers there could be. We'll see now that legislation was at least as necessary in positing as it might have been in proscribing!

137 See Ernst Zermelo, Beweis, dass jede Menge wohlgeordnet kann, 59 MATHEMATISCHE ANNALEN 514 (1904). 
the nth power. For, note: One set is a subset of another when and only when there is no member of the former that is not also a member of the latter. The null set is accordingly a subset of every set, and every set also is, trivially, a subset - sometimes called an "improper" subset-of itself. From the three-membered set $\{a, b, c\}$, then, two-raised-to-thethird-that is, eight-subsets can be formed. They are: \{\}$,\{a\},\{b\}$, $\{c\},\{a, b\},\{a, c\},\{b, c\}$, and $\{a, b, c\}$ itself.

Cantor generalized this familiar combinatoric principle from the case of finite sets to that of apparently infinite sets. ${ }^{138} \mathrm{He}$ called the set of all subsets of a given set the "power set" of the latter. If we call the number of elements within a given set that set's "cardinality," or "power," as Cantor did, then we shall say, with Cantor, that the power set of a given set is simply two raised to the power of that set-just as the power set of the three-membered set considered above is two raised to its power, three, yielding an eight-membered set of subsets. Now, assuming that it is not illicit to generalize in this way from the finite to the infinite case, we have in Cantor's "power set" notion a straightforward means of generating a hierarchy of infinite "powers" or "cardinalities," rather analogous to the way in which we have in the "successor" or "add one" operation a means of generating more and more natural numbers: Begin with the cardinality of the natural numbers $\mathbb{N}$ or, what we saw above to be the same, that of the rationals $\mathbb{Q}$. That is the first "level" or "order" of inifinity-the "denumerable" order.

Now take the power set-the set of all subsets-of elements in that order: i.e., the set of all subsets of naturals, or of rationals. ${ }^{139}$ This will then be the "power" of the "next order" of infinity. And, interestingly enough, as it might first strike us, it turns out that this is precisely the power of the continuum itself-i.e., of the reals, $\mathbb{R}$. Now once one stops to recall how the reals were defined by Cantor as discussed above, it is not really surprising at all that they should be found to be equinumerous to the power set-recall, the set of all subsets-of the

138 Hallett illuminatingly refers to Cantor's tendency to generalize from the finite to the infinite case "Cantor's finitism." See HALLETT, supra note 50 at 32 . The Axiom of Choice, to which we turn presently, can be viewed as another instance of this form of move. It seems to me that we can view this form of "finitism" as a euphemism for precisely what Wittgenstein diagnosed as a form of grammatical error in Cantor and subsequent "set theorists": the misapplication of a picture that is apt in the case of finite or otherwise determinate (because ruledetermined) totalities, to a case where it is inapposite-to wit, that of ill-specified, false-infinite totalities.

139 One might of course object here to the use of "all," since it is in the nature of this levelperhaps indeed the only level $\longrightarrow$ of infinity that it is never "a completed totality." That would of course be the Aristotelian objection, grounded in the "only potential infinite" idea. But this, as we noted above, is precisely the objection against which Cantor's "Domain Principle" is directed. If we know what a natural number is-if the term is possessed of determinate meaning-surely it makes sense to speak of "all" of them even if we could never "count" all of them. "Natural number" is a determinate intension, we might say in a Wittgensteinian mode, and so it picks out a determinate extension, even if the latter be infinite in size. 
rationals. For they are themselves defined as infinite sets (sequences) of rationals, hence as subsets of the already denumerably infinite set of rationals. But Cantor, while in this exploratory vein, of course did not stop here. For, how about the power set of continuum itself, i.e., of the reals $\mathbb{R}$ ? That would of course carry cardinality two raised to the $\mathbb{R}$. It is accordingly called, not surprisingly, the cardinality of the "supercontinuum." And then of course we might form a "supersupercontinuum" by taking the power set of the supercontinuum, and ... ready? ... so on!

That's right, Cantor projected a full hierarchy of these ascending cardinal "levels" or "powers" of infinity, each new level generated from that below it through the power set operation. To each such "power," accordingly, there corresponded what Cantor came to call a "transfinite cardinal" number. The first such was that of the denumerable sets, which Cantor designated " $k$," the Hebrew letter "aleph." Next came two raised to the aleph. Then two raised to the latter-i.e., two to the two to the aleph. And so on. Cantor also developed a system of transfinite cardinal "arithmetic" pursuant to which adding, subtracting, multiplying, dividing, exponentiating and so forth were defined over the full "set" of transfinite cardinal numbers themselves. The details, although intuitively straight-forward, would amount to distraction here, so I shall leave them to one side for present purposes.

Now, roughly in parallel to-indeed, temporally speaking, in at least one sense even before-his system of transfinite cardinals, Cantor was developing a system of indices that would ultimately develop into a system of transfinite "ordinals." What these were, and why they concern us here, relates back to what had set Cantor about his explorations in the first place. That was, again, this matter of arithmetizing the continuum. Once Cantor (and for that matter Dedekind) had developed a satisfactory definition of the reals, it was easily enough shown to follow on the definition itself that every point on any arbitrarily selected line segment can be indexed by a unique member of the thus-defined set of reals, $\mathbb{R}$. But to this point the converse, that to each member of the latter there corresponds but one unique point which that number indexes-hence that we had a full-bore, one-one correspondence between points and reals-could only be postulated, not proved. Cantor was happy enough to go ahead and postulate this, at least initially; but he wished ultimately to prove it. ${ }^{140}$

So Cantor worked with what he called "point sets"-sets of points rather like Riemann's earlier Punkmannigfuldigheiten - in attempting to determine the order structure of points on the line itself. He did so initially in the context of work on an "arbitrary function" question first

140 I trust you will see how this fact connects with the matter of ordering the reals themselves which we were discussing above in connection with diagonalization. 
posed by Dirichlet-the question of whether each such function was uniquely representable by one Fourier series-as mentioned above. But his work here led him to define a new notion which ultimately led far beyond that prosaic representation problem. The notion in question was that of the "limit point" of a point set itself-a point that would correspond to the limiting sequence of a set of Cauchy sequences (hence a real number per Cantor's definition of the reals discussed above). Assuming a line segment's points to be indexed by real numbers, then, Cantor defined a set of such points' "limit point" to be:

... a point of the line for which in any neighborhood of the same, infinitely many points of [the set] are found, whereby it can happen that the (limit) point itself also belongs to the set. By a "neighborhood of a point" is understood an interval which contains the point in its interior. Accordingly it is easy to prove that a point set consisting of an infinite number of points always has at least one limit point. ${ }^{141}$

Each point set, by this definition, includes a set of limit points, which Cantor referred to as the point set's "first derived set."

Now, things can grow quite distractingly complex at this point. Indeed we are now verging on what since has come to be known as topological territory, a terrain very well mapped over the century subsequent to Cantor. So for present purposes let us confine ourselves to this observation: In general, the operation of forming "derived" sets of point sets in the manner just suggested can be iterated. There are derived sets of derived sets, derived sets of those sets in turn, and so on. ${ }^{142}$ In the case of some but not all point sets, the process of iterated derivation will eventually terminate. It will come to a halt once we reach a derived set with but finitely many limiting points, of which there can be no further derivation yielding any but the null set. ${ }^{143}$ Such terminal sets, Cantor determined, would correspond to algebraic-style functions possessed of discontinuities-“jumps."144 They would effectively constitute the graphs of such functions-true Dirichlet-style functions. So this was all part, again, of the earlier-discussed matter of investigating arbitrary functions and, more generally, an upshot of the earlier discussed arithmetization of geometry. In this case, the problem was that of establishing isomorphisms between "jumping" graphs and "pathological" formulae via a mutually mirroring structure of point sets

141 See DAUBEN, supra note 1 , at 41 .

142 Rather as, as any student of "the calculus" knows, there can be "first," "second," and indeed " $n$ th" derivatives. But please bear in mind that the analogy here is rough.

143 Think of this, if you like, as (again, roughly) analogous to the process of taking derivatives in your secondary school calculus class until running out of exponents.

144 I use "algebraic-style" here to emphasize that at this stage mathemticians still distinguished between intensions-formulae, "laws"-and extensions-graphs or sets. As we'll see, it is now very common simply to identify the function as a set of ordered pairs-i.e., extensionally. 
and point-indexing reals. ${ }^{145}$

Now in the case of all rationals $\mathbb{Q}$, no point set corresponding to them could form the basis of a derived set from whence further iterated derivations might eventually terminate. For its first derived set would correspond to the reals $\mathbb{R}$, which recall Cantor had defined as limits of sequences of rationals, and one simply never arrives at a merely finite number of corresponding limiting points. ${ }^{146}$ The significance of this fact for our purposes is that the process of forming derived sets from point sets corresponding to $\infty$, which amounts to the process of forming derived sets from the continuum (any line segment) itself, can go on and on without ceasing. Derived sets from derived sets from derived sets, ad libitum.

Cantor initially employed the infinity symbol, " $\infty$ " to convey the idea of an ongoing iteration, or "infinite number of iterations," of this derivation operation. He then employed the symbol " $\infty+1$ " to convey the idea-assuming that any coherent such "idea" there be-of a set of points derived from (hence in some sense "after") "an infinite number" of such derivation operations. ${ }^{147}$ Initially, he did not think of these symbols as designating entities-numbers in this case-at all. They were no more than what Wittgenstein might have called "exponents of operations." 148 And at this point in his life Cantor appears, like Russell and others we noted above in opposition to Dedekind, to have thought of bona fide numbers as having to be something more than that. But later, perhaps under the influence of Dedekind (or Frege?) and certainly after having developed his arithmetic of the transfinite cardinals generated by the power-set operation, Cantor began to view these indices as representing bona fide numbers of a sort-numbers which ordered classes of points, hence "ordinal" numbers. Drawing a bead on the precise density structure of-that is, the specific distribution of points along - the continuum came to appear to Cantor to require their recognition as entities. 149

Now, just as in the earlier-elaborated case of his transfinite

145 Such "jumps" were characteristic of the earlier mentioned Dirichlet functions

$146 \mathrm{I}$ am afraid that I can find no way of explicating this that is less technical and more accessible than this, at least not without writing very much more. If the idea here remains a bit hazy to you, please not to worry. The punchline, which now follows, is what matters most for purposes of our story.

147 A Wittgensteinian will be apt to say that this is a point at which Cantor goes awry, misunderstanding the grammar of infinity in the very locutions "infinite number" and "after an infinite number."

148 See supra note 59

149 Wittgenstein, as we've noted, of course thinks that effort itself-that of "drawing a [discrete] bead" on the by-definition non-discrete continuum-to be misconceived, and to register a simple misunderstanding of the grammar, as it were, of "infinity." No surprise, then, that what such an error would appear to require-the notion of numbers that "follow" "an infinite number"-likewise will be nonsensical in its very articulation. 
cardinals, Cantor ultimately went on to develop a system of transfinite ordinals. The earlier index " $\infty$ " formed the basis of what became Cantor's first ordinal number, $\omega$, which he conceived as an infinite sequence $1,2,3, \ldots \omega$, the latter then understood as a sort of "limit point" to the sequence itself, demarcating or separating it off from other possible sequences. Underlying the whole idea, again, was Cantor's earlier mentioned "Domain Principle"-namely, that it made sense, if the notion of "number" was well defined at all, to think in terms of "all of them." The symbol " $\omega$ " would then correspond to-would "index," so to speak-a particular "all," in this case an unending sequence of point set derivation operations. Its use accordingly amounted to a manner of "closure" operation-it demarcated, bounded, indexed a particular infinite totality: that of an unending series of well-defined derivation operations commencing upon some initially given point set.

Next, "following" a sequence like this one, Cantor observed, we might imagine another number, or sequence of numbers, or even another infinite sequence of numbers. Hence there might be such sequences as $\omega, 1$. Or $\omega, 1,2$. Or $\omega, 1,2,3$. Or even $\omega, \omega$. And so on. Cantor indeed developed a full system of transfinite ordinal numbers possessing this form, complete with an ordinal arithmetic meant to mimic, so far as possible, the familiar arithmetic operations defined over the naturals-just as we saw above that he did in the case of transfinite cardinals. Whereas in the case of his transfinite cardinal arithmetic, the generating operation-i.e., the analogue to the naturals' successor, "plus one" operation-was that of power set formation, in the case of his transfinite ordinal arithmetic, Cantor defined what he called "classes" of ordinal number. The first class, designated $\omega_{1}$, was simply that of $0,1,2 \ldots$ onward. It was accordingly of the same cardinality as the naturals, so there was naturally a certain correspondence between ordinal $\omega$ and cardinal $\kappa$. The second ordinal class, designated $\omega_{2}$, was then simply the class including $\omega$ itself, followed by $\omega+1, \ldots \omega+n$, then $2 \omega, 2 \omega+1, \ldots 3 \omega, \ldots \omega \omega, \ldots$ "and so on."

The principle for generating further such ordinal classes, again formulated by analogy to the successor operation over the natural numbers, was simply that each new $\omega_{n}$ would be defined as "the next" number limiting and in that sense larger than all of the numbers belonging to the preceding class $\omega n-1$. In effect, each new $\omega n$ would stand to $\omega_{n-1}$ rather as $\omega$ itself did to $0,1,2 \ldots$-again, as a sort of "closure" or limiting point. If the Domain Principle warranted the notion of $\omega$ itself as a completed totality, I suppose we might say, then it could also be thought to warrant an ongoing proliferation-orgy, some might complain - of ordinals $\omega$. In effect, Cantor simply carried the logic of his own novel premise-namely, that per the Domain Principle 
it made sense to speak of "completed" infinite totalities—unflinchingly to its ultimate conclusion.

Now I recognize that this all probably is ringing a bit counterintuitive by now, so unfamiliar is the idea of a completed infinity itself let alone a proliferation of and arithmetic among such "infinities" and a separating-off of ordinality from cardinality within this "transfinite" realm. Perhaps, then, the following heuristic aid will help render things a bit more understandable in the ordinal case: Imagine that you set a computer about the process of forming derived sets from derived sets from derived sets ... and so on-in essence, operating upon Cantorian point sets as Cantor himself envisaged before actually making numbers of the indices of such operations. Now imagine that you set another computer next to this first one-to its right, say-doing the same thing but commencing with a different set of points. Then set yet another computer to the right of this one doing the same sort of thing. Then another one. And another. And so on.

Now you can, if you like, in a certain sense view all of this as a sort of "ordering of infinities," or at any rate of infinite totalities. For each computer is acting upon a determinate program, a defined procedure - the point set derivation procedure. And in that sense it is generating a determinate-even if infinite-domain. And you can proceed from left to right, so to speak, in consecutively pointing to or otherwise designating these computers busily churning out their derived sets unceasingly. Now if you call the first computer to which you point "one," and the second one "two," and think of yourself in doing so as pointing to the unending series of derived sets that each is generating rather than merely to the computer itself, then you can in a sense think of yourself as pointing to a $\omega$, "followed by"-i.e., to the left ofanother $\omega$. See? You are consecutively designating particular infinite totalities. Or, if you think of the second computer solely in terms of the first derived set that it generates-hence the first iteration of its ongoing sequence of derivation operations - then you can think of pointing to it after pointing to the first one as pointing to a $\omega$ followed by a 1 , hence to " $\omega+1 . "$

That's all that is going on here, in essence. Cantor is simply treating particular infinite totalities-in the first instance, sets of points and derived sets of points, then sets of such derivation operations themselves-as objects in their own right, which his Domain Principle seems to license. Then he is imagining an orderly ("left to right," as it were) count of such sets themselves. In this sense he is separating-off ordinality and cardinality, treating in an order a sequence of sets some of which are of infinite cardinalities. The idea of treating an infinite set as an entity of course seemed to be licensed by the Domain Principle. Calling the resultant ordinal entities numbers, in turn, seemed to be 
licensed by Dedekindian and Fregean considerations of the kind mentioned above, concerning what is required of a putative number if it is to be deemed legitimately - for mathematical purposes-to exist as a number.

Cantor famously proved, in connection with his ordinals, that no two such classes could be possessed of the same cardinality. He also proved that there could be no set with cardinality "between" the cardinalities of successive ordinals. There seemed no reason, then, to deny the existence of a sequence of ordinals, just as there was a sequence of naturals and a sequence of successively power-setgenerated cardinals. You could generate and operate arithmetically upon them without contradiction, so they existed. They existed as possibilities, you might say, and the investigation of possibility came to be for Cantor what mathematics effectively was.

Now since the cardinality of the first ordinal number class was just that of the naturals (and, as we saw, rationals), $\aleph$, Cantor began calling its cardinality "aleph nought," or "No." He called the cardinality of the second ordinal class, not surprisingly, "א1." And... here we go again ... "so on." Once Cantor had taken this path, it then became only natural that he should at some point endeavor to consolidate and "order" what he had developed along his two tracks - cardinal and ordinal. After all, in the case of finite and even denumerably infinite classes, as we have seen, cardinality and ordinality correspond. One, two, three and so on correspond to first, second, third and so on. What then of transfinite cardinals and ordinals?

So Cantor turned to the task of endeavoring to bring his exposition of the transfinite ordinal and cardinal systems into a semblance of conceptual unity like that of the natural cardinals and ordinals. Since (a) the cardinality and ordinality both of the naturals that made up the first ordinal number class, and, by extension, of the merely denumerably infinite rationals $\mathbb{Q}$ was "the first aleph," and since (b) the next aleph among the transfinite ordinals was $\aleph_{1}$ while that among the transfinite cardinals was two raised to the first aleph per the power set operation, i.e., two raised to the $\mathrm{N} 0$, Cantor hypothesized that (c) the latter two must be identical. This was the celebrated and illfated "Continuum Hypothesis," which nobody ever has succeeded in proving or disproving, but which Gödel proved to be consistent with all of the now standard axioms of set theory, ${ }^{150}$ while the negation of which Cohen proved also to be consistent with those axioms. (Hence the now

150 There is more than one axiomatization, of course-the systems of Zermelo and von Neumann serving as basis for most subsequent mainstream renditions. W. V. O. QUINE, SET THEORY AND ITS LOGIC (1963) remains a both elegant and enjoyable exposition of the chief contenders. The independence of the Continuum Hypothesis that Gödel's and Cohen's proofs jointly entail holds in respect of all of them. 
familiar "independence" of the hypothesis from the standard axiomatization.)

Now if this hypothesis was ever to stand any chance at all of being proved, Cantor quickly saw, it would be desirable to be able to show that every set-not just every finite, but every order of infinite set too"could" in some sense be well-ordered. For any such result then would entitle him to assert that every set of every cardinality-including but not limited to that of the continuum - has at least one ordinal number, ordinals simply being the "types" of the well-ordered sets. So Cantor had reason to hope for some means of proving the well ordering of nondenumerably infinite sets from both sides jointly and severally, as it were, of the generalized effort that we've been discussing-i.e., both to arithmetize the continuum and to "continualize," so to speak, arithmetic itself.

On the arithmetic-numeric-side, there was the desideratum of establishing an order among the reals $\mathbb{R}$, the non-denumerability of which we found above-not to mention in connection with "Class D" expressions earlier-to be tantamount to a form of non-orderability. ${ }^{151}$ On the continuum-point sets-side, for its part, there was the desideratum of establishing that there was indeed an ordinal number for every set in a hierarchy of sets generated by generalizing the index number corresponding to an infinitely iterated point set derivation operation. And finally on both sides, so to speak, there was the desideratum of harmonizing the ordinal arithmetic that grew out of point set operations with the cardinal arithmetic that grew out of power set operations. Could this be done non-arbitrarily, intelligibly-in a word, intensionally? Alas, yes and no.

\subsubsection{L'Embarrass du Choix}

Enter here, then, the notorious "Axiom of Choice," which I'll abbreviate as "AC." Strictly speaking, Cantor did not introduce any such axiom. But in effect he relied on something very much like it-as, it subsequently turned out, had many mathematicians prior to him over the ninteenth century in deriving many celebrated results-in endeavoring to "prove" the well-orderability of the continuum and indeed his full hierarchy of transfinite sets. It was Zermelo who first explicitly formulated the Axiom under its now familiar name. So Cantor, I shall say, appealed instead to something that I'll call the "Choice Principle" (or "CP").

151 Note, that the aforementioned failure of the Continuum Hypothesis to be borne out means, alas, that the continuum has not ever been proved noncontroversially to be well-ordered. But more of this momentarily. 
In essence, the Principle-and the Axiom, for that matter, at least in one possible articulation of it ${ }^{152}$-is to this effect: For any set $S$ of pairwise disjoint non-empty sets $S_{1}, S_{2}, S_{3} \ldots S_{n}$, there exists a "choice set" $S_{c}$ of $S$ comprising precisely one element from each of $S 1, S 2$, $S 3, \ldots$ and $S n$ of $S .{ }^{153}$ These elements are called "designated elements," "distinguished elements," or something etymologically cognate. What is critical here is that the "designating" or "distinguishing" in question is entirely arbitrary. There is no criterion or principle-no rule, recipe, method, algorithm or, in a word, intension by reference to which any such element is in fact intelligibly distinguishable. It is simply declared to be distinguishable by fiat, in order that an otherwise non-ordered set might be piece-wise ordered by fiat via putatively more managably sized subsets with arbitrarily "distinguishable" elements.

Now the choice principle, which seems intuitively plausible enough in the case of finite sets and even, one supposes, in the case of denumerably infinite sets, turns out on reflection to be somewhat more troubling - or at any rate puzzling - in the case of infinite sets, particularly nondenumerably infinite sets. ${ }^{154}$ For consider: What would it be to conduct a nondenumerable number of random selections? Can our intuitions or intellects attain any grip upon any such notion at all? It seems to be one thing to say that talk of "completed" infinite totalities is licensed by the determinacy of sense of such terms as whose ordinary meanings appear to apply to objects generated by indefinitely iterable operations (such as the successor, "+ 1 " operation on the natural numbers) - hence by the Domain Principle. But it seems quite another to say that talk of nondenumerably many criterionless "selections" bears any sense at all which might serve, through the Domain Principle, then to license the Choice Principle. For we are appealing to the latter itself in endeavoring to "prove" that there is sense-in the form of order-in the notion of "nondenumerable" infinities themselves! The $\mathrm{CP}$, that's to say, seems no more secure than the totalities whose intelligibility we would employ it to prove. But this is only the

152 There turn out to be many, as I shall note shortly.

153 Note, in anticipation of Part 4 below, that the notion of a "Choice Set" employed by welfare economists-among the first of whom to have employed appears to be Sen-is precisely this notion. See, e.g., Amartya K. Sen, Quasi-transitivity, Rational Choice and Collective Decisions, 36 REV. ECON. STUD. 381 (1969); Amartya K. Sen \& Prasanta K. Pattanaik, Necessary and Sufficient Conditions for Rational Choice under Majority Decision, 1 J. ECON. THEORY 1 (1969); AMARTYA K. SEN, COLLECTIVE CHOICE AND SOCIAL WELFARE (1970).

154 Like the case of the ordinals themselves, as noted, supra note 138 , it is clear that we have here another instance of what Hallett calls Cantor's "finitism"- - again, his tendency to generalize what is intelligible in the finite case to the infinite case-even the nondenumerably infinite case. Intuitionists, incidentally, reject the unrestricted $\mathrm{AC}$, but accept what is called an Axiom of "Denumerable" Choice, the idea being that at least there is something orderly-or at any rate orderable-about infinite totalities the members of which can be put into one-one correspondence with the natural numbers. 
beginning of our difficulties, in a way; for Cantor's problem quickly turned out to be extensional mathematics' problem more generally.

Why? Because the CP also turns out, in its axiomatic expression the $\mathrm{AC}$, to be either equivalent to, or required to prove, a distressingly large number of long-accepted and even celebrated mathematical results. ${ }^{155}$ If it is itself problematic, then, so too are they-just as with Cantor's account of the continuum and his transfinite cardinals and ordinals more generally. By way of a small sampling, consider the following: In set theory, the AC proves equivalent to Cantor's own well-ordering theorem to the effect that every set can be well ordered, which as observed above provides the desired consequence that every cardinal is possessed of an initial ordinal. These in turn both are equivalent to the widely longed-for "Trichotomy Principle," to the effect that for any two sets, transfinite as well as finite, either they are of the same cardinality or one is larger than the other. ${ }^{156}$

Turning from set theory more generally to order theory more particularly, AC proves equivalent both to Zorn's Lemma and to the "Hausdorff Maximal Principle." In algebra, for its part, AC proves equivalent to the proposition that every vector space is possessed of a basis, as well as to the proposition that every nontrivial unit ring possesses a maximal ideal. In general topology, $\mathrm{AC}$ proves equivalent to Tychonoff's Theorem, as well as to (a) the proposition that the closure of a product of subsets is equal to the product of the closures, and (b) the proposition that any product of complete uniform spaces is itself complete.

Other celebrated mathematical results prove to be, not equivalent to $\mathrm{AC}$, but to be unprovable in standard set theory without assuming the AC. There are quite many of these. Here is a random sampling: In algebra and group theory, Stone's Representation Theorem for Boolean algebras, as well as the Nielsen-Schreirer Theorem. In measure theory, the Vitali Theorem, the Hausdorff Paradox, and the Banach-Tarski Paradox. In function theory, the Hahn-Banach Theorem, the BanachAlaoglu Theorem, and the Baire Category Theorem. One could go on and on, but surely already I am likely bordering on tedious. You get the idea. The insecurity, intelligibility-wise, of the AC brings with it a similar insecurity as to significant tracts of modern mathematics-at least such of it as has gone fully extensional. In effect, then, Cantor carried the extensionalization of mathematics-i.e., the conversion of

155 "Equivalent" in this context simply means, derivable from one another, such that each logically entails the other.

156 It is worth noting in this connection that many objected to the Trichotomy Principle in connection with infinite sets even before it was well known that this was equivalent to AC. See, e.g., L. E. J. Brouwer, Begrundung der Mengenlehre unabhangig vom logischen Satz vom ausgeschlossenen Dritten, 12 VERHANDELINGEN DER KONINKLIJKE NEDERLANDSE AKADEMIE VAN WETENSCHAPPEN TE AMSTERDAM 1 (1918). 
mathematics to the idea of criterionless selection at what I have been calling Cantor's first "decision point"--to its outer limit. That is to say, he carried it to the point at which extensionalism itself bumps against the limits of intelligibility, such that one must resort suddenly to something like "faith."

In effect, then, all of Cantor's efforts as catalogued throughout this Part, as well.as a great deal more of mathematics as it had developed to Cantor's time and has developed since, turns out to ride critically upon acceptance of the CP. And this acceptance is precisely the pertinent decision, in effect, that Cantor-and most though not all other mathematicians, it has turned out-took at the first "decision point" that I have referred to ad nauseum. It is, in effect, the set-theoretic rendition of what proves to be a pregnant decision in favor of "arbitrary" or "purely" extensional/combinatorial, as distinguished from "criterial" or "intensional" choice. It is in effect the decision to believe that-or at the very least to proceed "as if"-it were intelligible to countenance nondenumerably infinitely iterated but unguided random selection. It is the decision that we can make sense of, or to proceed "as if" we could make sense of, the idea of not only quite literally never ending, but nondenumerably and in that sense non-orderably many, selections of objects with no criterion, rule, algorithim, recipe, idea, or what have you -in short, no intension-to guide such selections. It is accordingly to suppose we can make sense of the idea of making selections from some nondenumerably infinite extension conceived as existing even apart from any intension other than the minimally domain-defining pseudo-intension of "an object."

For mathematics to proceed on the Axiom's basis, then, is indeed for mathematics to "go extensional all the way," so to speak, indeed to go "whole hog" extensional-to go fully arbitrary or combinatoric. And if you think about it, this isn't really all that surprising in the end. For the whole animating idea behind this course of development as we have narrated it-this punctualization and arithmetization of the continuum in its linear, planar, volumetric, and indeed all $n$-dimensional forms-was, in effect, either to find or to impose (AC does turn out to be an axiom, after all) an arithmetic-like order upon something that (a) was treated as preexisting, and (b) for millenia had proved inexhaustible and quite intractable even by an arithmetic of infinitely dense, because infinitely divisible, rational numbers. ${ }^{157}$

Since one might, should one simply choose even on a whim, trace any shape or set of line or curve segments she fancies upon a surface

157 Wittgenstein, then, as we shall presently see, would view this entire trajectory as having proceeded from an error: the "original sin" of attempting to lay a grid, so to speak, upon something that cannot be captured, contained or "tamed" by any coherent (rational) mesh at allthe continuum. More on this presently. 
bounded by coordinate axes, it perhaps should not have been surprising that she might also, were she an algebraizer of geometry, come to view algebraic expressions meant to "code" her tracings in "laws" stated as relations between $x$ and $y$ variables, as equally subject to arbitrary formulation. And since one might also simply choose to formulate algebraic expressions arbitrarily, then she might equally, if again an algebraizer of geometry, readily think of "graphs" as no more than pictorial representations-or "would-be" such representations when such graphs prove beyond the powers of our intuitive imaginative capacities - of such "arbitrary laws."

And finally, if our hypothesized gamer were an arithematizer of the just alluded-to analytical geometry and thus functional analysis itself, meaning a punctualizer of line, plane and beyond and an assigner of numbers (real numbers) on a one-one basis to points, then to her randomly drawn graphs and randomly formulated algebraic expressions would of course correspond randomly selected point sets and, trivially, definitionally associated real number sets. So the Axiom of Choice, in the quite literally "final" analysis, is but the ultimate license for those very random selections. Even in the case of magnitudes as quite literally unimaginably - and perhaps, per Wittgenstein and others, quite literally inconceivably-dense as the continuum and its associated realm of the reals, it asserts by fiat, random selections and correlations - even non-terminating and non-finitely-specifiable such selections or correlations-are quite intelligible. And in that sense it likewise asserts, again by fiat, in its way that our Class $D$ expressions above are intelligible.

Now it is possible that I have given a false impression in some of my choices of word above. For I might have suggested in all of this that Cantor's final acceptance of what I have been calling the "Choice Principle," and mainstream mathematics' acceptance of the full Axiom of Choice, is somehow total, complete, final, and in retrospect even inevitable in view of the initial Cartesian ambition. But that would be rather to overstate things. For it is not the case that all mathematicians accept the principle.

For one thing, many-most notably intuitionists, perhaps, as well as so-called "constructivists" more generally-either explicitly reject it tout court or accept only some such weakened version as the so-called "Axiom of Countable Choice"-a version pursuant to which the Choice Principle is treated as intelligible only over a finite or denumerably infinite domain.

For another thing, many of the most acute mathematical foundationalists-most notably our aforementioned Kurt Gödel and Paul Cohen, who between the two of them proved the independence of $\mathrm{AC}$ and $\mathrm{CH}$ from the remaining axioms of mainstream set theory-long 
ago disavowed the ambition that prompted the $\mathrm{AC}$ in the first place. Indeed like the earlier mentioned Baire and Borel who rejected "ideal tables" and Zermelo's AC in 1905, so Cohen sixty years later suggested explicitly that the continuum (the set $R$ ), as the class of all infinite sequences of integers-i.e., as our earlier "tree" of all possible Class D expressions - is so utterly dense and complex that it is manifestly absurd, once you think about it, to suppose it could ever be well ordered in the way that the simpler, denumerable sets can be ordered. ${ }^{158}$

Finally, perhaps owing to all of this, even mathematicians who in some sense accept the CP generally do so only in a conditional sort of way: A typical strategy is first to attempt to derive desired results without the AC. Then, if it turns out not to be feasible, the AC or some equivalent will be employed, but of course explicitly flagged as essential to the result. So it is fair to say, I think, that even those who employ the AC as, in effect, did Cantor, for the most part either (a) are hesitant or ambivalent about it, or at the very least (b) are prepared to accommodate the concerns or ambivalences of others about it. We recognize, in effect, that we have elected to license arbitrary choice by fiat-i.e., arbitrarily. Hence we are all, in a couple of senses, what we might call "self-conscious" about it. And that makes for a lovely segue indeed into the second Cantorian decision point.

\subsection{The Sorrows of Self-Reference}

Where Gödel and Cohen leave us in respect of arbitrary choice as expressed in the Axiom of Choice, then, is that the choice whether to reject or accept the Axiom is itself in a certain sense arbitrary. We do not seem to be logically compelled, to reject or accept it, by any of the other, more intuitively attractive axioms of post-Cantorian set theory itself. But the qualifier that I have just introduced-"post-Cantorian" set theory-amounts to a clue as to where we might look for some other indicator as to how we should regard the AC. For set theory as axiomatized post-Cantor, first by Zermelo and subsequently by Gödel, von Neumann, Parsons, and others, is itself in strong sense quite

158 On the observations made in this sentence and the preceeding sentence, see Kurt Gödel, The Consistency of the Axiom of Choice and of the Generalized Continuum Hypothesis, 24 PROC. NAT'L ACAD. SCI. 556 (1938); KURT GODEL, What Is Cantor's Continuum Problem?, in 2 COLLECTED WORKS 176 (Solomon Feferman ed., 1986); Paul J. Cohen, The Independence of the Continuum Hypothesis 1, 50 ProC. NAT'L ACAD. SCI. 1143 (1963); Paul J. Cohen, The Independence of the Continuum Hypothesis II, 51 PROC. NAT'L ACAD. SCIE. 105 (1964); PAUL COHEN, SET THEORY AND THE CONTINUUM HYPOTHESIS (1966). Cohen also helpfully points out how rudimentary and "plus 1"-like the generators are in the case of Cantor's ordinals as compared to the power-set generator of transfinite cardinals. Compare the generators, and it seems likely that two raised to the aleph-nought is indeed larger than any and all of the ordinals. 
arbitrary-much more so than Cantor's. Certain of the axioms, that is to say, are quite manifestly ad hoc in nature, having been formulated for no reason other than to avoid certain antinomies - and in effect anomies too, as we shall see - that are occasioned by the forms of self-reference to which unrestricted extensionalism-i.e., "pure" arbitrariness - opens the door.

Revisiting this phenomenon-reflectivity and its attendant paradoxes-from "square one," so to speak, accordingly affords us an opportunity to inquire whether some non ad hoc, nonarbitrary response to self-reference and its attendant perplexities might recommend itself. And if the answer to that question is "yes," we'll be invited as well to inquire whether the favored response likewise affords reasonnonarbitrary reason - to decide one way or the other about the $\mathrm{AC}$ and arbitrariness itself, hence ultimately about intensionalism and extensionalism. In the end, we shall see, I think that it recommends precisely that "thin" form of intensionalism that we found in Cantor's Domain Principle. I'll lead us into this matter, as in the case of intensional versus extensional choice, "geneologically." That is, I'll give a brief historical sketch as to how the matter with which we're concerned here emerged.

\subsubsection{Securing the New-Found Foundations}

As mathematical development neared the tail end of the period during which Weierstrass, then Dedekind and Cantor, first hit upon and then in effect demonstrated the utility of thinking in terms of operations on "manifolds," "multiplicities," and, ultimately, "classes" in rigorizing the study of continuous magnitudes by combinatorializing and numbering them, some mathematicians-Dedekind, Frege, and Russell among them-began entertaining the prospect that sets and operations thereon might serve as a manner of "ur-mathematics," or "foundation" for mathematics. ${ }^{159}$ They speculated that perhaps all of mathematics could be viewed as being in effect "about" sets, or as a matter of operations on sets.

Dedekind in particular, whose style of mind was that of the rigorizer and conceptual unifier and systematizer, seems to have been taken with this prospect. Others were quick to join in the effort, and in

159 Today this role seems increasingly to be played by category theory-in significant part, one suspects, because it eschews precisely that freedom-restrictive ad hocery we'll find in a moment to characterize post-Cantorian set theory. On category theory, its ambitions and basic contours, see generally SAUNDERS MACLAINE, CATEGORIES FOR THE WORKING MATHEMATICIAN (1971); STEVE AWODEY, CATEGORY THEORY (2006). On its eschewal of what I just called "freedom-restrictive ad hocery," see infra, note 183, and associated text. 
at least one case - that of Frege, possibly the most rigorous of allindeed to have been in on the project independently, from the ground floor on up. Given that analysis and thereby the continuum itself had apparently been rigorized by being algebraized and then arithmetized, it was perhaps only natural to investigate whether arithmetic itself might not be yet further rigorized by being shown to be, in effect, none but an outgrowth of the seemingly most certain "science" of all-logic. For logic was not only both firm and, as Boole, Peirce, and DeMorgan had shown, closely linked to the mathematically rigorous subdiscipline of algebra itself; it also in effect had a set-like notion already - that of a concept's extension. It was but natural, then, to wonder whether the last step in rigorizing mathematics might be simply to show it to be in effect logic - the algebra to which geometry had been reduced being a matter of logical operations, and the sets toward which Weierstrass, Riemann, Dedekind, and ultimately Cantor had groped being but logical "extensions." The prospect was now live, then, that arithmetic itself might be, in a word, "logicized."

At least initially, prospects here looked rather good. For sets, after all, as noted above could be readily viewed as themselves "logical objects" of a sort: 160 They could be viewed as extensions-collections of objects to which intensions, in this case predicate concepts, could be ascribed. Since the notion of an extension conceived this way as coordinate with an intension had been familiar to logic for centuries, it was in a certain sense only natural that some should view Cantor and his immediate predecessors and colleagues as having in effect stumbled back into logic in combinatorializing the continuum.

Moreover and quite relatedly, recent logical developments themselves seemed to buttress this synthesizing view of the matter. The aforementioned Augustus DeMorgan, for example, had in effect shown Aristotelian category logic and algebra to be largely coextensive; garden variety algebraic operations could be translated into logically familiar syllogistic patterns, and vice versa. George Boole, John Venn, and C. S. Peirce, for their parts, had effectively shown how familiar logical operations such as conjunction ("and") and inclusive disjunction (Latin "vel," English "or" in the "a, b or both" sense) could be translated into now familiar set-theoretic operations-disjunction amounting to a "union," or "logical sum" operation and conjunction amounting to an "intersection" or "logical product" operation-upon extensions. And these latter themselves could conveniently be visualized as variously

160 Note that even quite early on in his philosophical reflections, Wittgenstein would reject this very notion, the idea that there were "logical objects" or Russellian "logical constants" for that matter. Logic was structure, "scaffolding," while objects were items arranged per such structure. The same in effect held of mathematics, a "logical method," as noted above. See TRACTATUS, supra note 49 , proposition 6.2 . 
disjoint, overlapping, or conjoined spatial enclosures-a bit like the topological spaces that developed out of Cantorian point sets and Riemannian manifolds. ${ }^{161}$

Toward the tail-end of these mentioned developments, Guesseppe Peano and, independently, Frege, developed axiomatic systems from which all of the salient features of the natural numbers and arithmetic operations thereon could be straightforwardly derived. Frege also worked out the first known complete reduction of these axioms themselves to familiar logical operations upon concept-extensionsagain, in effect, sets. ${ }^{162}$ Frege also indicated how all of the remainder of mathematics as to that point developed could be derived from arithmetic as logistically reduced in his formal system. Russell, at first working independently of Frege and then subsequently learning from him, accomplished much the same thing at the beginning of the twentieth century. And Russell and Whitehead of course ultimately carried out a cognate such derivation in full by the end of that century's first decade, in their epoch-making - and, as we now know in retrospect, -closingPrincipia Mathematica. ${ }^{163}$

It looked, then, by early in the twentieth century that the long march toward fully rigorizing the whole of mathematics was nearly completed. It seemed, indeed, to amount to a triumph quite on a par with that of Euclid millennia earlier in fully systematizing and axiomatizing geometry. If anything, in fact, this apparent triumph looked yet more impressive, given that geometry itself had been reduced to the very arithmetic that the "logicists" now had apparently reduced to logic. 164

It was precisely at this point that there was discovered a worm in this bright shiny apple. For it emerged that the notion of an arbitrary set or extension as thoroughly explored and developed by Cantor and unreservedly employed by Frege and other logicists in grounding mathematics was itself in an important sense ungrounded and indeed prey to inconsistency. ${ }^{165}$ A sequence of now notorious paradoxes came to light in rapid succession.

161 This is of course the origin of familiar Boolean algebras, often exposited to youngsters through the use of heuristically friendly Venn diagrams.

162 See GotTloB FrEge, BEGRIFFSSCHRIFT (1879).

163 See WHITEHEAD \& RUSSELL, supra note 30. Note that even the symbols for such operations ended up similar, the vel - "v"-of logic corrsponding to the union- "U"-operator on sets while the and-“" $\wedge$ "- - of logic corresponded to the "inverted ' $U$ "'-intersection operator on sets.

164 Probably the capstone to that development was Hilbert's Foundations of Geometry. See DAVID HILBERT, THE FOUNDATIONS OF GEOMETRY (E. J. Townsend trans., Open Court 1902).

165 I say particularly in connection with intensions because in Frege's system it was the "Comprehension Axiom," which asserted the existence of an extension-a set-for every stated criterion-intension - that underwrote the difficulties I am about to describe. 


\subsubsection{Extensionalism, Abstraction, and Unrestricted Self-Reference}

To draw an anticipatory bead on the role that unrestricted extensionalism played in the reflexivity "crisis" that was soon to emerge, note what appears to be a "deep" distinction between the most abstract extensions- - "pure sets" - on the one hand, and at least what I shall call "thick" intensions-i.e., intensions singling out objects other than sets (or intensions, for that matter) themselves on the other hand. The latter - thick intensions - might be thought of initially at least as concepts that either do or do not hold true of various non-abstract objects. The predicate "green," for example, holds true of non-dormant grass, some traffic lights, some eyes, etc. One speaks of such objects in predicating greenness of them; and those objects then constitute the extension of the predicate concept-the intension-itself. No question arises, in such case, of self-application, self-membership, or selfreference of any sort. It does not so much as occur to most of us to inquire whether the concept of greenness, be it intensionally or extensionally considered, is itself green, thus whether a set of green objects might belong to itself. You'll likely be thought crazy-or, perhaps what is the same, a philosopher-if you ask of such things.

When we turn our attention to concepts or their extensions considered as objects (objects of attention) themselves, on the other hand, matters change rather quickly. Indeed there appears to be something self-referential in such talk quite immediately. For we speak then "in" concepts, so to speak-i.e., in a language of conceptexpressions-about concepts, be it of predicate-intensions or conceptextensions. Indeed, in a manner reminiscent of Cantor's Domain Principle itself, we might notice that even the concept of an extension itself is an intension, which carries with it an extension - the extension that contains concept-extensions. 166 As soon as we commence talking in this way-which it seems we're quite able to do quite intelligiblywe are of course talking at so "high" or "thin" a level of abstraction that it now becomes sensible to speak of such things as the self-applicability of concepts, and what amounts to the same thing, the self-membership of extensions. Things become thoroughly self-referential at least in potential. For we are talking and thinking about that which we talk and

166 There's a rough parallel between this odd business and Frege's notorious difficulty with "the concept "horse," in which his fundamental distinction between concept and object was in a sense given the lie by his discussion itself, which "objectified" the concept by dint of referring to it. See Frege, On Concept and Object, in TRANSLATIONS FROM THE PhILOSOPHICAL WRITINGS OF GOTTLOB FREGE, supra note 54, at 54-55. Frege famously requested a "pinch of salt"-a pinch which bears comparison to Wittgenstein's "ladder," more on which below. (The Tractatus, as we shall see, purports to "say" what by its own lights can only be "shown.") By the end of this Part, I shall hope to have indicated a more satisfactory, less strictly metaphorical way of regarding such puzzles. No ladders or pinches of salt required. 
think "in," so to speak-in concepts.

So potential self-reference of a kind lay in the background to Cantor's-and the logicists' - work all along. Cantor, along with other punctualizers of the continuum and then numberers of the points, had been trafficking in sets of sets all along, for example: A real number as a set of sequences was a set of sets of digits, for example. And a power set was a set of subsets, hence a set of sets. And so on. So the project of extensionalizing and logicizing mathematics as a means of conceptually unifying and rigorizing it all the way "down" to its "highly" abstract fundaments was, eo ipso, a project that opened the door to reflectivity. And the ultimate guarantor of the propriety of this process-Cantor's Domain Principle, that "thinnest" of all thin intensionalisms-was none other than the actualization of that possibility. For the domain of sets themselves was of course "the" set of sets. And if "the" is the singly designating "definite" article, then that domain of sets, as both a set and as "the" set of sets, would presumably belong to itself. You can see now already, I trust, from whence the trouble will come.

\subsubsection{Antinomies and Anomies Abound}

It didn't take long for the prospects implicit in what we have just observed to be realized. Paradoxes rapidly proliferated just as the logicist program was nearing completion. Probably the best known among these is Russell's paradox, concerning the putative "set of all sets that are not members of themselves." Essentially the idea runs thus: Reflexive phenomena are quite common and indeed all around us. There are barbers, for example, who trim not only the hair of others, but their own hair as well. There are other barbers who do not. There are speakers who speak of themselves sometimes, and at other times not; we are probably all of us speakers of this sort. Most of us likewise without a doubt think of ourselves sometimes-many of us indeed probably too much.

But it isn't just people who self-refer. The language they use to refer, to communicate and to think, and many of the concepts that find expression therein, also can be used to refer to themselves. Being aware of ourselves, we are also aware of the features and uses of our language and symbols more generally; and it is presumably therefore unsurprising that we are able to impart, as it were, our own self-referential capacities to the media of our own referring. Hence there are adjectives, for example, that can be truly asserted of themselves- "polysyllabic" is one-and there are others that cannot-"monosyllabic" is one. And there are concepts that hold true of themselves-the concept "easily 
learned" is presumably easily learned-while others do not-the concept "orange" is not orange.

Now suppose we consider this prospect-the prospect of selfapplication or self-reference-in connection with sets in the manner anticipated above. Surely there are sets that in a certain sense must be members of themselves and others that must not, just as there are concepts and predicate expressions (concept words) that can be predicated of themselves and others that cannot. For there are sets that correspond, as extensions, to predicate intensions that can be predicated of themselves, and there are others that do not. To the concept "easily learned" mentioned above, for example, there presumably corresponds the set of concepts that are easily learned. This set is itself an extension, to which the associated intension-the concept "easily learned"presumably therefore also belongs.

Consider now an especially compelling case-a case carried "all the way out," so to speak: As noted above, by Cantor's Domain Principle, upon which talk of "completed" (i.e., determinate) infinite totalities is predicated, if our talk about "sets" bears a determinate sense, then there is a domain of all sets-all of those things of which we speak in employing and understanding the word "set." This domain is itself a set-the set of sets, i.e., the extension of the concept or intension "set" itself. This domain then would be the set of all sets. But if it is truly the set of all sets, then it is a member of itself. Right?

Now at first pass this might ring a little suspicious. A hatbox contains hats; could it contain boxes? Presumably yes, but then could it contain even itself? Surely not. There can be boxes of boxes, but there could not be a box of quite literally all boxes, since such a box could not contain itself. So perhaps there cannot be a set of all sets either?

But sets are not boxes. They're not physical objects at all, any more than numbers or words or other abstract objects are. (We speak of sets of numbers, but there can be no boxes of numbers.) Since sets are abstract objects, not concrete ones, there would seem nothing impermissible about self-membership, any more than there is about adjectival self-application. (Again, "polysyllabic" is polysyllabic, is it not?) A set is no more than the extension of an intension--the latter being a concept expressed by a word, like an adjective-and accordingly is no more subject to physical laws than are concepts themselves. (Ask: Can a concept be hot?; cold?; tall?; short?; fastmoving?; subject to the laws of thermodynamics?; etc. Well then how could a concept's extension be like a hatbox?)

Moreover, sets belong to an extension-a set-that is correlate to a word whose meaning-whose intension-seems to suffer no ambiguity or want of determinacy: That's right, the word "set" itself, a.k.a. "aggregate," "collection," "ensemble," "multiplicity," etc. We use such 
words often enough, indeed very often; and there seems no confusion about them at all. Moreover, consider: There are many, many sets additional to the set of all sets that would seem to be self-membered: The set of all sets possessed of more than one member, for example. And so on.

But now wait a minute, not so fast: For here also is where another perceived problem arises, one that both grows out of this sometimes odd-seeming idea of sets which "contain themselves" but is more starkly problematic rather than simply suspicious: Grant for the moment that some sets are self-membered, and others are not. The set of all sets is self-membered, as is the set of all non-empty sets, all non-singleton sets, and so forth. The set of all apples, on the other hand, not being an apple, is not self-membered. So let us partition the set of all sets into the sets of self-membered and non-self-membered sets. We'll say accordingly that there is a set of all self-membered-sets, and a set of non-self-membered sets; between the two of them these two sets comprise all of the sets. ${ }^{167}$

Now the troublesome question: Ask of the latter set-the set of all non-self-membered sets-whether it is a member of itself, or whether instead it is a member of its complement. (Since the latter two exhaust the universe of sets, it must be in one of them.) ${ }^{168}$ Ask first, then, whether this set of non-self-membered sets is itself self-membered.

Is it? Well, if it is, then it isn't, and if it isn't, it is. That is the problem. See? If it is self-membered, then by the defining criterion for membership in itself, it must be non-self-membered, thus must belong to its complement; so it must belong both to itself and to its complement. That's a contradiction. If on the other hand ${ }^{169}$ this set is not self-membered and thus belongs to its complement, then again by the defining criterion for self-membership, it must be self-membered as well. Contradiction again. From both sides, then. Crazy, no?

This is the so-called "Russell Paradox," a straightforward settheoretic analogue to an ages old "Paradox of the Barber" concerning a fellow who "shaves all and only those people in the village who do not shave themselves." 170 There are other analogues too: Take "right now telling the truth" as the criterion of membership in a set, and you'll see that we have here a set-theoretic rendition of the old Epimenides paradox ("the Liar," who says of himself that he is not at that moment telling the truth) as well. The incompleteness-proving Gödel sentence is

167 Assuming tertium non datur, which we'll see has been questioned in consequence of the tale we're now telling.

168 I hope that this "since" might have given you pause. We'll come back to it.

169 You might ask whether there are only two hands here. We'll come to that.

170 A moment's reflection reveals there can be no such barber. The defining criterion is as it were of a piece with expressions like "the round square." Perhaps the same holds of Russell's set, then? Perhaps. But hold on-we'll find reason to query that easy conclusion momentarily. 
another instance: It says of itself that it cannot be proved. If true, it is unprovable, and if false, it is true; so it must be unprovable. ${ }^{171}$

\subsection{4 "Crisis"- and Opportunity}

Russell's paradox seems to have caused something of a stir. Frege portentously murmured that the "foundations of mathematics" had been "shaken."172 Poincaré rubbed his palms and exhalted that logic was not sterile after all, as it generated antinomies. ${ }^{173}$ People talked of a "crisis" in mathematics rather in the manner that some later spoke of a "crisis" in physics - and even in morals (would you believe?)! - occasioned by sundry paradoxes of relativity and quantum mechanics. Folk also hastened to find-or to fashion-" "solutions" even as other, rather cognate paradoxes came to light. (We'll come to some of these below.)

Meanwhile, as all of this noisy fracas was underway, a sort of flipside to the Russell Paradox went comparatively ignored. For go back to the two sets I partitioned a moment ago. There was another one, remember? Not just the set of all non-self-membered sets, but its would-be complement, the set of all self-membered sets. Let's call it "the Russell Complement," since the other one's oft-called "the Russell Set." Now ask: Is this one-the Russell Complement—self-membered? How would you ever find out? ${ }^{174}$ Do you see any way even to begin to address this question? I don't. And if we can reckon on no way what ever-even "in principle"- to find out, is it correct to say that it either is or is not? ${ }^{175}$

171 For reasons like this one, the early attempts by Ramsey and others to distinguish radically between "set-theoretic" paradoxes like Russell's and merely "semantic" ones like the Liar seem a bit of a Hail Mary. See Frank P. RAMSEY, The Foundations of Arithmetic, in PHILSOPHICAL PAPERS (D. H. Mellor ed., 1990). There is a straightforward sense in which the Gödel proof amounts to a variation on Cantorian diagonalization as discussed above. Cantor shows how to construct a new real number, from any table of reals, which cannot itself be on that table. And he does so by reference to what is there, which then is expressly "negated" in construction of the new element. Gödel similarly shows how to construct a "Gödel sentence," saying of itself that it is unprovable, in any consistent axiomatic system of logistic whose axioms are sufficient to derive Peano arithmetic and thus the remainder of mathematics $\dot{a}$ la Russell and Whitehead.

172 Frege was "shaken" by Russell's discovery, and said so both in correspondance with Russell and in an appendix to Grundgesetz. See FREGE, supra note 54, at 214.

173 See Henri Poincare, Les mathematiques et la logique, 14 REVUE DE METAPHYSIQUE ET DE MORALE 294, 306 (1905).

174 As with the Russell set, of course, there are analogues we can construct in non-set-theoretic terms. How about him whom I'll call "the Other Barber," who shaves all and only those who shave themselves: Does he shave himself? Or "the Truth-Teller," who says "I am now speaking the truth." Does he speak the truth in so sayıng? Or what I'll call the "Self-Confident Gödel Sentence," which effectively says of itself, "I am provable"-is it? How would we go about finding answers to these "questions?"

175 If the answer is "no," then note that we might have opened the door to some non-classical logic in which bivalence, excluded middle, or both fail to hold. But of this, more presently. 
I've always found it a bit curious that the complement set never seemed-nor does it seem now-to cause quite the stir that the Russell Set did. It sometimes is noticed, but it is treated at best more as a poor relation than as a full sibling. ${ }^{176}$ Yet it would seem to me that a strong hint as to how best to regard the Russell Set sort of problems might be forthcoming through consideration not of the Russell Set in isolation, but always with the complement set. For the latter would seems as it were to be "on the same level" as the Russell Set itself. Both of them seem rooted in a single and most fundamental source-self-reference itself, being a subject and object (a class and a member) at once, so to speak.

And relatedly there is rather an attractive symmetry to them, it seems to me, when you think about it: To the "antinomy" generated by the one corresponds an "anomie" generated by the other; to the paradox of one corresponds a deep indeterminacy in the other. Self-cancelling law and hence lawlessness in the one case, immediate lawlessness in the other: One minus one in the one case, so to speak, and zero in the other. The role of negation in the one case is not "more fundamental" than, or "as fundamental" as, that of self-reference in both cases; it simply serves to distinguish the two equally deep cases. It affords selfreferential paradox its Janus-like nature-an anomie side and an antinomy side.

Now it seems to me fairly clear that both the antinomy and the anomie, both the paradox and the indeterminacy, are rooted in none but the selfsame self-reference involved in the notions of self-membership in the set-theoretic case, self-application or self-ascription in the nonset-theoretic counterpart cases - e.g., the barber who shaves all and only those who do shave themselves, the "truth-teller" who claims to be speaking the truth at the moment of her utterance, and so on. Indeed, as I'll indicate below, there likewise are counterpart anomies and antinomies lurking where ever we-human beings, self-observing and self-editing agents-have occasion to examine ourselves and inquire, "what to do?, what to be?" All here seems to stem, that's to say, from the fact we're not boxes. But more of this, too, below.

\subsubsection{Opportunity Squandered}

Now, in a certain sense people do seem to have taken account, in effect or perhaps indirectly, of the counterpart indeterminacy problem as

176 Look into any book about set theory, for example, or any history of the foundational debates, or any book about paradoxes, and you'll find the Russell Set and the Liar. In virtually no case will you find any mention of what I've called the Russell Complement or "the Truth-Teller." Self-contradiction seems to be taken more seriously than immediate indeterminacy. Why? 
well. For most of the proffered "solutions" to the paradoxes that people came up with were directed, not simply to the matter of negation in connection with self-reference as figured into the Russell and cognate paradoxes, but to self-reference itself. Indeed, nearly all of these wouldbe solutions amounted, in effect, to one or another form of fiat proscription of self-reference itself. To safeguard otherwise arbitrary classes, we might say, we arbitrarily prohibited self-membered classes. In effect we demanded that sets be like boxes, or like Russian dolls. And in so doing we also, in a sense to which I shall return below, elected to perform a sort of self-lobotomization; it was as if we'd decided we'd all be much happier if only we all had a bad case of Asberger's Syndrome. ${ }^{177}$

The problem with this strategy, at least for mathematics, was that it rendered the long sought "reduction" of all mathematics to arithmetic and then logic impossible-as perhaps the self-referential nature of Cantor's diagonal method of argumentation in proving the nondenumerability of the reals might have led you to anticipate. ${ }^{178}$ Instead we had arbitrary mathematics "supported" by arbitrary rulethe earth supported by an elephant supported by a tortoise supported by ... what? The whole founding project then comes to look like an enigma or joke. It is as if all that mattered was that some suitable axiom scheme be developed from which all of mathematics might then be derived, irrespective of what ever independently compelling principle, "ultimate truth" or "self-evidence" those axioms might stem from or possess. ${ }^{179}$ What then would be the point of the "reduction"?

One might rejoin that reduction need not have a point; perhaps it can happily be pointless, perhaps it's just "interesting." But the whole idea of axiomatization, ever since Euclid's first comprehensive employment of the method, has been to ground sundry results in a minimal number of truly "self-evident," indubitable principles. It was never simply to show that one could come up with something from

177 Actually, this is not simply a weak (or sick) joke. One influential theory of schizophrenia-Bateson's "double bind" theory-attributes the characteristic communication problems experienced by schizophrenics to impairment of the self-referential faculty. See, e.g., Gregory Bateson et al., Toward a Theory of Schizophrenia, 1 BEHAV. SCI. 27 (1956). The idea is that communication involves not only consciousness of objects discussed in a language, but of the acts of linguistic communication themselves in the acting as well. Schizophrenics are said to lack that latter consciousness, and this accounts for communication failures, including conspicuously the blindness to irony. Would that we could interrogate this further; but we can't do so here.

178 If it did not, and you do not see why it would, please see supra note 129 and accompanying text.

179 Here a remark made by Wittgenstein of Frank Ramsey is apposite. He described Ramsey as "a bourgeois thinker," in virtue of his tendency to look simply for quick, ad hoc "solutions"patches for the dyke, so to speak-rather than fundamental errors to which the "problem" could be more deeply attributed as symptom. There's a nice symmetry here, by the way, to Ramsey's own jibe leveled at intuitionists - that they sought to bring "Bolshevism to mathematics." But more on that one below. 
which what one wanted to derive could be derived. Had it been that, it would be exceedingly mysterious why we should ever have wished to do any "deriving" at all. And as the very proliferation of proffered "solutions" to the paradoxes itself, in addition to the particular such profferings themselves, tended to show, the solutions in question were anything but indubitable. ${ }^{180}$

Seen against the backdrop of mathematical history from Descartes to Cantor, moreover, there is something yet more specifically troubling about the ad hoc "solutions" to paradox to which I'm alluding. For recall that Cantor's own principled justification of the arbitrariness-the "freedom"- that was mathematics' move toward extensionalism, itself was intensionalist. He showed that intensionalism, if followed-through "all the way out" per the Domain Principle, was what underwrote wholesale extensionalism. But now note that this "all the way out," "thin" form of intensionalism was both (a) non-arbitrary-it was principled-and (b) precisely what sanctioned self-membered classes themselves.

The paradoxes of self-membership, that is to say, are the very price of one's salvaging the coherence of completed infinities hence extensionalism and Cantorian "freedom" in mathematics-precisely the freedom that was required if geometry and the continuum, hence analysis and topology, were ever to be rigorous. If you proscribe selfmembership, you effectively proscribe the Domain Principle itself. And the latter was the only good argument that could be offered against millennia of persuasive intensionalist attacks on the coherence of "completed" infinities and thus extensional mathematics itself. So arbitrariness about self-reference ends up rendering arbitrariness about classes and extensionalism-Cantorian "freedom"-in mathematics impossible. It is a full-blown incoherence, of a kind that makes Russell's Set look quite tame by comparison!

Now as in the case of the criterial versus arbitrary choice decision point that occasioned our historical recounting in earlier sections above, in the present case too we must regrettably pass over much of the detail in this case. For such detail in this case includes several full families of strategies offered for skirting the paradoxes. Suffice it for present purposes, then, to note that all of them involved one or another ad hoc restriction or set of restrictions upon the free play of self-reference and hence full-bore extensionalism and Cantorian "freedom" itself.

In some cases the "solution" was effected by imposing a hierarchy- "cumulative" in the now dominant approach, "ramified" in

180 Doesn't "solution" here, by the way, remind you a bit of the names of all too wearyingly many companies now, who do not sell desks, desktops and laptops, or toothbrushes and toothpaste, but "office solutions," "dental solutions," and so forth? Wittgenstein's remark about Ramsey, per the previous footnote, seems all the more apt! 
at least one once-influential approach-of iterative "orders" or "types," pursuant to which self-reference hence self-membership was rendered syntactically impossible by fiat across the board. ${ }^{181}$ Not surprisingly in this case, of course, one had to violate such restrictions in describing, discussing and justifying the approach itself to one's colleagues while speaking in natural language. As one wit once put it, these people have two set theories, one in which they "do" set theory, the other in which they talk about it.

In other cases the strategy was to give effect to one or another "limitation of size" doctrine pursuant to which some, though not all, sets were prevented from growing in such manner as might leave selfmembership possible. ${ }^{182}$ In some versions of this strategy-including one proffered by von Neumann that was quite influential for a timethe trick was simply to draw a distinction between sets that could be self-members on the one hand-now called "sets"-and others that could not on the other hand-called "classes" or "proper classes." As if there were any intuitive distinction what ever between "sets" and "classes."

Note now that all of these proffered solutions flout Cantor's Domain Principle. See how? Well, as we noted above, we seem to have a perfectly intuitively clear notion of "set," "class," "aggregate," "collection," "ensemble," "multiplicity," and so on. And this notion involves no more proscription of self-reference than does the idea of the adjective "polysyllabic's" itself being polysyllabic (again, a set is the abstract correlate to an abstract concept, it is not a physical box). And again, what is yet more compelling, this concept would seem to be presupposed by our very talking of sets and explaining why we "must" stratify or impose cognate restrictions upon some or all of "them"-i.e., all of the sets as a whole, as a single domain of objects-in the first place. One doesn't know whether to laugh, then, or simply to weep over "solutions" like this. Again, we must ask, what is the point of the foundational project when things have come to this? If we're willing to flout all first principle in such manner, why bother working to "derive" mathematics from first principles at all?

In any event it will accordingly come as little surprise, I take it, that those who presently work in the mathematical domain of category theory - that subdiscipline which investigates mathematical structure in its most abstract reaches and accordingly strives to the greatest degree of mathematical generality (Cantorian "freedom") possible-have come to find that the stratification and "limitation of size" and "cumulative hierarchy" restrictions that have hamstrung set theory since the 1920 s or

181 For a useful survey, see, for example, QUINE, supra note 150

182 Id.; see also HALLETT, supra note 50. 
so must now be jettisoned. ${ }^{183}$ It is accordingly in category theory, and no longer set theory, where we find the Cantorian project in full flower. That is where foundational mathematics is Cantorianly "free" now. And that is where those who'd examine and explore the implications of first principles in mathematics must turn now.

Now in view of this last remark, you might be beginning to wonder what Cantor himself had to say about all of this-i.e., what he decided at this second Cantorian "decision point," as I am calling it. For he was around and aware of developments at the time that most of all this was afoot. And he seems indeed actually to have discovered some of the paradoxes himself well before they came to light and occasioned perceived "crisis." So let us now turn to that, albeit briefly. I do so not simply to satisfy your curiosity. I do so because, once again-as in the case of the criterial choice juncture-Cantor was rather more sensible than many of his followers. Another nice parallel with Wittgenstein.

\subsubsection{Cantor and Wittgenstein Redux}

The paradox that Cantor first spotted was what subsequently came to be known as the "Burali-Forti" paradox, concerning "the largest ordinal." It can effectively be viewed as a paradox directly concerning the earlier mentioned "set of all sets," springing from the conjunction of the defining operations by which we found Cantor above defining and forming ordinals on the one hand, Cantor's Domain Principle on the other. Here's how it runs: On the one hand, there seems no end to the ordinals, given how they are constructed; just as there is no "final" natural number. The generating principles are as non-terminating as is the successor ("plus one") operation defined over the naturals. But there being no end in this case-the ordinal case-seems to entail, by the ordinals' own definition also supplied in terms of their rules of generation, that there can be no totality of them either. For each ordinal contains all its predecessors; it "sweeps them up," so to speak. But there being no totality in turn runs up against the Domain Principle. For there seems to be something we're talking about-and we seem to know what we're talking about-when we speak of "the ordinals."

See? The principles by which the ordinals are defined and generated is, as we saw above, indefinitely iterable: Each new ordinal effectively "scoops up"-includes within itself-all of its predecessors, such that a set of "all" ordinals would be, by definition, "the last" ordinal. (That distinguishes them from the unending naturals $\mathrm{N}$, which

183 See, e.g., J. Bell, Category Theory and the Foundations of Mathematics, 32 BRIT. J. PHIL. SCI. 349, 356 (1981); ABRAHAM FRAENKEL ET AL, FOUNDATIONS OF SET THEORY 143 (1973). See also MACLAINE, supra note 159; AWODEY, supra note 159. 
do not "sweep up" their predecessors.) ${ }^{184}$ But this means the Domain Principle as applied here-the principle that seems to underwrite our talking of "the ordinals" and other sets in the first place-is in conflict with the very principles that define ordinals. It's another antinomy.

Now as I say, this one was named for Burali-Forti, who first brought it to (published) light. ${ }^{185}$ But Cantor was aware of it at least a year earlier, as evidenced in a letter that he wrote to Dedekind. Why then didn't Cantor bring it to light? Well, perhaps in part he was hoping to buy time, given that set theory was at this point under attack and the presence of paradox at its core wouldn't have been helpful to its cause. But that would at most be but part of the story. And I actually doubt it's a significant part, if a part at all. For it seems more likely that Cantor just wasn't much bothered by the paradox. My bet's he exalted in it.

Why would I say that? Well, Cantor seems forthrightly to have recognized-and even indeed happily to have embraced, on theological grounds - that at the outer reaches of his work, which you'll note I keep. describing as taking certain principles "all the way out," our thoughts tend to bump up against something or Someone whom Cantor called "the Absolute." Huh? That's right, "the Absolute," which in much of his private correspondence Cantor identified with God. Cantor seems indeed often to have written to the effect that God not only got "bumped up against," but had "revealed" set theory itself to him. And as I mentioned earlier, Cantor corresponded at least as much with theologians and philosophers as with mathematicians. ${ }^{186}$ Moreover, God was for Cantor, just as God has been in various strains of the several Abrahamic religious traditions, inherently paradoxical, beyond comprehension by "mere finite" minds. Cantor's God, like the God of Nicholas of Cusa and the God of the Kabbalah for that matter, embraced everything, even contraries. ${ }^{187}$ Cantor was accordingly no more

\footnotetext{
184 At least provided we not define them as sets of their predecessors, as some have done, and define them instead and more perspicuously as sets of equipollent sets, as Frege did, supra note 29.

185 See Cesare Burali-Forti, Una questione sui numeri transfinitie, 11 RENDICONTI DEL Circolo Matematico di Palermo 154 (1897).

186 It also is not without interest in this connection that the one fellow who seems most to have anticipated Cantor, Bolzano, was a priest and theologian as well as a mathematician. (He was toward the end of his life defrocked for his left-leaning radical politics.) See generally THE MATHEMATICAL WORKS OF BERNARD BolzaNo (Steve Russ trans. \& ed., 2005). And the life and reported mystical experiences of Pascal, who we noted above also to have anticipated Cantor a bit on the infinite and the Domain Principle in particular, need scarcely be recounted. Finally Wittgenstein too, as is well known, was of a deeply religious temperament, and was of course forthrightly "mystical" in orientation at least during his "early" period. See, for example, the later passages in the Tractatus on "das Mystische."

187 There are of course parallel views in most major non-Abrahamic traditions. Brahma, Dionysus, Shiva, Heraclitus, Zoroaster, Lao Tzu, the Zen masters, the Yin and Yang of the I Ching, ... yes, "and so on." Duality at the edges of cognition seems to be universally recognized across times and distances, and seems always to be associated with some form of divinity or
} 
consciously troubled by paradox in the outer reaches of the set theory that God had "revealed" to him than he was consciously troubled by God Himself. ${ }^{188}$ The matter is perhaps best put by Cantor's principal biographer:

By recognizing the connections Cantor drew between his transfinite numbers and the Absolute, it is easier to understand why the paradoxes of set theory did not upset him as they did so many mathematicians at the turn of the century. Essentially, he had recognized the impossibility of subjecting the entire succession of transfinite numbers to exact mathematical analysis. The nature of their existence as a unity in the mind of God constituted a different sort of perfection, and Cantor was not disturbed that it was beyond his means to comprehend it precisely. In fact, the inaccessibility of the Absolute to any maximal transfinite determination seemed both fitting and appropriate. ${ }^{189}$

So Cantor seems more to have embraced than attempted to dodge the set-theoretic paradoxes, which he saw more as vindicating than vitiating his work. He happily pointed out that there are some sets which are what he called "unthinkable," "non-comprehensible," or "inconsistent multiplicities" (we might nowadays call them "transconsistent" or "paraconsistent" multiplicities, in keeping with the preferred term for modern logics that track such phenomena) ${ }^{190}$. These were multiplicities that were in effect "all the way out," as I have been putting it, at the farthest reaches of that domain implicated by the Domain Principle itself. And, as Cantor pointed out with equal readiness, there were other multiplicities that are not thus "all the way out" and accordingly remain quite consistently thinkable. That is all. ${ }^{191}$

Now in all of this, in a curious symmetry with the discussion of our other decision point, we once again find an intriguing resemblance between Cantor and Wittgenstein. For Wittgenstein, notoriously to some (Turing in particular) ${ }^{192}$, rather mocked what he called the "superstitious veneration and dread" shown by metamathematicians and

sacrality.

188 Some claim he was unconsciously troubled, indeed mad, but this tends to be overblown and is in any event another story. It might be worth noting, however, that madness itself is typically associated with religious ecstasies in most traditions. Simply look once more at the names rattled off in the previous footnote, and ask with how many of their bearers certain dances and festivals and intoxicant substances have been associated.

189 DAUBEN, supra note 1 , at 246.

190 A bit more on these presently.

191 Here is Dauben again: "In the end, Cantor regarded the transfinite numbers as leading directly to the Absolute, to the one 'true infinity,' whose magnitude was capable of neither increase nor decrease but could only be described as an absolute maximum that was incomprehensible within the bounds of man's understanding." DAUBEN, supra note 1, at 246.

192 See, e.g., LUDWIG WITTGENSTEIN, WITTGENSTEIN'S LECTURES ON THE FOUNDATIONS OF MATHEMATICS: CAMBRIDGE, 1939 (Cora Diamond ed., 1975); see also ANDREW HODGES, ALAN TURING: THE ENIGMA (1992). 
logicians in the face of contradiction, as manifest in particular in the "formalists" frantic metamathematical searches for "consistency proofs." 193 Moreover, in a certain sense Wittgenstein even affirmatively embraced contradiction-out at the limits-much as Cantor did, rather than merely mocking those who were frightened by and sought artificially to banish it. He did so, albeit in different ways, both in his "early" and in his "later" philosophy-just as we noted him to have retained an intensionalist orientation, both early and late, in respect of mathematics more generally.

In the case of the earlier philosophy, I am alluding to the Tractatus's forthright acknowledgment that its own propositions failed of its own Domain-Principle-reminiscent meaning-strictures, and in that sense constituted a "ladder" which those who understood him aright would "throw away" post-ascent. In the case of the later philosophy, in turn, I am alluding to Wittgenstein's scattered remarks concerning what we might nowadays call "inconsistency-tolerance."194 Indeed, in one particularly remarkable such remark, Wittgenstein seems in effect to have "prophesied" one of what I shall in a moment be calling the more "principled," non-arbitrary-indeed intensional-means of handling the anomies and antinomies to which self-reference gives rise:

I predict a time when there will be mathematical investigations of calculi containing contradictions, and people will actually be proud of having emancipated themselves from consistency. ${ }^{195}$

That "predict[ed] time" has now long since come, as we shall see presently.

But now let us note a compounding irony. For Wittgenstein also embraced contradiction in the later philosophy in a manner more reminiscent of the way in which he did so in the earlier philosophy-in effect, by engaging in it (dare we say "showing" it?), rather than simply endorsing it. And, yet more ironically still, in light of the course of our discussion over this Part, he did so in effect by denying Cantor's Domain Principle in practice, in a manner that rendered his denial itself indeterminately meaningful! For just as the propositions of the Tractatus notoriously-and to its author quite cognizantly-failed of their own criteria of meaningfulness (they were not "logical pictures" of "states of affairs" that amounted to configured "objects")196, so does the so-called "later" philosophy seem to be expressed in a manner which, by its own refashioned take on linguistic meaning, could not actually be

193 It was this family of searches, and with them the "formalist" school itself, that was laid to rest by Gödel's second incompleteness proof referred to supra note 171. In short, if it's consistent, it ain't sufficiently complete to derive arithmetic from.

194 Another term for paraconsistency, more on which presently.

195 WITTGENSTEIN, PHILOSOPHICAL REMARKS, supra note 104, at 332.

196 See, of course, TRACTATUS, supra note 49, proposition 6.54 (the "ladder"). 
meaningful.

Why? Because if rule-following and meaning were ultimately not accountable for in terms of anything that was determinacyunderwriting - if it was all a manner simply of repetitive practice accompanied by "this is what we do" admonitions ${ }^{197}$ - then it is difficult to know what to make of the sundry claims made in the Investigations themselves. ${ }^{198}$ It is not, after all, as if this work itself were simply one more "language game" found among and on a level with all of the others. It speaks of such "games" quite in general, after all-as all jointly constituting that which underwrites meaning, and yet no particular one or group of which seems to underwrite the meanings of the claims of the Investigations themselves. Nor is it as if there were a well-worn general practice of speaking globally about linguistic meaning and what it consists in, for that matter. ${ }^{199}$ Absent any such widespread practice serving behaviorally to fix meaningfulness, then, what served as the basis for what ever sense the remarks of the Investigations themselves possessed?200 I see no answer, nor can I see anything improper in the question.

So Wittgenstein, just like Cantor, seems both to embrace contradiction and to fall into it willingly. And also like Cantor, his attitude toward what he did seems to have been deeply God-haunted, as one supposes any sustained dwelling at the edges of meaning-of

197 I am now implicating not only upon my own reading of the Investigations, but Kripke's influential reading as well. That latter reading is contestable, of course. See, e.g., SAUL KRIPKE, WitTgenstein on Rules and PRIVATE LANGUAGE (1982); G. P. BAKER \& P. M. S. HACKER, WitTGensteIn, RUles, AND PRIVATE Language (1984). I don't think that I here commit myself to the Kripke reading however. For I take Kripke's mistake, if one there be, to be attributing to Wittgenstein an affirmative claim or set of claims about what it is, if anything, in which how we "go on" with new applications and extensions of a rule to consist. I take Wittgenstein, by contrast, to intend no such affirmative claims at all. The reason that this itself places him into an antinomian position, however, is that his apparent denial of all existing claims meant to ground determinate meanings, along with his refraining from then putting anything into their place. He has left things quite groundless, so to speak, and at least suggested that the quest for an Archimedian point is a fool's errand. But if that be so, then one of course wonders from what position the Investigations's observations are made. Those certainly seem to be speaking of "how things are" in respect of meaningful linguistic behavior. There is in that sense an appeal to a sort of Domain Principle-in this case, the domain of linguistic behavior-even while the notion that there is any one phenomenon here is expressly denied.

198 LudWig WitTGenstein, Philosophical INVESTigations (G. E. M. Anscombe trans., 3d ed. 1972) (1958).

199 As G. E. Moore observed, Wittgenstein certainly did not use the word "grammar" in anything like its ordinary sense in the later writing. See G. E. MOORE, Wittegenstein's Lectures in 1930-33, in PHILOSOPHICAL PAPERS 252, 276 passim (1959). A counterpart, to his, in reference to the "later" philosophy, to Ramsey's earlier quip about the Tractarian say/show distinction: If you cannot say it, you cannot say it-and you can't whistle it either. See RAMSEY, The Foundations of Arithmetic, supra note 171.

200 Hilary Putnam once observed that all "criterial" accounts of meaning seem to founder in this way; their articulations never seem capable of satisfying themselves. There seems to be something to this. 
intension - might tend to be. It is natural to wonder, then, whether as in the case of criterial choice, so in the case of self-reference, we might find a pointer or two to the right route, the "principled" and in that sense intensional route, even if both blessed and cursed as it were, in some manner of reconciliation between Cantorian and Wittgensteinian orientations? I am inclined to think that we might, as I'll now explain.

\subsection{Healthy Choice}

We come, then, to the question of how we ought to regard the phenomenon of self-reference and the anomies and antinomies with which it is associated. For where Cantor and Wittgenstein leave the matter, I think, though rather more sensible than where the ad hoc strategies take it, nevertheless falls a bit short of closure. If the right route is in systematically reconciling the Cantorian and Wittgensteinian positions, as seems to me to be the case, we must draw out their principles a bit further, just as we did in the case of criterial choice. Moreover, I have suggested that the means that were employed to avoid self-referential antinomy (and with it, anomie) in the case of Cantorian set theory are ad hoc and "unprincipled." What, then, would it be to be "principled" here?

Here, then, is how I'll proceed. First I shall briefly characterize some of the more principled-looking responses that have been proposed. In so doing I'll highlight what they share in common. I'll also fall back on my earlier strategy of speaking mainly of two poles - or in this case, category theoretic "duals"- that between the two of them wellcharacterize the menu. (That's what we did, recall, about the criterial choice with the help of Cantor and Wittgenstein.)

First let us turn back for one moment to our earlier-considered complement to the Russell Set, what I called the Russell Complement. That was the set of all self-membered sets. We noted, in connection with that one, that there seemed no way so much as even to begin to address the question of this set's self-membership or otherwise. Why, then, assume there's an answer? Why assume that either it is or is not self-membered? Why, relatedly, then assume that either it is true or is false (but not neither and certainly not both) to claim that it is, or that it isn't? All principled means that have been suggested over the decades for dealing with set-theoretic and cognate paradoxes, I believe, can be helpfully viewed as stemming effectively from questions of this form.

Of course, as I suggested earlier, there is a sense in which the "unprincipled," ad hoc "solutions" do so as well. For as I noted, they effectively rule out the existence of the Russell Complement as surely as they do that of the Russell Set. But their problem, as we saw, is that 
they do so by ruling out something that there seems no independently principled reason for ruling out-viz., self-reference itself. ${ }^{201}$ They do so, in effect, by proscribing certain forms of locution in their formalisms to which they themselves must resort in explaining and justifying their formalisms themselves. Thus they effectively refute themselves in justifying their means of purging their systems of self-refutation. They accordingly do not eliminate paradox, but simply relocate it from system to metasystem. They treat as "nonsensical" a word like "selfmembership," as if this were nonsense of the same sort as "xbrynokoff." Yet to explain what they have in mind and why they are prohibiting it, they trade on "self-membership"'s actually being understandable-i.e., meaningful-in a way that "xbrynokoff" is not. So they elide over a fundamental distinction, treating as one thing what actually are two things, in tossing out both. In so doing they throw out the baby with the bath water, so to speak. That's what's unprincipled about them.

But now suppose instead we note that, while there is nothing suspicious or illegitimate-as distinguished from perplexing and revelatory-about self-reference itself, there is something vain and indeed inappropriate in expecting self-referential phenomena, which seem always to reside at the outer reaches of cognition - they are, so to speak, matters of cognition's cognizing cognition itself ${ }^{202}$ - to exhibit the same manner of determinacy and hence truth/falsity-aptitude as do non-self-referential phenomena. The structures or contours or boundary-drawing that are applied in and constitutive of acts of cognition itself-which seems always in critical part to involve parceling things out or carving things up, to be a matter of distinguishing and "boundary-marking"-cannot generally be straightforwardly applied to those acts of cognition itself in a manner that yields the same manner of determinacy-of-result as we find in the nonreflexive case. We cannot reasonably expect this any more than one might straightforwardly "think behind her thinking," or "be conscious of her unconscious." We can think on or about-or perhaps better, recognize, or find it impossible (per Kantian "transcendental" style argumentation) not to posit-something "behind" thinking, or an "unconscious." Indeed it would seem that we must so posit. But we cannot then think it-our posit-itself; nor can we be directly conscious of it.

This is of course, as hinted at parenthetically just above, a quite Kantian problematic. The logic of our own concepts-"thinking," "consciousness," etc.- -seems to require we posit a thinker, a "seat" or

201 They simply assume that the circle is vicious and thus to be squared, rather than recognizing the circle's naturalness and thus looking for more plausible vices.

202 Back to Descartes, and doubt, and arbitrary functions! 
locus of consciousness. ${ }^{203}$ But we cannot straightforwardly then apply the categories that are constitutive of such thinking, or consciousness, back "behind" them to the inevitably posited "thinker" or "seat" themselves. And yet these are the only categories we have in our thinking, and so we are naturally enough drawn to try thinking behind thinking, or observing - being conscious of - the unconscious. We are insatiably curious, after all. We wish to observe and to think about everything - even what we cannot see but are forced by our own logic to posit. So we think about thinking, then thinkers, and then can do nothing but apply the categories we have-to that one realm where the categories cannot be straightforwardly applied without paradox.

Et voilà. This is our curse and our blessing, it seems. It is our "tragedy"-in the full classical, not modern trivial sense. You're damned if you do, damned if you don't - and blessed as well. If you do not reflect, you're self-lobotomized, a self-consigned automaton. And so you are "damned." But at least you are spared all those vexatious puzzles. "Consciousness," as Dostoevsky's Underground Man said, "is a disease." "Language," as the Burroughs's Junkie said later, "is a virus." "The riddle," said Wittgenstein in a manner I've often found chillingly reminiscent of his confessed longings for suicide, "does not exist." "The solution of the problem of life is seen in the vanishing of this problem." Peace at last—oblivion, nirvana. Silence. Absorbed into immediacy -into a film, as according to Norman Malcolm seems to have been Wittgenstein's want after lecturing.

But now you feel an urge not to be damned to that status; you're aware that in some sense you're blessed by this curse, blessed with reflection-you are human. "The unexamined life is not worth living," as Socrates might have put it. To be human, it seems, is to be reflective, to be self-examining, hence self-conscious, hence self-referring. Or, as one well-known cognitive scientist might put it, "[you] are a strange loop."204 "Strange" indeed: For now you find that the categories you employ in reflection are the same that you employ in nonreflectionthey're all that you have, word-wise. But, again, they don't seem to work the same way in reflection. They often can mire you in selfcontradiction or in no diction, in indeterminacy. Antinomy or anomie. Is that clearly better than lobotomy?

So you're left with a question mark, perhaps followed by an exclamation point. This seems to be who we are. It's evidently our lot. Some label its recognition "nihilism." Others call it "mystical understanding," or "-flight." Still others call it encountering

203 In a more Wittgensteinian idiom, the "grammar" of these concepts seems to be such that there must be a subject for the verb "think," and a "seat" of this phenomenon "consciousness," etc.

204 I am alluding to Douglas HOFSTAEDTER, I AM A STRANGE LOOP (2007). 
Nothingness, or the Absolute, or indeed God-“"theophantic encounter." And some-including, intriguingly, Aquinas-have found in it the core of our "freedom." But it's in each case one thing, the same thing; and the differences in label seem little more than differences of tone. Nietzsche, the orphaned son of a deceased pastor, seems to have reacted with dread, speaking of "God's death," and of nihilism as "crisis." Others have long said this "death" and this "crisis" are just what God is, what God always has been, and that there is something quite wonderful about it. ("I Am." Not much more to report here.) ${ }^{205}$ And given its seemingly ineluctable implicature by our cognition itself, these people have perhaps sometimes reckoned that here lies the basis of the ancient idea that we ourselves partake of divinity of some sort-precisely the sense in which we can be said to have been created "in God's image." These people don't seem to know less than Neitzsche. Perhaps they are simply less fretful about it, exaltant in fact. Perhaps they are "Overmen." 206

Now zany reflections like these find more earthly, prosaic expression when we're in the precincts of logic and set theory, of course. But these same expressions all seem to be nevertheless rooted in reflections of the sort I've just registered. For all of them involve recognition that there are meaningful, cognitively intelligible propositions that either cannot be said, semantically speaking, to be determinably true or false, or that cannot be asserted even as their contradictories cannot be asserted. The challenge lies simply in formalizing this recognition in some manner that does not render us formally speechless at the core of cognition in the way that we're rendered at the periphery of cognition.

Some carry out this program by positing "third" or yet more semantic values additional to truth and falsity. There might be truth, falsity, and indeterminacy, for example. ${ }^{207}$ Some do so by positing truth value gaps, such gaps being a bit like, but not quite the same as, third values. ${ }^{208}$ There might be truth, falsity, and "neither," for example.

205 Ever notice that when God appears to Moses in the burning bush, He predicates nothing of Himself? His name itself is "I am," that is all. He is a Robert Musil sort of god, a "god without qualities." A bit like the set of all self-membered sets, seems to me-there seems no denying that it exists, but damn if you can determine one way or the other whether it meets its own membership criteria.

206 It is odd how many people know this word as "superman" and do not know that it's a crib from Emerson's "oversoul." And that they do not know that Neitzche kept a copy of Emerson's Essays by his bedside. A metaphor, this, for the difference between "new world" and "old world" temperaments, perhaps. The new worlders know what the old worlders know, but are happy about it. (There are of course plenty of "old worlders" in this sense in the new world-especially among fundamentalist religious sects. And there are plenty of "new worlders" in the old world as well-especially, curiously enough, in new churches!)

207 This is the solution adopted by Lukasiewicz. See, e.g., JAN LUKASIEWICZ, ARISTOTLE'S SYLLOGISTIC (1957).

208 See Saul A. Kripke, Outline of a Theory of Truth, 72 J. PHIL. 690 (1975). Kripke in 
Others do so by recognizing truth value gluts-i.e., circumstances in which there is equal reason to assert a proposition and its contradictory alike. So there is truth, falsity, and "both." 209 And finally for our purposes, still others do so by in effect assimilating truth to "warrant," or "assertibility conditions," such that the absence of such warrant or conditions can render it illicit to assert a proposition (such as that the set of self-membered sets is self-membered), can also render it illicit to assert the contrary of such a proposition (such as that the set of selfmembered sets is not self-membered), and thus ultimately can amount to such propositions' simply lacking any truth value-which in the logics of these folk tends more often to be called "epistemic" value. ${ }^{210}$

Now the differences among these programs can at some points of course prove significant. I do not wish to suggest that they all come to precisely the same thing or are prompted by precisely the same set of considerations in each case. But for our purposes what matters is what they all have in common, which I think is much more profound than their distinctions: That is their forthright recognition that there are meaningful, cognitively intelligible claims-or claims that, if "meaningless," are meaningless in a very different way than are "claims" such as "zberkill tzu bobo"-in relation to which there might be no fact of the matter that we can access in seeking to confirm or disconfirm. ${ }^{211}$

Again, such recognition amounts to a quite Kantian form of humility, I think. It amounts to a recognition that at the outer reaches of our cognitive capacities - the reaches that mark off domains of the sort figuring into Cantor's "Domain Principle" - our categories lose traction and leave us with "?" rather than "T" or "F." You can register that "?" as an "I" for "indeterminate," as a "_" for "no truth value," as an "N" for "neither," as a " $1 / 2$ " for "between the ' 1 ' of truth and the ' 0 ' of falsity," as a "B" for "both," or perhaps in some other manner. ${ }^{212}$ But the point is you're recognizing a semantic value or something functionally much like one, assigned to what you recognize for a semantically nonempty formulation, that is not itself either straightforward truth or straightforward falsity. You are saying, in effect, "in this case I do not know what to think."

Now in view of how sensible this orientation would seem, at least at the borders of cognition and rationation, why on earth hasn't it been universally accepted? Why are the logics to which I've alluded all

particular insists upon the distinction. I confess to finding it subtle.

209 See, e.g., Graham Priest, Logic of Paradox, 8 J. PHIL. LOGIC 219 (1979).

210 See Robert Hockett, Noncomparabilities and Nonstandard Logics (under revision for Econ. \& Phil., 2008), available at http://papers.ssrn.com/sol3/cf_dev/AbsByAuth.cfm?per_id=602726.

211 The interwar "Dada" poetry of Tristan Tzara, I find, is the most entertaining compendium of such "language." Much better even than Dylan's Tarantula or Lennon's In His Own Write.

212 A fulsome compendium is found in Hockett, supra note 210. 
characterized as "nonstandard"? Why is the alternative "classical"? Why isn't all debate actually between advocates of these logics themselves inter se, rather than between their advocates on the one hand, "standard" or "classical" logicians on the other?213

Well, apart from the obvious general answer that what's new must near always begin heterodox (just as did Cantor himself), I think there's at least one more specific explanation: It is that each of the approaches that I've briefly sketched would require the reinterpretation of one or more of the standard logical operators along ... ready? ... intensionalist lines! And the whole course of the formal disciplines from Descartes to the twentieth century, as we've seen, has been in the extensionalist direction. All's been a movement in favor of arbitrary choice, combinatorialism, Cantorian "freedom." That is so not only of mathematics, but even of the logic that Frege and then Russell mathematicized-"truth-functionalized"-in developing his would-be logicist "foundations" for mathematics.

What the paradoxes that attended the effort actually show, I believe, is the limits of extensionalism itself. A residue of intensionalism-a "thin" Wittgensteinian-Cantorian intensionalismremains as the price we must pay for continued intelligibility. For the only logics that neutralize the antinomies and anomies in principled, independently attractive and non-self-subverting fashion are logics that de-combinatorialize one or another of the standard logical operators that Frege and his successors all combinatorialized.

\subsubsection{Intensions' Remainder}

Let me elaborate just a bit. As suggested a moment ago, the whole trend of logic since Frege until recently has been as extensional as the mathematics that it was to "found." One takes simple indicative statements-"cats are good," "yes we have no bananas"-as "atomic" formulae. One then defines standard logical operators-negation, conjunction, disjunction, implication, equivalence, etc.-as combinatorial mappings from semantic values assigned to such formulae onto semantic values in turn. Negation is accordingly the function that maps true formulae onto falsehood, and false formulae onto truth. Conjunction maps non-singleton sets of true formulae onto truth, while mapping any such sets of formulae with at least one falsehood onto falsehood. Implication maps ordered pairs onto truth

213 It is somewhat amusing, you might find, that the earliest advocates of one of the logics to which I've alluded-the intuitionist, now a.k.a. "epistemic" one-once were reviled for seeking "to introduce Bolshevism into mathematics." See Ramsey, supra note 171. But it is error to suppose that all who oppose fascism are Bolsheviks (i.e., fascists as well). 
when ever the first member is false or the second member is true. And so forth. This is the nature of "standard" first-order propositional logic since Frege.

Now when you see the word "standard," you know there's a category of "nonstandard" as well. And there are indeed many nonstandard logics, some of which were developed as early as the 1920 s, but most of which have come to flower only since the second half of the twenieth century. It would be as futile as it would be inefficient to attempt to describe these developments in detail here. Our present point will be made if we simply point out what is common to two of the most influential, and in my view consistently principled, such nonstandard logics. As with the strategy of taking Cantor and Wittgenstein as polar ends of a contiuum in order to characterize the continuum itself, so here it will be best simply to choose those two nonstandard logics which at first glance are "opposites"-categorytheoretic duals, in fact. So I'll take "intuitionist" logic in the one case, the best-known "paraconsistent" logic in the other.

In the case of "intuitionist" (sometimes called "epistemic") logic, then, which denies excluded middle, what is most conspicuously different from the case of standard logic is that the negation operator is reinterpreted along non-truth-functional lines. ${ }^{214}$ In contrast to the standard, truth-functional negation operator mentioned a moment ago, intuitionist negation does not operate as an "automatic" complementcreator in effect designating "everything else in the world" to which the negated proposition does not apply. (Note that that is as ontologizing or ontology-ratifying, indeed extensional, as the Axiom of Choice itself.) Instead intuitionist negation operates as a sort of closet assertion stroke. That is to say, it serves as a non-combinatoric, intensional operator, indicating that some state of affairs or construction has been found or constructed which affirmatively warrants the judgment that the negated proposition cannot hold true. (You might think of it as in effect meaning that we have determined a surface to be green, hence that it is "not" red.) The role of "warrant" implicit in this treatment of negation, of course, accounts for the name "epistemic" sometimes given to intuitionist logic. It also, of course, means that negation in intuitionist logic is intensional; it's no longer just combinatoric, extensional, automatic.

The most obvious-perhaps even notorious-manifestation of intuitionist logic's intensionalizing of negation is that logic's rejection of double negation elimination: That is to say, its not licensing, from $\neg \alpha$, the inference to $\alpha$. When negation does not merely cancel itself, so to speak, but instead serves assertively to negate a negated

214 See Hockett, supra note 210. 
proposition now treated as self-standing, the negated proposition clearly is something that in part stands on its own as an affirmation. It's not merely an atomic proposition that has been truth-functionally "operated upon" or "flipped," such that $\neg \alpha$ is true precisely when $\alpha$ is false and vice versa. You cannot just combinatorially "flip" any longer in intuitionist logic. You must have grounds to deny just as you must have grounds to assert. ${ }^{215}$

Now let us turn briefly to another well known family of nonstandard logics, one member of which is a category-theoretic dual of intuitionist logic. ${ }^{216}$ In the case of so-called "paraconsistent," or "inconsistency-tolerant" logics it is not so much the negation operator that is intensionalised (though in some of them negation does seem to work more as a subcontrary operator than as a contradictory operator, hence as another case of closet assertion), but the implication operator. ${ }^{217}$ Implication in these logics no longer is treated as the "material" (i.e., extensional) implication familiar to "classical" (i.e., early twentieth century) logic, but as something more restrictive which accordingly licenses fewer inferences. In contrast to the case of classical truth-functional logics, in these logics the schema " $\alpha \rightarrow \beta$ " no longer is equivalent to " $\neg \alpha \vee \beta$," or to " $\neg(\alpha . \neg \beta)$." There must, rather, be some cognitively recognizable link between antecedent and consequent in paraconsistent logics. ${ }^{218}$ And that means that implication in these logics is, like negation in intuitionist logics, intensional.

One reason for this intensionalization-the reason appealed to most notably by advocates of "relevance logics," one subspecies of paraconsistent logic-is that a claim such as "if Felix is a dog, then Felix is a cat," which on material implication will be valid by dint of the truth of the consequent (for I promise you, Felix is a cat), does not correspond to the employment in natural languages of the implication relation. We generally expect there to be some reason that or sense in which antecedent might be thought to warrant consequent in an implicative claim. For if logic is not about consequence, advocates of

215 Id. See also WhAT Is NEGATION? (D. M. Gabbay \& H. Wansing eds., 1999); NEGATION AND POLARITY: SYNTACTIC AND SEMANTIC PERSPECTIVES (Laurence R. Horn \& Yasuhiko Kato eds., 2000); LAURENCE R. HORN, A NATURAL HISTORY OF NEGATION (2001). Horn's work is a classic here, as is FRED SOMMERS, THE LOGIC OF NATURAL LANGUAGE (1982).

216 "Duality" in this context is a category-theoretic term that is perhaps best explained, for present purposes, by recourse to specific example-indeed the details of the example I have just mentioned. So, whereas in intuitionist logic, $\rightarrow \alpha$ fails to license $\alpha$ (there is no "double negation elimination"), in the best known paraconsistent logics it is the reverse that is unlicensed. Further, whereas in intuitionist logic, $\beta \rightarrow(\alpha \vee \neg \alpha)$ ("excluded middle") is unlicensed, in paraconsistent logics it is $(\alpha, \neg \alpha) \rightarrow \beta$ ("ex contradictione sequitur quodlibet") that is unlicensed. And so on.

217 See, e.g., Priest, supra note 209.

218 Id; see also, and quite comprehensively, RICHARD ROUTLEY ET AL., RELEVANT LOGICS AND THEIR RIVALS (1983). 
these logics query, what is it about?219

The relevance expectation, then, can be thought of as part of the "intension" inhering in the concept of implication as it figures into familiar patterns of reasoning and argumentation. And this is an intension that licenses implication in fewer circumstances than those in which so-called "material" (extensional, truth-functional, merely combinatoric) implication is licensed. There is accordingly a straightforward analogue, I trust you will see, between "relevant" implication's contrast with material implication on the one hand, and meaningful, rule-generated non-periodic (Class $\mathrm{C}$ ) sequences' contrast with non-rule-generated (Class D) such sequences on the other. The contrast in both cases is that between intensional intelligibility and extensional "freedom."

Relevant logics implement the "relevance" requirement by requiring either shared atomic propositions (in the case of the propositional calculus) or shared variables (in the case of the predicate calculus) on either side of the conditional - the "arrow." In so doing, it happens that they also eliminate the principal fear typically raised by "classicists" in the face of suggestions in favor of paraconsistent logics: That is, of course, the fear that "from a contradiction, everything follows"-sometimes called "explosion," or "trivialization." That takes us to the most obvious and generally applicable reason of all for paraconsistent logics to intensionalize implication.

Paraconsistent logics, as the very name suggests, generally recognize that there can be circumstances, even if but rarely encountered ones (e.g., at what I have been calling the "outer reaches" of concepts' applicability) in which both a claim and its negation might be equally well or equally poorly warranted. ${ }^{220}$ The claim concerning the Russell Set's self-membership is a case in point, as are counterpart claims concerning the Liar, the self-application of the concept "heterological" (the concept of a concept's not applying to itself in the way that "easily learned" seems to be), and so on. Counterpart claims concerning what I called the Russell Complement, and about analogous

219 It's tempting to look for a link here to the notion of "irrelevant alternatives" in social choice theory, though there would be irony in doing so, since those who reject that axiom do so in part on the theory that the alternatives aren't really irrelevant if vector components are not really orthogonal. But more of this later.

220 See, e.g., Priest, supra note 209; see also SERGEI P. OdINTSOV, CONSTRUCTIVE NEGATIONS AND PARACONSISTENCY (2008); HANDBOOK OF PARACONSISTENCY (J. Y. Beziau et al, eds., 2007); ROSS BRADY, UNIVERSAL LOGIC (2006); JOHN WOODS, PARADOX AND PARACONSISTENCY: CONFLICT RESOLUTION IN THE ABSTRACT SCIENCES (2003); FRONTIERS OF PARACONSISTENT LOGIC (D. Batens, ed., 2000). Finally, still unsurpassed in the clarity and vigor of its argumentation on behalf of a version of paraconsistency is GRAHAM PRIEST, IN CONTRADICTION (1987). A recent, and sensitive, "constructive engagement" with paraconsistency by one who was once less sympathetic is HARTRY FIELD, SAVING TRUTH FROM PARADOX (2008). 
complements such as "the Truth-Teller" or non-heterologicality, arguably constitute additional cases in point - cases in which warrant for assertion or negation is equally weak, to the point of sheer indeterminacy (anomie).

Paraconsistent logics register such recognition by assigning a "both" truth value to such claims, in contrast to the effective "neither" that intuitionist (and most three-valued) logics assign them. In so doing, they must, to avoid "explosion" or "trivialization" of what ever theory employs them, also deny the so-called "classical" principle ex contradictione sequitur quodlibet ("from a contradiction, anything follows"). But denying this, of course, is simply once again to deny that logical "following"-consequence-is merely "material"-i.e., extensional-implication. So there are more reasons than "relevance" alone to intensionalize implication, on paraconsistency reckoning. Relevance is but one instance, a sort of special case.

Now, there are of course what some would view as "costs" that attend the intensionalization of certain logical operators that "classically" have been read extensionally. Paraconsistent logics often drop the principle of disjunctive syllogism, for example: That is to say, the rule that licenses the conclusion $\beta$ from the premises $\alpha \vee \beta$ and $\neg \alpha$. This is a rule that many have "classically" found intuitively compelling. So they'll call its relinquishment by paraconsistency advocates a counterintuitive "cost."

But if you think about it, if there are indeed circumstances, at the "outer reaches" of cognition or elsewhere, 221 in which both a proposition $\alpha$ and its contradictory $\neg \alpha$ might both be equally weakly or equally strongly warranted or even full-blown true - as in the case of the Russell Set's self-membership, for example-then $\neg \alpha$ need not always rule out $\alpha$ itself (even if usually, in "relevant" circumstances, it will), right? And so $\neg \alpha$ 's holding true need have no effect what ever on whether $\beta$ holds true. So the advocate of a paraconsistent logic is not apt to view reliquishment of disjunctive syllogism as a "cost" at all. It is itself part of the perceived problem, like material implication itself. And the real problem that lurks in the background of these cases, I am suggesting, is our old friend extensionality again. The paraconsistent logic advocate, then, per the same principles that prompt the move to accepting some contradictions as "true"-perhaps "transcendentally" true, on "the other side" of the boundary between what is cognizable and what isn't-will also remove such classicist logical rules as render

221 Some of the "elsehere"s are quite interesting in their effectively highlighing another intriguing resemblance between paraconsistent logics and their intuitionistic "duals," which we've noted already sometimes are called "epistemic" logics. Where paraconsistent logics have been found especially useful is in computing theory, where belief revision is recognized to be an important by-product of a growing knowledge base over tıme, for example. 
such truths "dangerous" on our side (the intensional, meaningful side) of that boundary. Disjunctive syllogism and ex contradictione sequitur quodlibet are simply among such unwarranted, and extensionalist, rules.

Note here also, by the way, for symmetry's sake, that there are counterpart "costs" which attend the earlier noted intuitionists' intensionalising negation. Most of these take the form of certain cherished mathematical results' either being more difficult to prove or not being provable at all in intuitionist logics. ${ }^{222}$ Such costs are a straightforward counterpart to the paraconsistent "relevant" logics" refusal to warrant some implications that would have been "materially" warranted. Like the case of material implication and disjunctive syllogism in paraconsistent logics, however, so in this case the putative "costs" will not be perceived as such to the reform advocates themselves. For once again the same considerations that prompt the adoption of the particular logic tend to change one's assessment of what actually is "sacrificed."

Intuitionists, for example, regard the classical "proofs" that they prune as having been illusory in the first place. For they assimilate mathematical objects to actual constructions rather than "inevitable posits" posited only via question-begging, hubristic "closed universe" type claims to the effect that every proposition or its negation is true. And they assimilate mathematical truth, in effect, to warrant, knowability, assertibility, or some such cognate state falling short of full certainty. 223 Thus, again as in the case of paraconsistent logics, what some "classicists" will decry as vices-such as its dispensing with excluded middle and double negation elimination 224 -intuitionists themselves will regard as virtues, on the same grounds as prompt their going intuitionist in the first place.

Also as in the case of paraconsistent logics' willingness to license fewer implications, so is the case of intuitionist logics' licensing fewer mathematical results hardly surprising-at least once we call back to mind yet again what it is to insist upon intensional intelligibility. For to insist on the latter just is to license less. It is to restrict latitude, "freedom," or arbitrariness of the kind that's run free since Dirichlet down through Cantor to the present. And the lesson of the quandaries of self-reference that have afflicted foundational mathematics since

222 Hence the earlier mentioned charge of "Bolshevism" levelled by Ramsey, perhaps.

223 See, e.g., Hockett, supra note 210. Of course, for such replacements themselves not to be question-begging, some independently compelling account of what it is to know, or to have warrant, or to observe "directly" must be given, a matter about which you can imagine that there is much room for dispute. But in the case of our Russell Complement, I trust you'll agree, there would seem no theory of knowledge, warrant, or so forth that would seem to license an answer in favor of or contrary to its own self-membership.

224 The first is the claim that, for all $\alpha$, either $\alpha$ or $-\alpha$ hold true. The second is the claim that, from $-\alpha$, we may infer $\alpha$. 
Cantor, again, just is that the "price"of more arbitrary/extensional mathematics is, on pain of intractable paradox and indeterminacy, a less arbitrarily combinatoric, more intensional logic.

But I doubt, on reflection, that Cantor himself would have regretted this. I think he would have been pleased with it-as, in a way, would have Wittgenstein. For the intuitionist and paraconsistent means of handling the puzzles that not surprisingly attend unrestricted"free"-combinatorialism in dealing with totalizing and infinitizing concepts at the very borders of cognizability are principled, unflinching, indeed consistent means. They simply acknowledge and tag what occurs at cognition's periphery, and note that such occurrences do not in fact logically entail anything "trivializing" or explosive back here at home in the core. That is what I would call an extensionalism-tolerant intentsionalism. It is what I have been calling a "thin," simultaneously Cantorian and Wittgensteinian intensionalism. It should, I believe, be our intensionalism.

We are effectively right back where we were, then, in connection with Cantor's first decision point: There is conflict, again, between positions that we can call intensionalist on the one hand, extensionalist on the other. This time the disagreement is in respect of how best to respond to the anomies and antinomies generated by self-reference. Once again, unsurprisingly, the extensionalists favor the ad hoc solutions - the "arbitrary" ones-of posited hierarchies and unprincipled (though perceived "problem-solving") proscriptions. The intensionalists favor the "principled" solutions that not only forthrightly address and hold harmless the puzzles of self-reference, but on the same basic grounds-intensionalist grounds-can quite happily dispense with precisely what their detractors fault them for jettisoning, namely, some extensionalist logical operators and schema themselves.

The principal difference between the conflicts at the first decision point and those at the second, I think, is this: By choosing in favor of the intensionalists in the second case, we license ourselves to choose in favor of the extensionalists at the first. We thus allow ourselves Cantorian freedom at no "cost" save that of acknowledging, and happily accepting, some puzzlement (some paradox and/or indeterminacy) at what are readily recognized as the outer reaches of our cognitive capacities.

\subsection{2 "Thin" Intensionalism Again}

What, then, should our attitude be? Well, I trust that I haven't been too effective in hiding my sympathies! It seems to me that the most satisfactory posture is that I've described as a "thin" form of 
intensionalism. It is a form of intensionalism that embraces all and only as much extensionalism as the Domain Principle itself forces us to embrace on pain of self-stultification. It is the one form of intensionalism that in principled fashion can sanction-as Cantor himself sanctioned - that form of cognitive freedom which is extensionalism itself, without loss of all vestige of intelligibility.

On the one hand, then, this position recognizes, per the Domain Principle, that meaning-determinacy itself requires our countenancing at least some completed infinite totalities-i.e., extensions-that in one way or another-be it through what I called "weak" diagonalization or through full-bore "strong," large-cardinal-implicative diagonalizationoutrun our capacities to generate them with algorithms. That means we acknowledge at least some extensions that in principle outrun intensions, rather as possibilities simplicitur outrun possibilities that are actualized. To reject this as hard-core intensionalists might is, as we noted above, to be hoist with one's own petard. It is to deny the determinacy of meaning in one's own language.

But what I am calling the "thin" intensionalist position also recognizes that the aforementioned extensions, extending as they do as it were to the very periphery of our rationative-indeed our intensional-capacities, invariably give rise at that periphery to cognitive conundrums-to antinomies and anomies. And it recognizes that the only honest, principled, intelligible way to track and accommodate such puzzlement is to acknowledge that our logic itself must remain at least partly intensional rather than wholly combinatoric - be that residual intensionality in the form of our logic's negation operator per intuitionist logic, in the form of implication per paraconsistent logics, or in some other form. To deny this as do hardcore extensionalists is to beg questions quite arbitrarily, hence to forgo intelligibility just as surely as hard-core intensionalists forgo meaningdeterminacy. For then one has simply decreed on behalf of extensionality by fiat, not justified it, while likewise decreeing against self-reference by fiat-effectively self-lobotimizing-meaning that questions are ducked rather than answered.

We might then say, in conclusion, that the price of more extensionalist freedom in our mathematics and set theory is more intensionalist intelligibility in our logic. ${ }^{225}$ It seems the only way to give the infinite, and irrepressible self-reference, and the cognitive quandaries to which these both unsurprisingly give rise, all their due. It also appears, by way of side benefit, to be the only non-arbitrary, non-

225 Another nice dual here: Note that Wittgenstein, who we noted above to have been quite intensionalist about mathematics, was also the principal extensionalizer of logic; one of the central doctrines of the Tractatus having been precisely that all propositions are truth-functions of bipolar elementary propositions. 
ad hoc way to register recognition that such inevitable quandaries need neither trivialize nor immolate us-us or our theories.

Now, I don't know about you, but I find in this "thin" form of intensionalism a quite fitting metaphor for the task of our lives as selfconscious creatures with a sense of the infinite and a sense of the random and arbitrary and unpredictable - in a word, of unbounded freedom-on the one hand; and a simultaneously felt urge to understand, to find sense in, to find intelligible, orderly, familiar and sustainable - and in this sense indeed bounded-on the other hand. To eschew living in either form of what Kierkegaard well described as "despair"-or with "the sickness unto death," as he also quite nicely described it - is to walk a narrow path between counterpoised illusions: The task is to eschew the despair that is illusory pure finitude (what above I called "self-lobotomy") on the one hand, which is not really us; and the despair that is illusory pure infinitude (what Freudians perhaps would call "grandiosity") on the other hand, which also is not really us. For we are not one or the other, it seems, in this case. We are both-a strange and perplexing, sometimes vexing meld of the finite and definite on the one hand, the infinite and indefinite on the other. Or, once again as Kierkegaard-he whom Wittgenstein often called the most able and admirable mind of the nineteenth century - might put it, a "synthesis of the finite and infinite."226 Or, as my beloved friend since youth, Scott Von-who I'm delighted to report is right here among us today-once put it when we were still very young: We live both transcendently and imminently, at once.

So, as I shall try putting it, we live finitely for the most part, and infinitely for the least and yet in a way largest part. We live finitely, and love infinitely, one might say. We encounter one another in, and as, finite and fragile and vulnerable forms, in bounded bodies. Yet we find in one another quite indefinite possibilities and seemingly infinite multiplicities. ${ }^{227}$ Just as it is possible mathematically to construct a solid of revolution with both infinite surface area and yet finite volume, so are we, in a sense, at least in our quotidian lives the reverse: finite in surface area, seemingly infinite in volume. And just as any segment of the real line is both bounded by other such segments, while yet still containing an uncountable infinity of points, so is it with us: quite unbounded internally, all while mutually bounded-beautifully enough, by one another-externally. ${ }^{228}$ This is our tragedy, this is our comedy, and, if you ask me, this is our ecstasy too. It is often infuriating, it is

226 See Søren KIERKEGAARD, THE SickNESS UNTO DEATH 3 (Walter Lowrie trans., 1939).

227 Perhaps not our bodies, but we ourselves, who are somehow our bodies "and more," seem in a sense to be "open ended," indefinitely extensible. (Indeed sometimes, albeit rarely, it almost seems as if we and those we love most are in a sense all of our bodies at once and still more.)

228 We'll find a very nice normative application of this metaphor below, in Part 4. 
frequently maddening, it is occasionally dispiriting. But it is a joy and a miracle in sum when you view it from above, as it were, through what I sometimes am tempted to think of as your "third eye"-sub specie aeternitatus. ${ }^{229}$

Would we could linger on this longer. But alas, we must turn now to the matter of how the just mentioned "tragedy" and "comedy," if not quite the ecstasy - that's for our loves, not for our laws or the dismal science! - find expression in two very august but rather less "pure" fields of inquiry, fields with which prosaic professors like me spend the greater, even if not always the better, part of their time. On, then, to the "applications" segment of our discussion.

\section{FOUNDATIONAL JURISPRUDENCE}

\subsection{The Decision Points' More "Practical" Manifestations}

Let us turn now to what light controversies concerning the Cantorian "decision points" might throw upon debate at the foundations of law and of welfare economics. We are accordingly turning, in a sense, to the matter of some of our Part 2 "theoretical" discussion's more "practical applications." 230 As in the case of foundational mathematics, so here the matter of meaning-of finding or making sense, and hence the relations among arbitrariness, boundedness, and cognizability - will prove to be central. What will be different is simply that the cognizability in question will now be of a more practical and transparently normative sort- "practical" here to be understood in the "practical reasoning" sense, "normative" in the "what should one do?" sense. The meaning with which we're concerned, then, will be as it were "meaning for action"-practical significance. We'll be thinking in terms of intelligible reasons for action, rather than intelligible criteria for singling out putative mathematical objects. We'll begin here with foundational law, then proceed in the next Part to foundational

229 One might even say here that it is precisely this "third eye," often found represented on images of Hindu deities, to which "third semantic values" between ordinary truth and ordinary falsity in nonstandard logic give what is due.

230 This way of phrasing the distinction $I$ have in mind is not altogether felicitous, although it is time-honored. (Compare the Kantian distinction between "theoretical reason" and "practical reason.") See supra, Part 1.3. Theory is central to both sides of the divide. What is different is that on the first side the theory in question concerns less how we are to act in relation to one another, and think to and about those actions, than how we are to carry on with and think about such imaginative and calculative activities as mathematics. The distinction might best be put thus: In the "pure" or "purely theoretic" case, we theorize our own (mathematical) theorizing. In the "applied" or "practical theoretic" case, we theorize our practical-our political and economic-actions toward and with one another. 
economics.

A brief disclaimer might be in order before we proceed: General jurisprudence, or "philosophy of law," can be construed to embrace a good many questions, modes of approach to such questions, and proffered answers to the same. Most such questions and modes of address touch on matters of great moment and broad consequence for our lives in political communion with one another. The subject, moreover, is closely bound up with what often are treated as distinct subjects of similar moment-for example, normative political theory and even indeed anthropology or sociology - so that many, at times, disagree very vehemently over questions of appropriate scope. I hope that I won't seem to be merely artfully dodging, then, if I endeavor to prescind from a good many such disputes here. For I intend to limit myself simply to two clusters of questions that I believe most would agree to be at least among those most central-and perhaps even most crucial of all-to general jurisprudence.

\subsection{Law \& Obligation}

First off, then: There do seem to be at least two quite important kinds of question that lie close to the heart of most jurisprudential discussion. They are distinct and yet closely connected sets of questions, in that some plausible answers to questions from the one set tend to constrain what will count as plausible answers to questions from the other. The first set that I have in mind is that of questions concerning what counts as "law," or a law, or legal proposition, or legal rule, or legal principle, or legal practice or institution or system-or even, at the limit, "legality" or "rule of law."

Questions from this set often are formulated as queries into "the nature" of the phenomenon in question. Debate then ensues over not only how best to characterize the matter selected, but prior to that, over even such foundational methodological matters as whether the concepts invite "essentialist" characterizations, or are instead "family resemblance"-type concepts, or perhaps better reductively viewed as behavioral-regularity matters or something else. Each such question can also, of course, for many purposes be taken as crucially distinct from the others: It might be thought foolish to ask about legal "rules" rather than "principles," for example, or to ask about either of these in abstraction from "systems" or "practices." And indeed one way that one might classify jurisprudes is accordingly by the degree to which what they say tends to address more or fewer of the questions in this cluster at once, in relation to one another.

The second "family" of questions that seem central to what most 
would call jurisprudence has fewer members. This is the set of questions concerning the nature of legal obligation, or the sense(s) in which, the degree(s) to which, or circumstances under which putatively legal claims will carry bona fide normative force, or constitute or afford reasons for action. These questions themselves, moreover, can each of them be understood in a first, second, or third person motivational or justificatory way-as addressing a "what should I, you, she do?" question-or in a more strictly third person, descriptive or explanatory way-as addressing a "why did she do it?" or "what is he likely to do?" question. And of course any or all of these questions might be treated from either point of view or both points of view by the same theorist.

As in the case of the first family of questions, then, one could in theory (or, perhaps better put, "metatheory") classify or compare jurisprudes according as they address questions in this family jointly or severally, and according as they trade more in justificatory inquiry, explanatory inquiry, or both. Once again for our purposes, it will be sensible to keep the questions in this family together in mind jointly, not severally; but it will at certain points prove helpful to recur to the justificatory/explanatory perspectival divide in this case. What is more, in view of the normative coloration that the very word "law" and its cognates tend to carry, it will be clear at various points that answers to questions in the second cluster of questions - especially when addressed from the justificatory perspective - both bear upon and are borne upon by what can be taken for plausible answers to questions in the first set.

\subsection{Extensionalism and Intensionalism Again}

All right, so those are the classes of jurisprudential question with which we'll concern ourselves here. Who are the jurisprudes I have in mind? Well, I trust it will not be objectionable if we identify and classify these personages according to what they have to say in respect of one or more questions found in one or both of the two classes of question I've just identified. Moreover, it seems to be possible to classify their positions by reference to a range of possible answers falling between two ideal types, rather as we saw in Part 2 in connection with what I called "Wittgensteinian intensionalist" and "Cantorian extensionalist" positions in foundational mathematics.

Indeed, if, in place of the intelligibility demands that we associated above with intensionalist positions we substitute what I shall call "ethical intelligility" demands, we'll see that positions in jurisprudence can even be classified according to where they fall on the extensionality-intensionality continuum itself. I find that intriguing, and as I said in Part 1, ultimately quite helpful. I shall characterize 
jurisprudential positions in what follows, then, by reference to what relation, if any, they take the answers to law-related questions to bear to answers to justice-, ethics- or morals-related questions. We'll have to qualify all of this, of course, but I think I can do so in the course of discussing particular oft-named "schools" of jurisprudence.

Here, then, are the two "endpoints" of the continuum in this case. Please once again bear in mind that I don't take anyone or any school of thought solely or exclusively to occupy either of these: There is no actual Cantor or Wittgenstein in this case, although an Ockham or Austin or Bentham in past times might have served as our Cantor, and a Cicero or Aquinas as our Wittgenstein. The first extremum, then, would be that according to which answers to law-related questions taken from either of the two families of question I identified are in no sense posterior to the answers to moral or ethical questions. On this view, one would be able to identify a legal norm, specify the content of such a norm, identify and characterize a legal obligation, a legal personage, a legal practice or institution or system, and so on, without reference to any extra-legal such norm, content, obligation, etc. In this sense, legal data are not required to be ethically or morally interpretable or intelligible. Ethically speaking, then, we can describe this position as extensionalist in spirit. Legal phenomena can be ethically arbitrary.

The other extremum, predictably, would then be that at which one would say nothing can be counted for "legal" in the senses just indicated unless it not only (a) is so identified by reference to some moral or ethical norm, content, obligation, or the like of which I just indicated, but also (b) is indeed justified by that ethical datum. A middling position then might perhaps insist upon (a), while either relaxing (b) or, what might come to the same thing, insisting upon (b) but distinguishing between decisive or dispositive justification on the one hand, merely prima facie justification on the other hand. In other words, one might insist that legal data be interpretable as giving expression to extralegally understandable ethical imperatives in order to count as legal, while not demanding that the imperatives in question actually succeed in trumping all possible competing imperatives in all situations in order for the legal obligations that give expression to them to count as indeed "legal." In either case, though-the "middling" one just mentioned or a full-bore demand that all "legal" obligations be extralegally understandable as ethical obligations-what is distinctive is the demand for ethical intelligibility. We can accordingly think of these positions as ethically "intensionalist" in spirit.

Now as it happens, the extensionalist and intensionalist extrema just envisaged in effect already have names: They track what typically are called "positivist" and "naturalist" positions, respectively - although again, do bear in mind that few modern theorists are found all the way 
at the endpoints. Theorists commonly labeled "positivists" generally occupy positions closer to the extensionalist end of the spectrum. The "posits" in question are communicative artifacts-texts, utterances, repeated practices apparently intended to be followed, etc.--that can be recognized for veritably "legal," whether pursuant to an articulated "rule" of such recognition or otherwise, independently of any process of ethical inquiry. Things accordingly stand rather as they do with the question "What time is it?" That question can be answered reliably without reference to moral criteria of any sort, it would seem. One can ascertain the answer simply by looking to a clock or watch that can more or less confidently be assumed to be properly set. Of course, my having had to use the word "properly" here hints that fuller elaboration of this position requires some subtlety: It is quite difficult to specify how any normative system, including law, functions without falling into some form of normative language that is not itself antecedently understandable as legal in nature. And sophisticated positivists do not suggest otherwise.' This is a matter to which we'll return.

Now in contrast to positivists, those commonly labeled "natural law theorists," or simply "naturalists," are for their part readily characterizable as lying closer to the intensionalist end of the spectrum. The "nature" in question is understood to be something like "human nature," construed in the "what's fitting," or "proper" sense, in light of our natures not only as animals of a certain sort, but as rational and indeed political animals who plan narratival lives in cooperation and political communion with others. My having had to make reference to a recurrent human "nature" which includes polticality, however, hints that fuller elaboration of this position will lend itself to lapsing into something very much like "law talk," both in the regularity, "law of nature" sense and in the normativity, "law of the polity" sense. So law language creeps readily into would-be extralegal normative talk rather as, just a moment ago, we found extralegal norm talk to creep into would-be positivist law talk. So this too is a (related) matter to which we shall have to return.

Now there is of course plenty of variation among positivists themselves along the putative "continuum" that I have myself now provisionally "posited." One division figuring prominently in recent years has been that between so-called "inclusive" and "exclusive" legal positivists, Coleman being perhaps the best known "inclusivist" and Raz being surely the most influential "exclusivist."231 (There seems to be some uncertainty over how best to characterize Hart, owing to the

231 See, e.g., Jules Coleman, The Practice of Principle (2002); Joseph Raz, The AUTHORTY OF LAW (1983); JOSEPH RAZ, THE CONCEPT OF A LEGAL SYSTEM (1980). The taxonomy of legal positivisms into "exclusive" and "inclusive" figures prominently in W. J. WALUCHOW, INCLUSIVE LEGAL POSITIVISM (1994). 
fact that there is evidently a "pre-" and "post-Postscript" Hart.) ${ }^{232}$ That which is implicitly referred to for inclusion or exclusion is precisely that which naturalists take for essential in one sense or another-extralegal normativity, i.e., moral or ethical norms, in particular such as sound in some conception of justice, fairness, or equity. ${ }^{233}$ The "inclusion" and "exclusion" in question, for their parts, have to do with the degree to which, the sense(s) in which, and the circumstances under which extralegal moral or ethical norms or principles might be incorporatedby general or specific reference or otherwise-into statutes or regulations or judicial decision-making, particularly when more canonically legal documents or precedents appear to be silent on an issue in need of resolution.

There has likewise, historically, been considerable variation among naturalists. Some have come very close to the "thick" intensionalist extremum posited above, pursuant to which ethical criteria determine not only laws' semantic contents, but also their capacities legitimately to oblige. ${ }^{234}$ Such a position might be called "Thoreauvian." Others have held there to be at least weak moral obligations to obey even an unjust law, save in extreme cases, or have treated the "natural law" as a sort of Platonic template against which temporal law is measured, such that it is more "fully" law as it more closely approximates the template, but is nonetheless law (to varying degree) so long as it does not stray too far from that standard. There is "law," "Law," and then "LAW," so to speak. The views of Aquinas and such later medieval, early modern naturalists as Suarez, then Grotius, seem to have featured nuance of this sort. Still other naturalists have taken a more "advisory" and "interpretive social science" tack, in effect arguing that the relation of moral or ethical normativity to law is such as: (a) to warrant legislating in conformity to broadly socio-moral considerations; and (b) to inform to some degree what an anthropologist or a visiting stranger will tend to recognize as "legal."235 Neo-naturalism of this sort is perhaps best exemplified in the work of Finnis and George. ${ }^{236}$

There seems even to be something a bit like a "midpoint" along the continuum that I have provisionally posited, which might be roughly

232 See generally HART'S POSTSCRIPT: ESSAYS ON THE POSTSCRIPT TO THE CONCEPT OF LAW (Jules Coleman ed., 2001). The "Postscript" in question is that to the second edition of Hart's Concept of Law. See H. L. A. HART, THE CONCEPT OF LAW (2d ed. 1997).

233 Depending upon one's conceptions of these concepts, of course, the terms might be taken to name but one concept.

234 Once again we find ourselves lapsing into legal language even in articulating a would-be extralegal moral claim: "Legitimate."

235 Note that even the word "recognize" in this context is ambiguous as between normativityas in "formal recognition"- and positivity-as in "cognizing again," seeing again, etc.

236 And critiqued, on grounds of the "neo" status, by such as Hittinger. See JOHN FINNIS, NatURAL LAW AND NatURAL RIGHTS (1980); ROBERT P. GEORGE, IN DEFENSE OF NATURAL LAW (1999); RUSSELL HITTINGER, A CRITIQUE OF THE NEW NATURAL LAW THEORY (1995). 
analogizable to some of the "intuitionist" and "constructivist" positions noted in Part 2 to lie between Cantor and Wittgenstein. It might be tempting, for example, to view adherents of the Dworkinian and Habermasian views of law and legality as representing a "third way" or "via media" along these lines, so to speak. 237 Indeed, Habermas for his part is quite explicit about law's being something "between facts and norms," as he puts it.238 And one might interpret Dworkin as treating "posits" as critical to the enterprise of ascertaining legal content and obligation at least in the sense that the actual practices to which he views his account of the law as accountable in integrity are, indeed, empirical phenomena.

At the same time, however, Dworkin and Habermas both, in their ways, emphasize the unavoidability of critically employing extralegally intelligible normative understanding in interpreting what such practices actually indicate or amount to, hence as in at least that sense constitutive of (what we identify as) the practices in question. And Dworkin, moreover, famously (or notoriously, in some peoples' view) argues that we must interpret such practices as giving expression to what we would take for the "best" moral-political theory consistent with the practice-data themselves over time. ${ }^{239}$

It seems to me plausible, then, to suggest that jurisprudential positions occupy points along a continuum running from the crude "command" understanding of law at one extreme, proceeding thence to so-called "exclusive" species of legal positivism, thence to "inclusive" such species, thence to the Habermasian "normative facts" and Dworkinian "best interpretation" or "integrity" views, thence to "approximable form" naturalists, and finally to hard core "lex iniusticia non est lex" naturalists. In other words, things might be pictured more or less thus:

Com'nd-Excl. LP-Incl. LP-Habermas-Dworkin-Soft NL-Hard NL

Though I harbor some doubt as to how distinct all of these positions ultimately are rather as I suggested above in connection with Cantor and Wittgenstein - for reasons suggested by my recourse to "legal" language in characterizing naturalist thinking and to extralegal normative language in characterizing positivist thinking-I shall nevertheless proceed for the time being upon the assumption that the

237 Though some, including Dworkin himself apparently on at least one occasion, have suggested that Dworkin is a naturalist; see STEPHEN GUEST, RONALD DWORKIN (2d ed. 1997)all the more reason to think in terms of a continuum here, I suspect, rather than hard categories. For Dworkin's and Habermas's mature views, see, for example, RONALD DWORKIN, JUSTICE IN ROBES (2007); RONALD DWORKIN, LAW'S EMPIRE (1986); JURGEN HABERMAS, BETWEEN FACTS AND NORMS (1997).

238 See HABERMAS, supra note 237.

239 See sources by Dworkin cited supra note 237; see also RONALD DWORKIN, FREEDOM'S LAW (1996) (elaborating a "best moral interpretation" view of constitutional interpretation). 
schematism here amounts at least provisionally to a workably accurate map of the jurisprudential terrain.

\subsection{Historical Linkages}

All right, now as I've suggested, naturalist positions in respect of law bear resemblances to what we saw in Part 2 to be intensionalist positions in respect of numbers, classes, and other mathematical objects. Positivist positions for their parts bear resemblances to extensionalist ones. And there are even intriguing historical linkages here, as I intimated above in Part 2: For example, the same gent whose name typically comes up first in connection with legal naturalist positions, St. Thomas Aquinas, was precisely the fellow whom we found Cantor to have taken most seriously in seeking to justify his extensionalism about infinite series by reference to an intensionalist-flavored argument for his extensionalism-justifying Domain Principle.

By the same token, early progenitors of "command"-style positivism about law-the "voluntarist" theologians Ockham and Scotus probably best known among them-were also well known as "nominalists" about universals, i.e., concepts. 240 That is to say, the same thinkers who argued that what is normatively required is simply what God demands, how ever incomprehensible those divine requirements might be to human intellection, also argued that concepts are no more than the objects that instantiate them-those concepts' "suppositios," or what we now call "extensions."241 Moreover, these latter thinkers expressly characterized all criteria by which extensions are determined-what we now call "intensions"-as no more than arbitrary conventions, rather as if conceptual criteria were as "voluntarist" (i.e., merely willed) a matter as are God's demands themselves. And, if I may thicken the plot yet further, the same Hobbes who stands to the so-called "empiricist" tradition in philosophy much as our earlier-encountered Descartes, stands to the "rationalist," is himself often described as a "conventionalist" positivist, and took an Ockhamreminiscent "nominalist" line about concepts in written controversy with Descartes!242

I don't think any of this is mere historical curio or accident. I think it reflects a quite deep philosophic, and indeed perhaps temperamental, divide that appears to run across disciplines throughout history. It is a

240 See generally KNEALE \& KNEALE, supra note 11; see also J. M. KELLY, A SHORT HISTORY OF WESTERN LEGAL THEORY (1992).

241 See supra note 11.

242 See generally RiChaRd TUCK, HobBes (1999); Richard TUCK, NATURAL RightS THEORIES: THEIR ORIGIN AND DEVELOPMENT (1982). 
divide between those who are more demanding or discerning of sense or conceptual intelligibility on the one hand, those who are more comfortable with or aware of arbitrariness or merely willed determinacy on the other. It is almost as if we were dealing with yet another instance of the venerable "Dionysus versus Apollo" divide-the sublime and the beautiful. ${ }^{243}$ It's Archelaus versus Homer, Euripides versus Aeschylus, Hölderlin versus Goethe, Dostoevsky versus Tolstoy, Rolling Stones versus Beatles, and so forth all over again-those drawn more to darkness and chaos and "innate depravity" on the one hand, those drawn more to light and to natural order and "innate goodness" on the other. But let's stick to jurisprudence and flesh all this out a bit more.

Now at the heart of the naturalist reading of law, I think, is an insistence that for some purported imperative or mandate to be recognizable and obligatory as law, the apparent imperative must be interpretable as stemming straightforwardly from some discernable reason, purpose, or point by reference to which its propositional content can be understood and its illocutionary force experienced as binding. ${ }^{244}$ One must be able to speculate intelligently as to why this particular imperative might have been issued, what it has to do with "us." One seeks a latent, "internally" action-guiding meaning in the imperative-a telos that the recipient of the imperative might experience as actionguiding even independently of the imperative's issuance by somebody with "authority." The implicit requirement seems to be that all might be able to appreciate what it would be to experience the answer to the aforementioned "why" question as a reason for acting or refraining from acting even were the imperative in question not coercively enforced. Absent that, the requirement here seems to run, the putative norm will be indistinguishable from the mere arbitrary fiat of one who simply happens to be better armed than you. That might be thought no more "law" than the demand of an armed bandit or terrorist or even, for that matter, a hungry bear at a campsite.

Legal norms are not extra-normatively interpretable "natural kinds" or "self-identifying objects," on this understanding of law. Their bearing what, as a statistical matter, proves often to be the outward form of commands or requirements- "thou shalt," "you must," "if you don't... see this stick?"-will not suffice to render them legal or independently experienceable as obligatory. The outward form in such case would be scarcely better than the apparently numerical form of our

243 The allusions here are to FRIEDERICH NEITZSCHE, THE BIRTH OF TRAGEDY (Ronald Speirs trans., 1999) (distinction between "the Apollonian" and "Dionysian"); and EDMUND BURKE, A PHILSOPHICAL INQUIRY INTO THE ORIGIN OF OUR IDEAS OF THE SUBLIME AND BEAUTIFUL (1998).

244 See generally Robert Hockett, Why Paretians Can't Prescribe: Preferences and Principles in Law and Economics (working paper, 2007). 
Class D expressions above in Part 2. They'll be but good mimics, and they'll fool only form-fetishists. Such putative norms, then, will be no more than arbitrary demands, insipid and even comical pseudo-laws in more or less precisely the sense that many of the putatively legal and related "official" processes encountered in many of Gogol's and Kafka's remarkable stories are comical. The disjunction between external trapping (including even the writer's own deadpan "reportage" voice) and internal unintelligibility is precisely what renders these stories so deeply amusing and unsettling at once. They impress one as, so to speak, "metaphysical jokes." 245 And it is precisely such disjunctions as these, I think, that we can usefully view naturalists as refusing to warrant or countenance-at least where real life and real law are concerned.

In similar fashion, the naturalists' theological antecedents-those who viewed God's will as being ultimately intelligible, and indeed revealed in ethical precepts themselves, which seemed often to be shared widely across jurisdictions and cultures then known to the theorists in question-eschewed countenancing God as senseless. It was one thing, these thinkers appear by and large to have held, to admit that God was in a certain sense beyond human comprehension and nonobligated to human beings or their expectations. It was quite another to suppose or to act as if God herself would implant in everyone an intuitive sense of fairness, and design nature pursuant to an order so readily apparent to human intellection, all while nevertheless actually preferring something else or not caring one way or the other about ethics. That would be to view God as a sort of cosmic trickster, or as the "malign genie" whom Descartes refused to believe God would be, or as the enigmatic joker whom Kafka at times seems to have toyed

245 Wittgenstein once said that one could imagine a philosophical treatise being written that consisted entirely of jokes. Though he did not, apparently, think highly of Kafka, it seems to me that many of his stories, along with many of those of Gogol and Tertz and some of those of Dostoevsky (not to mention many Russians and other East Europeans of the Soviet era), fit the bill here. That is precisely what accounts for the temptation of many to find even the more hilarious of such stories "philosophical." (It also accounts, I believe, for much of the remarkable humor exhibited in much of the work of Kierkegaard.) They are simultaneously "deeply" and unsettlingly funny ("nervous" laughter) and seemingly "philosophical" precisely because they violate the conceptual order of a sort of "philosophical grammar"- they disassociate what we feel ordinarily to be deeply and necessarily associated, and associate what we symmetrically feel does not belong together. Lest, by the way, you doubt that Kafka's stories were intended in this way, please see the biography of Kafka penned by his close friend Max Brod. Brod's biography is itself amusing reading at many points; and among its treasures is the revelation that Kafka often read his works in progress aloud to small gatherings of close friends, which readings frequently were interrupted by shared uproarious laughter by all of those assembled, not least of them Kafka himself. Before coming upon this many years back, incidentally, my dearest friend, his older brother and I used to do the same-both with stories that we were ourselves writing and with Kafka's own. 
with God's perhaps being. ${ }^{246}$ It would be to view God, and thus to view the ultimate Authority to which we were subject, as something quite radically alien and indifferent to us. It would be to view God and all normativity as ultimately inaccessible nonsensical. Naturalists seem to object to such remoteness and senselessness much as intensionalists object to such counterpart "transcendences" and unintelligibilities as inaccessible and unnamable real numbers.

Now just as the full-blown naturalist view of law and legality appears at first pass to resemble the intensionalist understanding of numbers, functions, and classes more generally, so does the full-blown positivist view look at first pass to resemble the extensionalist understanding of the same. Pursuant to the latter view, recall, the objects are simply there, and can be arbitrarily selected, Choice Principle style, ad libitum as to constitute classes and underwrite orderings. They need not be generated by any particular principle of selection or construction, nor need they bear any apparently defining property in common by reference to which their all figuring into one class or extension might be found intelligible or be understood. They need not "make sense" together, they need exhibit no pattern. They're simply selected at random, arbitrarily.

That is indeed why merely extensionally or combinatorically understood functions and other sets are called "arbitrary." Such collections need not be interpretable at all or "make sense" in any sense at all. They are what they are solely by dint of their existence and their having been selected or "assigned." What is more, per diagonal-style argumentation we know that such entities always exceed our capacities to single them out or to name them. They "transcend" our designatory capacities just as the continuum transcends denumerability. We can't claim to be able to order or find order in them either, unless we quite arbitrarily claim to be able to do that which the Choice Axiom stipulates we can do. And that is mere stipulation, no more independently appreciable as true than would be the mere stipulation of order itself.

It is easy to see how at least the extreme old line positivist, "command" theories of law might be found at least superficially to resemble the arbitrary, extensionalist view of functions and sets more generally. The commands that might constitute laws on the command theory can be quite arbitrary commands and still count as laws, and even still be obligatory as laws. They might, in theory, be no more than whims of someone who seems to be sovereign, someone bearing the trappings of someone "in charge" in a Kafkaesque fantasy in the way that our Class D expressions bore some of the trappings of bona fide

246 See, e.g., FRANZ KAFKA, BEFORE THE LAW (1925), available at http://www.mals.bc.ca/ johnstoi/kafka/beforethelaw.htm (translation of Ian Johnston, Malaspin University College, Canada). 
numerals. They accordingly need not be intelligible by reference to prompting or antecedent reasons or purposes or principles of any sort at all, let alone by reference to reasons that the command's recipient might experience as "internally," independently motivating. What matters is their pedigree. If they are issued by God, or "the sovereign," they are lawlike in the requisite sense, and obligatory. All is always a matter of will. And if the will in question is God's or the sovereign's, then what is willed is incumbent.

I think that we also do well to note here that the intensionalism of naturalists and the extensionalism of positivists appears to be more than a matter of differing tastes, at least at the polar extremes on the continuum that I have suggested. For recall that intensionalistsincluding not only Wittgenstein, but intuitionists and constructivists more generally, including Kronecker, Baire, Borel, et al.-in mathematical foundations deny not only the intelligibility of arbitrary choice of the Choice Axiom variety over nondenumerably infinite domains. They deny the existence of such domains themselves in anything save a "potentialist" or "indefinite iterability and diagonalizability" sense. And for reasons of those very denials, in turn, they deny also the existence even of such objects as cannot be defined, hence as whose decimal places could not be filled, within a finite number of steps. They deny, that is to say, that our Class D expressions above were in any way meaningful.

There is a parallel in the hard core naturalist position in respect of laws. The most extreme form of naturalism, recall, views putative laws not only as less normatively binding in so far as they are arbitrarily laid down or "randomly selected" by putative sovereigns. They view them as not even existing, not even individuable as laws in so far as they are arbitrary in this way. They're no more than senseless utterances or at best mere demands issued by one who by dint of the arbitrariness itself is devoid of legitimate-lawlike, legal-authority. Such putative "laws" bear at best some of the external clothing of authoritative prescriptions-rather as "7.821947..." is no more than a senseless, "unlawlike" string of numerals bearing the external-numeralclothing of numbers per the constructivist view.

I think that one is apt to view the naturalist or positivist positions on law as plausible, then, respectively on quite similar grounds as one might view the intensionalist or extensionalist positions on mathematical objects as plausible. If you think that putative objects, including putative numbers but also putative laws, might exist in some sense quite apart from any particular "sense" that might be made of them, such that they can be identified, individuated and "selected" or "laid down" and "obeyed" arbitrarily or at random without any reference to any such sense, then you will be less chary about 
transcendental numbers or "sovereign command" laws than will be sense-demanders. You might even in effect fetishize these objects, treating them as freely existing and possessed of properties-including normative properties-quite independently of their scrutability, like trickster gods.

\subsection{Collective Intentions, Self-Reference, and Liberalism}

I don't wish to be stacking the deck, however, in the way that some of the language that I've been employing might suggest. For while I must confess to finding intensionalist positions in general and legal naturalist positions in particular at least initially intuitively congenial, I think that there's also a sense in which no ethically tenable position about law can be intensionalist in any but a "thin" sense today. Modern naturalists, that is, must come to terms with the truth that the positivists have glimpsed, somewhat as Wittgensteinians must reckon with Cantorians in foundational mathematics. In effect, there is a form of "tragedy" that must afflict any modern polity that on the one hand is committed to each citizen's autonomy in deciding in what a good human life consists, and on the other hand is committed to its laws' moral intelligibility. It is a tragedy which is diffused only insofar as the intensionalist requirements to which law is held is a "thin" form of intensionalism such as might characterize collective intentions held even by citizens with very diverse values.

What I have in mind here is best drawn out by consideration of the legal-foundational counterpart to the second Cantorian decision point, which I've thus far not treated of here. So what does self-reference have to do with foundational law? Well, I don't have in mind what you might think I have: I'm not going to talk about constitutions containing provisions for their own amendment, or statutes' employment of selfreferential indexical expressions like "this" or "herein," as in "nothing herein shall be construed to mean [bladdidy-bla-bla]." Those are occasionally interesting phenomena but they are not foundational in anything like the sense that we have in mind here today. What I have in mind here is this: If you think about it for a moment, I think you'll agree that what hard-core naturalists demand of a legal norm is that it give expression to something very like a collective intention. They want a law to be extralegally compelling, as a reason that you and I each will experience "internally" as a reason for action irrespective of anyone's threat of coercion. They want it in effect to formulate an intention that can be your intention and my intention-and, as a law that is meant to bind all of us, in effect our (cooperatively shared) intention.

Now, what that has to do with self-reference is this: As has been 
well limned by philosophers of action for very long indeed, intentions typically bear essential self-referential components. ${ }^{247}$ When I intend to do something, I do not simply intend "that it happen." I intend "to do it." I intend, that is, both to be the one who does it and to do it pursuant to that intention itself. If I don't do it pursuant to the intention itself, it simply happens, even if the end result of what happens is favorable or desired. See? Think of it this way: You intend to walk over to the courthouse. You step out through the door and begin to walk there. Unexpectedly, an automobile screeches ahead of you, pulls over onto the sidewalk, and hooded figures then pull you into the car. The car then pulls into the street, proceeds quickly to the courthouse, and the hooded figures then let you out. "There," they say, "you're at the courthouse." Did you execute your intention? No. You're where you wanted to be, but are there by virtue of events that appear to have had nothing to do with your intention and might very well have turned out differently. When you intend, then, you do not simply hope that something will occur, but intend that it occur and that you make it happen, and then you act so as to make it happen. You do it. And "doing" is very much richer than hoping, at least as much richer as driving is than idling.

Now note that your intention can fail to be fulfilled, notwithstanding the end result's eventuation, for reasons other than difference of mode as in the hypothetical courthouse case just countenanced. There can be differences of reason as well. For generally we intend for reasons, which are as constitutive of our intentions as are our plans of execution. In that sense the reasons amount to intentions' intensions. For example, you might intend to touch your knee in order to see whether it is as swollen as it was earlier in the day. As you are reaching to do so, you might feel a sudden itch in the same knee. You might accordingly reach down quite suddenly to scratch the knee, and while doing so you might notice that it is less swollen as well: In this case you have accomplished what you had hoped to accomplish pursuant to the first intention, but never did execute that original intention. The original intention was aborted, in effect, by the sudden new intention's formation and execution, which, by dint of its "two birds with one stone" attribute, rendered the first

247 See, e.g., Gilbert Harmon, Practical Reasoning, 29 REV. METAPHYSICS 431 (1976). The idea figures prominently in J. DAVID VELLEMAN, PRACTICAL REFLECTION (1989). It also figures into Kant's discussion of the "causality of the will" in IMMANUEL KANT, CRITIQUE OF PRACTICAL REASON (Mary Gregor ed. \& trans., 1997), and is discemible in much of Aquinas's thought on practical reason as well. Velleman finds a version of the idea in Anscombe's Intention as well. See VELLEMAN, supra, at xxi-xxv, 18-22, and passim. And Anscombe, in turn, famously views her work as recovering something central to Aristotle's and Aquinas's accounts of practical reasoning, something lost to the thitherto "modern" accounts. See ANSCOMBE, supra note 48 , especially at $57,87-90$. 
intention no longer necessary and in that sense redundant or otiose.

All right, now this sort of inquiry can quickly grow tedious and irrelevant to our purpose, so let's cut it short and move on to its cardinal point. The point here is that the reasons that prompt the formation of an intention are typically as constitutive of the intention as are the means by which one intends to execute the intention. And it is precisely here that the naturalist position in respect of law, I think, runs into trouble in modernly "liberal," pluralist societies. Why? Because to require of a law that it embody a collective intention-at least a "thick" one-is to require of the law that it then formulate reasons that those who would follow the same law will share. And in many cases, sharing a reason is sharing a conception of the good-precisely the sort of conception that liberal, pluralist societies aim to leave to individual discretion.

Do you see what I'm driving at here? Suppose that we have a law against marriage before the age of 21 . Some favor such a law because, in their religion, one is not permitted conjugal relations before 21 , and also is not permitted such relations out of wedlock. Others favor the law, say, because statistics show that marriages contracted after the age of 21 will end less often in failure. Still others favor the law for a multitude of other, differing reasons. Now, if reasons are partly constitutive of intentions as seems to be the case, and a law is to embody a collective intention per the intensionalist/naturalist aspiration, then how can this law indeed be everyone's law? It would seem that it cannot. Does that then mean that a pluralist polity must view laws altogether extensionally, hence as ethically unintelligible, devoid of intension? Do we have "tragedy" in liberal polities that is so acute that, in effect, the same ethical imperative that prompts liberalismindividual autonomy-also eviscerates the ethical imperativity of law itself?

Ultimately, I think, not. For we can append, to what I said a moment ago ("It would seem that it cannot") the following: "一unless we pitch the would-be collective intention that the law is to embody at a higher level of abstraction. That is to say, unless we view the law as embodying a much "thinner" intention than any one person's reasons, say, for the marriage law considered a moment ago. That's right: As in Part 2, so here I believe that a "thin" form of intensionalism affords means of dissipating the "tragedy" that is thick intensionalism's and full-bore extensionalism's joint unacceptability.

The need to go "thin" on collective intention, I think, is inevitable in any polity that we would call "liberal"-i.e., any polity that aspires to be "tolerant" in respect of differing views of "the good" or what constitutes a human life well led. Most "pluralist" polities-polities that comprise persons with significant cultural, religious, and other valuational differences - for obvious reasons aspire to liberality of this 
sort. And what this in turn means is that the collective intentions that they can consistently act upon must be "thin" ones. They must be intentions to "go on together," to "get on together," and thus in essence to structure "outward" or "civic" or "public" life in a manner that is sufficiently orderly and fair to each member as to render all more or less equally able to live partly "private" lives that are consistent with "their own values"- their conceptions of the good. This is not to say that we can "get on together" no matter what disparate values we individually hold. Nor is it to say that demarcating the line between "public" and "private" is straightforward and easy, or that any given line is itself every beyond context. It is simply to say that a liberal polity recognizes that there is some such divide, as a manner of regulative ideal, and that recognizing such a divide entails abandonment of intensionalist/naturalist views of law as formulating collective intentions actuated by shared "thick" valuational reasons.

Now, it would be a mistake, I think, to interpret this claim as meaning that hard-core positivist, full-bore extensionalist positions in respect of the law are inevitable in liberal, pluralist polities. For note, there is nothing in what I just said to suggest that laws must-or even can-be recognizable as laws when simply arbitrary impositions. Indeed, I have just "rationalized" laws in the liberal polity by reference to what is itself a value-or perhaps a "meta-value"-that I've assumed people with otherwise differing views of the good life might nonetheless share: That is the value of justice - of political justice, of a well ordered set of arrangements that are fair to all in the sense that they afford all citizens equal opportunity to succeed in living what they take for good lives. This is a foundational-legal analogue, I think, to the "thin intensionalism" that we found to be more sustainable than either thick intensionalism or full-bore extensionalism in respect of mathematical or any other form of theoretic cognition in Part 2. Thin intensionalism about foundational law is a view of law as justice-as giving expression to our collective view of what venerably has been called "the right" rather than "the good." We'll see something very much like this again in the next Part, when we turn to foundational economics.

\subsection{Thin Intensionalism, Justice, and "the Rule of Law"}

Are there any "thin intensionalist" jurisprudes? I am perhaps insufficiently expert to say categorically one way or the other whether this legal theorist or that one fits the description in all of her or his characteristic claims. But I do think there is something very like a thin intensionalist vision at work both in the views near the "middle" of the 
spectrum suggested above, and in a recently articulated view that we might call the "disagreement" view of the law. Consider the latter first, since I have just introduced it. Pursuant to this view, associated with recent writing by Waldron and by Wendel, the law is in important part a matter of settling contested matters with some degree of finality, in order that people might get on with their lives. Issues can later be revisited, of course, according as opinions change or new data or other developments come along and change the balance of opinion decisively. But between such occurrences it is important that people have things settled, even if provisionally, and be able to move on. And so it will not do for people to be deciding for themselves all of the time whether each particular legal norm is "moral," or consistent with their own views of what ought to be done, or is phrased as they would phrase it, or is actuated by the reasons that they would have legislated in response to, or what have you. The point is that we delegate to certain people among us the task of repeatedly settling disagreements, even if admittedly only provisionally and even if in full knowledge that the settlements will themselves be quite regularly revisited.

None of this renders the law any less authoritative —or, more to the point, even any less morally authoritative or obligatory. For the role itself - that of dispute settlement-is in a very important sense morally required. It is required because life in society is in general betterethically more salutary, more ennobling, more enriching and more valuable in a multitude of ways - than life out of society. And life in society, in turn, is not compatible with moral equality, human dignity, human autonomy, or therefore with basic human rights unless disagreements rooted even in different views of the good are both permissible and yet periodically settleable. So the disagreement view is a thin intensionalist view par excellence, it seems to me.

I think that something quite similar can be fairly said of the "inclusive" positivist and Dworkinian "best light" conceptions of law. Dworkin's conception of the law is integrated into a larger conception of the just polity, a political community whose members treat one another as equals. Treating as equals, on the Dworkinian conception, involves recognition of individual autonomy in determining what a good or successful life consists in, and recognition that all are entitled to roughly equal opportunity - including procedural fairness and material, resource opportunity - in their law-constrained pursuits of their visions of the good. The law, in turn, including not only documents and decisions, but also the practices by which law is formulated and vindicated, is to be understood in its "best" light, with "best" in turn understood in light of the just-described characterization of the political community of equals.

Now there are "integrity" constraints that operate in addition to the 
ideal of "best light" interpretation in construing and applying the law, to be sure: Interpretations must be vindicable in actual legal data, for example, and in this sense the Dworkinian view, like positivist views, recognizes the critical role of legal "posits." But the posits are understood as giving expression to a broad normative ideal, and in that sense they are not extensionally, but intensionally understood. (Hence, presumably, Dworkin's own self-characterization, at times, as something like a naturalist.) But the intension in question is "thin" because liberal, because justice- and right-based rather than "thick"conception-of-the-good-based. Indeed, in more recent writing, Dworkin has emphasized that the ideal pursuant to which our law should be understood is a broad "rule of law" ideal which is a legal counterpart to the just liberal polity's political ideal. That ideal, I think, accordingly corresponds rather closely to the "thin" intension I've proposed just above as sufficient to underwrite a plausibly thin intensionalism about law.

I think that we can readily speak similarly of thin intensionalism's compatibility with some forms of positivism. The "disagreement" view discussed above, for example, is itself generally presented by proponents as a moral argument for positivism itself. Insofar as that's true, it can be viewed as a form of "thin" intensionalization of positivism. The case of so-called "inclusive" or "soft" legal positivism, at least in some renditions, is another that I think can be thinintensionalized. There is more nuance in these forms of positivism than I can do justice to here. But suffice it for present purposes simply to observe that these forms of positivism happily recognize that initially extralegal norms of morality or ethics can be "legalized," provided that the legal order itself authorizes such forms of incorporation in stipulated contexts. It can sometimes grow difficult to distinguish these positions from some early articulations of the Dworkininan view pursuant to which our law is best understood as always incorporating such extralegal norms via the broad "principles" in terms of which it is often articulated. But how ever distant or proximate the views in particular instances, insofar as the legally "incorporated" norms in question are, say, broad "rule of law" or procedural fairness norms brought to bear, for example, in interpreting very generally worded constitutional texts, it grows all the easier to interpret the law itself as embodying a thin collective intension to order our lives together along lines sketched above.

I trust, then, that the point has been made. Hard-core extensionalism seems quite implausible, but so is thick intensionalism in any liberal, pluralist polity. But a thin form of intensionalism, sounding in the thin collective intention on all our parts to "go on together," in a shared regime meant fairly to facilitate each of our 
individual pursuits of the good, seems a plausible way of investing our law and our legal order with ethical meaning. And I think most of us would agree it's an august meaning. A bit of attention paid the second Cantorian decision point here, then, helps to resolve long dispute at the first point. We'll now find a similar story-indeed, one that more starkly tracks the dynamic we traced in Part 2 on foundational mathematics - at work in foundational economics.

\section{Foundational ECONOMICS}

\subsection{Criterial Choice and Self-Reference Again}

I find it easy to spot what appear to be versions of our Cantorian decision points in the foundations of welfare economics. That is particularly so once we have done so in what I've been calling "foundational law." For the economic case tracks the jurisprudential one rather as Bentham's views upon what ought to actuate legislators cohere with his views as to how what they legislate is best regarded. As with the law, then, so in welfare economic inquiry: We find puzzles and controversy over the divide between ethical arbitrariness on the one hand, ethical intelligibility on the other quite immediately implicated by differing positions staked out in a discipline possessed of mixed normative and positive attributes. And once again, we shall find, closer consideration of the role of reflection in the discipline in question assists us in finding a sustainable middle course between problematic extensional and intensional extrema.

I'll begin, then, with a quick characterization of the criterial choice juncture as it shows itself here. That is in the question of how we are to understand "welfare" as experienced by or attributable to persons and political societies. Then I shall show how the ineluctably selfreferential nature of normativity constrains plausible answers to that question. As with mathematics and jurisprudence, then, careful consideration of the second Cantorian decision point yields dividends again to those who face quandaries at the first.

\section{2 "Welfare," "Welfarism," and Unbounded Preferences}

Let's start with the "welfare" that interests the welfare economist: There seems to be broad agreement among most welfare (or "social choice") economists, and among many legal theorists influenced by them, that social policy ought to concern itself with human "wellbeing," well-faring, or "welfare." There also appears to be broad 
consensus that welfare or well-being, for their parts, are best construed simply along preference-satisfactionist lines. One's welfare or wellbeing, that is, is taken to be a straightforward function of the degree to which her self-declared, or even undeclared but choice-revealed, desires are fulfilled.

The alternative, most appear to agree, would seem to be some form of "dictatorship" or "perfectionism"-i.e., a view according to which someone or some ideology other than you or yours is deemed a better determinant than you are as to how well you "really" are faring. Such views are found to offend deep-seated values of individual autonomy and its upshot, tolerance or pluralism in respect of defining "the good." Contemporary normative economists accordingly eschew them on grounds not unlike those assayed in Part 3 for relaxing prospective demands for most full-bodied-_"thick"-collective intentions.

Now the mentioned desires in terms of which welfare is now understood per the dominant view, for their part, can be desires for anything at all. And they can be held on the basis of any taste, or justified by reference to any reason-or indeed even no taste or reason-whatever. Preferences are neither "founded" nor "grounded" for welfare economic purposes, we might say, but are themselves the foundations or grounds of our welfare analyses. In effect this is no more than a corollary to the definition of "welfare" itself on the dominant understanding. For to demand a foundation or ground would effectively be to unseat the individual as absolute sovereign where her own welfare is concerned. And the "consumer," as we say, again "is king."

So preferences need not be sensible or comprehensible or intelligible on the dominant conception of welfare. They need only be there. In this sense, the preferences taken as data by welfare economists are of course "arbitrary." They are fully as arbitrary as the choices that reveal them. They can be as capricious as the voluntarist's God or the legal positivist's sovereign. Or they can be, for that matter, just as unpredictable as the random selector of digits or correlations or choice sets we saw in connection with Class D sequences, Dirichlet functions, and the Axiom of Choice, respectively, in Part 2. So we see straightaway that modern welfare analysis is extensionalist at least where individual "welfare" is concerned. Welfarist preferences need not be "enlightened" or "informed" preferences, "considered" or "deliberated" preferences, ethically permissible or "unobjectionable" preferences, or indeed, again, preferences meeting any particular description-hence criterion-at all. They need "mean" nothing, ethically speaking. They simply are.

Now, what does this mean for the welfare economist or social welfare "analyst"? What does she make of or do with such preferences? 
Well, the analyst-or, in a more venerable idiom, "the planner"-for her part will not "presume to judge" the source or the content of anyone's preferences. 248 She scrupulously abstains from ethical evaluation of preferences. She'll only "count" them. She'll do so in order, in "the final analysis," to arrive at a "social" choice. This choice, quite crucially, is typically purported to be fully as arbitrary and hence "objectively" or "scientifically" treated, normatively speaking, as the individual choices thus aggregated. This latter, "simply summed," "social" arbitrariness, we shall see, turns out to be analytically problematic-indeed incoherent. But more of this momentarily. The cardinal point for the moment is simply that social welfare, as determined by the analyst, is intended to be treated as extensionally as is individual welfare. It is no more than "aggregated" such welfares, with nothing else added.

Now, what is it for the planner to "count" and "aggregate" preferences in the manner just mentioned? It is, to return to the mathematical idiom, to quantify over them in calculating a social welfare ordering or aggregate. One calculates the latter, in turn, through the apparatus of what long since have come to be called "social welfare functions" or "-functionals" (SWFs) 249 The idea, in broad outline, is this: We consider various possible worlds, and we calculate welfare measures of one sort or another - real number values are heuristically convenient, but ordinal rankings or partial orderings are all that strictly speaking are necessary-for each of them. Possible worlds, for their parts, in more detailed analyses will be characterized in terms of particular properties that hold true of them-features in virtue of which they are deemed to be better (more well-faring) or worse (more illfaring). A fully elaborated SWF is accordingly of the form:

$$
W(x)=W(f l(x), \ldots f f(x))
$$

where $x$ is a possible world and the vector components $f l$ through $f m$ are features of $x$ in response to which $x$ 's assigned welfare measure or

248 No operative imperatives stem from anything save those preferences themselves. A problem for the economists, we'll see.

249 The distinctions between social welfare functions, orderings, functionals, and so forth are rooted principally in the kinds of information to which they are sensitive, hence the algebraic groups of information-preserving transformations to which they belong. Individual welfare (or "utility") might be treated as merely ordinally, or as cardinally, or even as "absolutely" quantifiable; it might also, and quite distinctly, be treated as non-, unit- or fully comparable in the holding across persons. The stance that one takes in respect of such questions determines the form of her formalizations. See Robert Hockett, The Deep Grammar of Distribution: A MetaTheory of Justice, 26 CARDOZO L. REV. 1179 (2005). For present purposes, however, nothing will hinge upon such distinctions, and so I shall speak mainly in the heuristically more convenient language of real-valued social welfare functions, or "SWFs." The notion of an SWF originates with Abram Bergson, A Reformulation of Certain Aspects of Welfare Economics, 52 Q.J. EcoN, 310 (1938), who developed the apparatus with a view to "stat[ing] in a precise form the [hence, presumably, all] value judgments required for the derivation of the conditions of maximum economic welfare." Id. at 310 . 
ranking will tend to vary.

Now, analysts say that an SWF is "individualist" when it "counts" individual persons ' preferences in assigning values to worlds: That is to say, when $W(x)$ varies at least partly in positive response not just to any features $f$ of worlds $x$, but to individuals' preference-satisfactions in those worlds in particular. In effect, then, assuming that individual preference functions quantify over various preferred and dispreferred features $f$ of worlds $x$ as does $W$ in the formula just above, the individualist SWF is composite in nature. There are, first, individual preference functions that quantify over features $f$ of possible worlds $x$, of the form:

$$
U i(x)=U i(f l(x), \ldots f m(x))
$$

where " $i$ " indexes each individual's welfare function and " $x$ " and the " $f$ 's are read as mentioned before. And there are, second, social welfare functions of the form:

$$
W(x)=W(U l(x), \ldots U m(x))
$$

where the social welfare measure of each world $x$ is a positive function of the preference satisfactions $U$ of $x$ 's inhabitants. Formally, we might express this idea of compositionality thus:

$$
W=W \circ U i \circ f_{m}
$$

which simply signals that welfare-measures of worlds ride upon preference satisfactions of individuals, which in turn ride upon features of worlds that the individuals variously prefer or disprefer.

A final point to make about this apparatus of social welfare functions before we proceed is this: A social welfare analyst may be "individualist," in the sense described above, without being thereby committed to the view that social welfare is solely, or exclusively a function of arbitrary individual satisfaction measures. She may view social welfare instead, for example, as a function of individual preference satisfactions along with something else. Or, what can amount to the same thing (we'll specify when it does below), she may view social welfare as a function of individual satisfactions that are bounded in some way, such that the social welfare function does not count, say, certain satisfactions of Nazis or Inquisitors or "Honour Killers," or perhaps of contrarian or misanthropic "Social Welfare Haters," as bona fide welfare additives. Such an analyst will view social welfare as indeed riding positively upon individual welfare rooted in some kinds or increments of preference-satisfaction, but not as riding positively upon individual "welfare" rooted in every conceivable kind or increment of preference-satisfaction.

We'll return to such matters shortly. For the present I wish only to point out that, where the analyst is an individualist of the sort just mentioned-call her a "pluralist," or "small ' $c$ ' catholic" individualisther SWF will take the form: 


$$
W(x)=W(\bullet, U 1(x), \ldots U m(x))
$$

where all means what it did before, save with the added vector component " $\bullet$ " now standing-in for what ever set of features additional to individual satisfaction measures the analyst takes to influence veritable, normatively compelling social welfare as distinguished from merely positively present individual preference-satisfaction alone.

Economists who proscribe such components " $\bullet$ " from their SWFs - call them "monist," or "fundamentalist" individualists-for their part, sometimes flatter themselves with the moniker "welfarists," as if this were the only possible form of welfarism. But a less misleading name, for reasons we'll presently discuss, again would be "fundamentalist," or perhaps "strict welfarists." For less monomaniacal believers in preference-satisfaction are welfarists too, if welfare be at least partly a matter of preference-satisfaction. And strict welfarism, we'll see, turns out to be incoherent as a normative position in any event, such that the only analytically viable form of normative individualism or welfarism, in fact, turns out to be a non-strict, nonfundamentalist, non-monomaniacal-in a word, "pluralist"-form. That will make for a nice link, we shall see, to our discussion of pluralism's role in necessitating a "thin" form of intensionalism about law as discussed in Part 3.

\subsection{Domain Restrictions, Distribution Rules, and Bounded Preferences}

All right, so far so good, I take it. Now most welfare economists, be they pluralist-individualist or strict welfarist in orientation, admit quite up-front to being prepared to make at least some room for distributional considerations in their analyses. They'll agree, for example - as we shall see formally they must-that social welfare measures ride not only upon the satisfaction measures of those whose preference functions figure into their SWFs' argument domains, but also upon the manner in which those preference functions are aggregated. For the social welfare aggregate is a function of the SWF's arguments as combined in some way, such that the mode of aggregation is fully as aggregate-determinative as are the components that are aggregated. And any mode of aggregation is of course a mode of distribution-a distribution of "weights" over individual preference functions that figure into the aggregate social welfare measure. And indeed so is the choice of argument domain itself, when you think about it. For those whose preferences are not counted in the SWF-perhaps unborn children, for example, or chattel slaves or disfavored castes in some societies, or nonhuman animals—can be readily viewed as 
sentient beings with preferences, whose preference functions are simply weighted at zero.

Here are a couple of concrete examples of what I am talking about in speaking of aggregation methods and their distributive significance, for any of you who might be uninitiated. First, some of you will know that many welfare theorists have observed, particularly in the past, that diminishing marginal utility and rough similarity of utility functions among persons jointly imply that equalizing individual utility measures will maximize social utility. 250 This view has been a staple of many venerable Benthamite egalitarian positions, including those influentially advocated by Pigou and, a bit later, Lerner. ${ }^{251}$ The same tack has been taken by certain advocates of so-called "optimal taxation," including perhaps most notably Mirrlees. ${ }^{252}$ Such thinkers have typically advocated rough distributive income equality, in the name of aggregate social welfare maximization.

Other analysts, even when skeptical of the just mentioned predicate assumptions - viz. of diminishing marginal utility or, more often, of the comparability of individual utility functions - have sought to give sway to distributive norms in some other way. Some, for example, have recommended that society seek to maximize the welfare of its worst-off members, "worst" and the bounds of the class of such "members" then having to be defined and demarcated in some manner. This is of course the "maximin" idea, whose best-known modern rendition doubtless has been Rawls's influential "difference principle."253 Still other theorists have recommended, in a similar if more complex vein, differentially weighting certain kinds of preference or preference function in summing to an aggregate measure. ${ }^{254}$

Now the many differences between the sundry ways in which social welfare analysts (or, in Rawls's case, justice theorists) might make room for distributive considerations are not ultimately what concern us here. The important point for present purposes is simply that such considerations are acknowledged by nearly all if not literally all social welfare analysts to be important. We always address, that is to

250 This observation has a long pedigree, going back to the earliest of the "marginalists" of the mid-to-late nineteenth century. But it is probably most associated nowadays with Abba Lerner. See, e.g., ABBA P. LERNER, THE ECONOMICS OF CONTROL (1949).

251 See Id.; A. C. PIgOU, THE ECOOMICS OF Welfare (1920).

252 See the seminal papers collected in JAMES A. MIRRLEES, WELFARE, INCENTIVES, AND TAXATION (2006).

253 This suggestion too is a venerable one, but is nowadays most often associated with the "difference principle" of John Rawls. See, of course, JOHN RAWLS, A THEORY OF JUSTICE (1971).

254 See generally Robert Hockett, The Structure of Distribution in Law and Economics, in NORMS AND VALUES IN LAW \& ECONOMICS (Aristides N. Hatzis ed., 2007), for more on weightings in SWF aggregation rules. See also Robert Hockett, Taking Distribution Seriously, supra note 84 . 
say, questions concerning what might be called patterns of distribution-patterns such as equality, maximin, or some other form of differential weighting-just as surely as we address questions concerning what might be called objects of distribution-objects like "welfare," income, resources, or any other distribuendum to which we attend-in our social welfare or justice analyses. 255 And again, on reflection this is not surprising. For if we view social welfare as being a function of multiple individual welfares, then of course it rides not only upon those welfares themselves, but upon the mode of those welfares' combining.

Now, how does what I have called, since the Introduction, the Cantorian decision point concerning "criterial" or "intensional" versus "arbitrary" or "extensional" choice find itself implicated here? Well, I think we shall spot it at three related points implicated by the brief sketch of modern social welfare analysis that I've just provided. One of these points I shall call "merely deep," the other two "deeper." Somewhat regrettably thus far, disputation has occurred only at the "deep" point. We find how to resolve those disputes, however, only when we proceed to the "deeper" ones. And we'll see that the deeper ones are most readily appreciated when we consider how the second, reflectivity-related, Cantorian decision point is itself implicated by welfare economic analysis. And you won't be surprised by this point to hear that we'll end at a form of "thin intensionalism" as the only viable form of normative welfare economic analysis.

Now before we move on, to set the stage for the remainder of our discussion here please consider the following observation and question in connection with what we have noted already: The preferences over which modern welfare analysis quantifies, we have noted, are ethically arbitrary. So is, supposedly, the "social welfare" or "-choice" that is aggregated from them. But now, do you suppose that the decision itself, to quantify over preferences rather than something else, and then to aggregate them in one way rather than another possible way, can itself be ethically arbitrary? And relatedly, is the fact that we must aggregate preferences in some way consistent with the picture of social preference as merely "heaped" individual preference? Please hold that thought as we proceed.

\subsubsection{The "Merely Deep" Objection}

Now I have already, in effect, noted the "merely" deep point at

255 We also, when not being remiss, attend to recipients of distributions, mechanisms of distribution, and distributors. See both sources cited supra note 254. But for present purposes distribuenda and distribution rules are enough. 
which extensional versus intensional choice comes into dispute above. And as I say, it is the only one around which there seems to have been much debate in the literature. I am alluding to the so-called "objectionable preference" problem: Should "society," the objector to welfarist orthodoxy queries, really treat as socially cognizable all preferences in our analyses as to how well a society is faring? That is to say, is satisfaction of just any preference in fact normatively intelligible for purposes of what is after all meant to be normative economics, such that it can reasonably be said that "society" or its agents-government functionaries, say-“ought" to facilitate such satisfaction?

Suppose, for example, that I derive pleasure from your suffering, and my pleasure can somehow be known in some straightforward and acceptable sense to exceed your suffering: In such case should my preference really trump yours in the judgment of society? Isn't that in some sense perverse? This version of the objection sometimes is called the "objectionable"-or "nasty"-preference" problem. ${ }^{256}$ It is associated, canonically, with Sen. ${ }^{257}$

A cognate rendition of the objection that we're now considering takes this form: Consider preferences rooted in structural injustice or oppression and consequent "false consciousness," such as that of Victorian women to remain in the home, or of slaves to remain on plantations? Since preferences seem, in many if not most or indeed all cases, to be at least partly endogenous to social circumstance, and since social circumstances themselves, it would seem, can sometimes be judged problematic on the basis of factors other than or additional to preferences alone, does it make sense from a socio-ethical point of view to treat preferences as no more than data to be perforce accommodated in analyses that we dignify with such morally august terms as "welfarist?" Shouldn't we view some preferences as afflictions of a sort-akin to addictions-rather than simply as desires that we or our functionaries are to honor?

This rendition of the "merely deep" objection sometimes is called the "tamed housewife" problem, and is also associated with Sen. ${ }^{258}$ It is akin to the sadistic preference problem in its willingness to view some preferences as objectionable or not worthy of being simply honored without further inquiry. But it is potentially distinguishable from the sadistic preference problem in its implicit appeal to the welfare of the preferer herself in critiquing some of her preferences. In that sense it registers a partial departure from liberalism; it is willing to countenance

256 See, e.g., Hockett, Taking Distribution Seriously, supra note 84; JOHN E. ROEMER, THEORIES OF DISTRIBUTIVE JUSTICE 128 (1996).

257 See, e.g., A. K. Sen, Utilitarianism and Welfarism, 76 J. PHIL. 463 (1979).

258 See, e.g., A. K. SEN, THE STANDARD OF LIVING 11 (1987). See also Gerry Cohen's justly celebrated G. A. Cohen, On the Currency of Egalitarian Justice, 99 ETHICS 906 (1989). 
some preferences' being, in a sense, "false" —as not having validly been formed under conditions of liberal autonomy.

Finally a third and more generalized rendition of the class of objections that I am here considering, though I have not yet encountered it in the literature, might take this form: Doesn't normativity itself-in particular, the fact that in welfare economic analysis we are embarked upon an evaluative (a "world"-evaluative), judging enterprise-open the prospect that preferences, which are themselves after all positive features of worlds, can be normatively adjudged just like anything else? In particular, doesn't the fact that in welfare economic inquiry we are involved in a form of ethical assessment of worlds entail that we might plausibly require that the preferences we find in such worlds themselves be at least ethically intelligible, rather than permitted to be ethically arbitrary, before we will treat them as normatively compelling rather than merely positively present?

Put another way, this form of the objection might run: Can just anything found in the world be, as it were, "automatically" ethically compelling, or must that which is ethically compelling not first be ethically intelligible? Perhaps, one might argue, to be socially cognizable as something deserving the normative status of welfareadditivity, preferences should be required to be more ethically interpretable than the mere whim of a voluntarist God or Hobbesian positivist sovereign. Why, after all, should it be incumbent upon us to honor such preferences, if it is not incumbent upon the preferers to honor anything at all? Stated this way, the objection of course amounts to a variation on the idea essayed in Part 3, that it is one thing to call something a "law" (compare: "preference"), and quite another to say that for this very reason it is morally obligatory rather than merely coercively compulsory. The idea also amounts, of course, to an intensionalist demand to which preferers are held, in return for our holding ourselves in turn subject to the preferers demands themselves. It's not unlike a "clean hands" requirement of the sort that's familiar, not insignificantly in light of Part 3, less to commonlaw than to "equity" jurisprudence. 259

\subsubsection{A Cognate but "Deeper" Objection}

Now, I don't wish to denigrate such objections as these I've just

259 I'll note here that, while I have not encountered an argument thus sounding in equity or what we might here call "intensional reciprocity," it has nevertheless been forcefully argued by at least one legal scholar that preferences alone are not as it were "automatically" normatively compellıng. See Douglas A. Kysar, It Might Have Been: Risk, Precaution, and Opportunity Cosis, 22 J. LAND USE \& ENVTL. L. 1 (2007). 
registered by calling them "merely deep." I simply believe we can deepen them further. I think we can make their proponents' case easier, that is, by noting that there is a cognate yet "deeper" observation to make here. It is an observation pursuant to which the strict welfarist, who is the "merely deep" objector's principal antagonist, turns out to be rendered normatively speechless by his very own premises, thus effectively doing the objector's work for her. And, as we'll presently see, full elaboration of this observation brings into play not only that Cantorian decision point which I've been associating with intensional versus extensional choice, but that which I've been associating with self-reference as well. Here goes.

Please first recall something we noted above: Any individualist and, a fortiori, any strict welfarist SWF that quantifies over multiple individual preference functions in determining a social welfare measure effectively imposes a weighting upon its arguments. It does so quite "automatically," so to speak, whether by deliberate design or by default. Its so doing, that is to say, is what we might call an "internal" or "formal" feature of the SWF- any multivariate SWF-itself. The SWF might weight the individual preference functions that are or are among its arguments equally, or any number of ways unequally, but it weights them in all events. It weights them precisely because it aggregates them. Its weighting rule is accordingly oft-called its "aggregation rule," which with equal justice could be called its "distribution rule." 260 And as we noted above, the analyst's choice of argument domain works in similar fashion, in that those who might plausibly be thought to hold preferences but are not counted can be readily viewed as receiving weight zero in the analyst's aggregation.

Now suppose that I, a member of the society whose welfare some SWF purports to track, hold preferences at variance with the SWF's aggregation rule or domain restriction itself. How might that happen? Well, I might have a differing view of appropriate aggregation or distribution, perhaps a different conception of justice, than the analyst. Or I might be a welfare-contrarian or misanthrope: I might even be a Cantorian-style welfare-diagonalizer of sorts, deliberately framing my preferences so that they'll be, simply, "not" what ever social policy seems to be recommended by the operative SWF employed by the planner or functionary of the society in question. I'll explore prospects like these in a bit more detail below, in connection with self-reference, for it turns out to be surprisingly easy to derive analogues to the Russell Set discussed at Part 2 in the apparatus of SWFs. But bracket this for just a moment.

For the moment we'll keep things much simpler and merely

260 Or distributive structure, or pattern, or "weightıng structure," or "internal structure," etc. You get the idea. 
suppose that I prefer, not contra the operative SWF considered in toto, or even contra this SWF's aggregation rule-its particular weighting structure-as such. Instead we'll suppose that I simply prefer more than this SWF, with its particular weighting structure and argument domain and against a particular feasibility backdrop, allots me. There is accordingly a gap between what I prefer and what the SWF as feasibly maximized permits me. Such gaps are presumably quite common. Indeed there is always this gap wherever there are people who do not endeavor to conform their positive preferences themselves to that normative view of appropriately distributed welfare which finds expression in the SWF in question. And the analyst is happy enough if we all are such people.

Now in this altogether typical, prosaic case that I am envisaging, does the SWF itself, even though preference-regarding, not nevertheless effectively bound my preferences? After all, what ever I might prefer in excess of what the SWF with its weighting structure allots to me when maximized, given the backdrop of both the feasibility set and other persons' preferences as also weighted, simply will not be treated by the SWF as socially cognizable. The SWF, that is to say, partitions my possible satisfactions into those with a normative status, and those without such a status. That which I prefer which the SWF does not sanction lacks the mentioned status. It will be "ruled out of court" rather in the way that putative harms that are not legally recognized "causes of action" are ruled out as bases of stateable claims at bar. The preference overage simply will not be cognizable, socially speaking, as a preference increment whose satisfaction constitutes "welfare." It will be no more than unsatisfied positive preference-an "is"--with no normative "ought" claim upon society, its members, its "planners," or "analysts."

Now note how this observation connects with what I was calling the "merely deep" objection to strict welfarism above: The SWF itself, by dint of its very possession of an internal structure, in effect filtersand in that sense "judges"-preferences. It bounds them. Preferences at variance with the SWF itself are "the ultimate" in "objectionable" preferences, we might say: For even the analyst effectively "objects" to these preferences, in the sense that he will not count them at all in determining the welfare aggregate. Any individual preference in excess of the aggregation rule's allotment to that individual is "out of bounds," and effectively ruled out of court. It simply is not counted as something the satisfaction of which adds to the social welfare aggregate as defined by the SWF. And remember that this aggregate is the aggregate of everything that counts as veritable "welfare." All else is mere positive preference-satisfaction with no normative claim upon anyone, since the only socially normative claim is that the SWF is to be maximized. So 
even the self-proclaimed strict welfarist, it seems, filters preferences, just as would those raising "merely deep," objectionable preference objections to welfarism. He just isn't transparent-either to us or, presumably, to himself - about it. So he is not quite as extensionalist as perhaps he has hoped to be.

Now this observation amounts to what I am calling a "deepened" objection to strict welfarism in the following way: In effect, the observation highlights a logical truth that the strict welfarist is bound to find disturbing but does not yet seem to have noticed. It is that one actually cannot, in truth, coherently be strictly welfarist in social welfare analysis. In thinking that one can, we might say, one remembers the "welfare" (construed simply as preference-satisfaction) while forgetting the "social." No mindful, coherent welfarist can be strictly welfarist. She must be "something elsist" as well. To recur to the formal idiom employed above, her SWF must in effect quantify over at least one " $\bullet$ " in addition to all of those " $U i$ 's."

I hope that I wasn't too fast with that. Do you see what I mean? Let me try putting it this way: Any welfarist who views social welfare as riding upon the preference-satisfaction of more than one person ${ }^{261}$ must also view social welfare as riding upon those satisfactions' being distributed in conformity to her SWF's own aggregation rule, right? She is committed to that view by dint of so much as employing the SWF that she does as the standard by which social welfare is measured. For the patterning value pursuant to which the SWF is structured is no

261 Hence any non-"dictatorial" welfarist, if I may carry over the term employed since Arrow published his dissertation. See KENNETH J. ARROw, SocIal CHOICE AND INDIVIDUAL VALUES 1 , passim (2d ed. 1963). Incidentally, it is insufficiently remarked in the literature that Arrow was a student of Tarski's. See, e.g., id. at 13, 14 (citing ALFRED TARSKI, INTRODUCTION TO LOGIC AND TO THE METHODOLOGY OF THE DEDUCTIVE SCIENCES xiv (1941)) (expressing thanks for Arrow's assistance as proof-reader). It is also insufficiently remarked, I think, that Arrow, in the same seminal work, refers to the temperament which eschews values that can constrain-or in my terms, be "incumbent" upon-preferences as "nominalist." See ARROW, supra, at 22. That is suggestive in connection with what we observed supra Part 3, about nominalist logicians of the Medieval period's having been voluntarists and positivists in respect of normativity and legality. Unfortunately, Arrow seems to think opposition to these forms of what I am calling "extensionalism" to commit one to "the existence of the social ideal in some Platonic realm of being," which he observes "the modern period" to find "meaningless." The confusions embedded in this unfortunate aside are both too numerous and too tedious to disentangle here. Suffice it to note, first, that this lapse into nonsense is, happily, quite generally uncharacteristic of its author; and second, appeal to any "value" what ever, including those to which Arrow appeals in the work I am here citing, commits one to "ideals" and hence "Platonic realms" quite as much and as little as anyone Arrow might have had in mind would have been. I have come to suspect that confusion on this point is bound up both with tendencies to conflate the "is" of mere positive preference with the full "ought" of normative principle, and with the venerable distinction that ethicists draw between "consequentialist" ethics on the one hand, "deontological" ethics on the other. I no longer think the latter distinction any more tenable than the former conflation. See, again, Hockett, Taking Distribution Seriously, supra note 84. See also Robert Hockett, The Impossibility of a Prescriptive Paretian (Cornell Legal Studies Research Paper No. 06-027, 2008), available at http://ssm.com/abstract $=930460$. 
less a social welfare-determining value than is the choice-ofdistribuendum value (e.g., individual preference-satisfactions) pursuant to which her SWF's argument domain is selected. The analyst values both - the domain and the mode of aggregation which define her SWF. And in that sense, she is at least minimally-may I say "thinly?"intensionalist about welfare. There are some possible preferencesatisfactions-some satisfaction "extensions"-which she will not count as welfare, precisely because her SWF does not do so. So she is committed to at least some degree of what we might call, in the idiom of Part 2, intensionalism about welfare.

But it is precisely this that means, also, that our analyst is not after all a strict welfarist. She is one or another kind of "distributivist"-an advocate of one or another conception of appropriate distribution, i.e. fairness-as well. She becomes such an advocate, ipso actu, the moment she settles upon an aggregation-i.e., a distribution-formula for her SWF. And, as we've also noted, she is one likewise the moment that she determines an argument domain that excludes any creature with preferences. How, then, could anyone ever have come to think strict welfarism so much as conceptually coherent?

Well, some writers perhaps have lost sight of their situation owing to little more than an accidental feature of the particular formal apparatus in which social welfare analysis has been conducted since Bergson first proposed it seventy years ago: That is the fact that distributive values find expression primarily not in the vocabulary but in the syntax, so to speak of our formulae: They turn up mainly in the SWF's shape, which goes unnamed once a particular SWF has been chosen, rather than in the argument domain, which is a domain of named individual preference functions over which the SWF quantifies once constructed. (Though I hasten to add that, as noted several times already, the choice of any domain short of all sentient creatures bears distributive significance too.)

It is almost as if these analysts were unconsciously following an early Wittgensteinian "say/show" injunction ${ }^{262}$ - as if one could speak only of simple "objects" like individual preference schedules but not of such "structural" fare as an SWF's aggregation rule! And since, quoth the oft-quotable Quine, "to be is to be the value of a variable,"263 one apparently concludes that the patterning values that determine these rules do not themselves exist! The situation is not altogether unlike that in which orthodox set theorists find themselves, as discussed above in Part 2: In the latter case, one violates ad hoc stratification rules which one renders operative within one's axiomatization, in describing and

262 See, of course, TRACTATUS, supra note 49, proposition 4.1212 ("What can be shown cannot be said.").

263 Quine, On What There Is, supra note 72, at 32. 
justifying that axiomatization itself. 264 In the present case, analysts name and talk about patterning values in constructing their models, while permitting those values no names and hence no explicit normative status in those models once constructed.

But it is of course error to suppose that our not quantifying over distributive values in the apparatus of SWFs means that such values are not existent, namable and, most importantly, operative in those SWFs. Just as it is error to suppose that our not quantifying simultaneously over all "orders" of sets in one of the orthodox set theoretic axiomatizations means that we have not in fact done so in deciding upon and advocating for a particular axiomatization. Indeed the supposition boils down to a crude category error-the kind of error we find manifest in such strictly nonsensical locutions as "fairness versus welfare," which we nowadays find uttered with abandon by would-be strict welfarists. That is, of course, a phrase which is analytically on all fours with such readily constructed nonsense-oppositions as "warmth versus clothing," or " $35 \mathrm{mph}$ versus tennis balls." For "fairness" refers to a pattern of distribution, "welfare" to an object of distribution. And so of course welfare itself, like any distribuendum, is distributed fairly or unfairly; while the "analyst" deems it distributed fairly when it is her chosen SWF, with its aggregation rule, that is maximized against what ever constraints are at work in the constrained optimization problem that is her social welfare analysis.

So the error, again, might be rooted in part in the aforementioned accident of our formalism-the fact that the formalism does not include names for patterning values, but only manifests them in the SWF's "shape." But the error could also have been readily spotted and avoided, I'll argue below, by attending to our second Cantorian decision point-self-reference. For doing so yields a straightforward proxy for named distribution norms, a proxy that I'll call "incumbency." More of that in a moment.

\subsubsection{Another "Yet Deeper" Indicator}

Before we attend to the role that self-reference can play in avoiding much needless perplexity in respect of intensional versus extensional choice in welfare economic analysis, let me turn very briefly to a third and final way in which intensional versus extensional choice can be seen at work here in the matter of would-be "strict welfarist" SWFs, in a way that shows "strict" welfarism to be problematic. It proceeds straight from the second way just discussed rather as the latter

264 See supra Part 2.5.5. 
proceeded from the first, "merely deep" way. Here is the thing to note: SWFs, as I mentioned, are "constrained maximizing" formulae. The "analyst" or "planner" is charged with setting policy in such a way as will bring about that feasible world $x$ to which the SWF assigns the highest numeric value or ranking.

But now note that which worlds receive higher and lower numeric values or rankings is of course straightforwardly determined by the aggregation rule - the aforementioned "shape" - of the SWF. It's determined by the argument domain too, of course, not to mention the feasibility constraint; but focus for now on the aggregation rule, which is enough for present purposes. But now-and here is the crucial partit is actually quite easy to fashion an aggregation rule such as will adjudge virtually any possible distribution of goods and ills over the persons whose preferences figure into the argument domain of our SWF-indeed, even any Pareto Efficient such distribution-to be the distribution which maximizes the SWF against the backdrop of a given resource constraint: Assuming standard convexity, concavity, and monotonicity conditions such as are typically assumed in welfare functional analysis, all you need do is assign as weighting to each person's preference function the reciprocal of her marginal utility of income. It follows as a trivial consequence of the First Welfare Theorem that the SWF thus fashioned will be maximized at precisely this allocation of resources over persons. ${ }^{265}$

Now, I know that's a little bit technical-sounding. But do you nevertheless see what I'm driving at here, and why it's significant in connection with intensional versus extensional choice? The point is that you can arbitrarily choose virtually any world you wish-quite at random, quite capriciously, pursuant to no comprehensible ethical position at all, even just flipping a coin or drawing straws-and then can quite readily construct an SWF-a social "welfare" functionwhich precisely that world "maximizes." And then, by definitional fiat, "welfare" will be "highest" in precisely that world. That world will be that which "fares best" of "all possible (feasible) worlds." But isn't that strange? It's Pangloss or Pope with a vengeance. ${ }^{266}$ Instead of fashioning your SWF in response to an antecedently held ethical view or position-i.e., instead of designing a function that gives expression to an independently compelling normative theory-and then evaluating worlds accordingly with precision in the manner that SWFs were

\footnotetext{
265 A nice little proof is found in HAL VARIAN, MICROECONOMIC ANALYSIS 333-35 (3d ed. 1992).

266 Pangloss is of course the character who figures as the butt of Voltaire's joke in Candidethe fellow who incessantly claims, in the face of disaster after disaster, that our is "the best of all possible worlds." See VOLTAIRE, CANDIDE (John Butt trans., Penguin Books 1947). It is clear that Pangloss is meant as a parody of Leibniz. The Pope allusion is to ALEXANDER POPE, AN ESSAY ON MAN (1732), where one finds the line, "what ever is, is right."
} 
originally introduced to assist in doing, you can instead decide that "what ever is, is [what's] right," and then build an SWF to "rationalize" it.

Now I trust you will see quite at once the connection between this observation on the one hand, the matter of criterial/intensional versus arbitrary/extensional choice on the other. An SWF designed pursuant to an ethical view, which subsequently is used to judge possible worlds, will be ethically intelligible. It will be interpretable and understandable straightaway as bearing prescriptive significance, precisely because it is designed pursuant to an ethical view first, and then subsequently put to work in rendering precise judgments over states of the world. Such an SWF has a meaning, we might say - an ethical, or normative meaning, a prescriptive significance. It is, in this sense, as it were "law-like" or "rule-determined," quite as our Class C sequences in Part 2 were found lawlike, and as democratically teleological legal rules were seen to be in a normative sense more lawlike than were autocratically capricious decrees in Part 3. A recognizable "ought" will in general be informed by an "is," to be sure-that is the meaning of "ought" implies "can"”but it will not be simply determined by it. That is what makes it an "ought."

An SWF constructed post hoc, by contrast, so as to "rationalize" distributions already found, is not ethically intelligible unless you are Pangloss, in which case there seems no need for an SWF at all. (And Pangloss in all events was, please recall, a satirical figure.) An SWF of this sort accordingly is ethically arbitrary-as ethically arbitrary as the already present distributions that it is fashioned to describe. And "describe" is indeed le mot just here: For such an SWF is descriptivesimply describing in symbols an encountered distribution-but is not prescriptive-is not being employed to give formal expression to normative desiderata in accordance with which we are to act to bring states of the world into conformity. In such case the word "welfare" seems out of place, does it not? This is a descriptive "social distribution function," not a prescriptive social welfare function. It is as if a social welfare Dirichlet had found a distribution of goods and ills over persons, treated it as a pre-existing graph, and then set about working out a formula which simply translates that arbitrary bit of geometry into algebraic terms. But this simply means, once again, that such a function would be akin to a Dirichletian "arbitrary" function-at least ethically speaking. It would give expression to no antecedently recognizable ethical rule, law, or theory at all. 


\subsection{Self-Reference Again}

All right, so that is how intensional versus extensional choice figures into welfare economic inquiry. But you'll note I've said little as yet about how to decide at this rendition of the first Cantorian decision point. I've merely said thus far that would be strict welfarism--which amounts to a form of full-bore extensionalism-is incoherent. Does that mean we fall back to a full-bore intensionalism? Well, no. For that could amount, as in effect noted at the outset of this Part, to a "fallback" to dictatorship or perfectionism, hence to a putatively "ethically intelligible" evisceration of individual autonomy in determining the good itself. Where, then, are we to head, and how shall we go about finding an answer?

Well, you won't be surprised, after having been through Parts 2 and 3, to learn that I think we are heading again to a form of what I have been calling "thin intensionalism." And we're going to get there, again, by first taking a moment or two at the second Cantorian decision point once more-the reflectivity point. How, then, does self-reference get into the act here? Well, I think in two related ways, both of which would have served - had they been noticed - to head-off extensionalist excess and error of the kind elaborated just above, and both of which offer a means of going intensionalist without going dictatorial or perfectionist. The first way is intuitively easiest to elaborate, so let us begin with it.

\subsubsection{The Oldest Conflation in the Book}

One way of viewing the arbitrariness-rooted error elaborated just above is as the consequence of a crude conflation-that between "is" and "ought," description and prescription, preference and principle. By taking positive preferences themselves-an "is"-as normative dataas "oughts"- the strict welfarist sets himself up for troubles later. (Calling two distinct things by one name usually does.) For preferences held by multiple persons in a world subject to scarcity-hence subject to "feasibility constraints"-are apt often to come into conflict.

That is one reason, one supposes, that we find life in structured relation to one another, in well-functioning, distributively just societies and polities (not heaps), to be critical to our well-being itself. And where there is conflict, there must be some means of adjudicating it. And if we're to adjudicate preferences in a manner that is to be perceived by all as legitimate, we must do so by reference to something 
other than simply more preferences. ${ }^{267}$ By reference to what do we do that? Why, principles, of course. Principles of fairness, in fact.

Now the analyst who constructs an SWF appeals to such principles too. She appeals to them, indeed, in deciding who "counts" at all when it comes to aggregating preferences in her SWF. And, what is more immediately salient for present purposes, she appeals to such principles-again, fairness principles-in settling upon an appropriate distribution-cum-aggregation rule such as will structure her SWF. That aggregation rule, as noted above, can for obvious reasons just as well be called a distribution rule.

Now it is important, I think, to be clear that the analyst is not merely consulting her preferences-conceived as something on a level with and arbitrary like the preferences of those over whose preference functions her SWF quantifies-when she deliberates about and ultimately settles upon a distribution rule. She is much more likely, in fact-particularly if she is clear about being embarked upon a normative enterprise - to determine her distribution rule on the basis of ethical considerations, "oughtness" considerations of the sort that will render an SWF normatively intelligible. And this is simply to say, once again, that principles-conceived as something "above" preferences, something by recourse to which one might adjudicate preferences-are at work in the construction of the bona fide prescriptive SWF itself. If you wish to call the analyst's decisions here preference-based, then you are at the very least going to have to call them something like "second order" preferences, since they are preferences concerning how to adjudicate preferences. The important point is less what we call them, than noticing that what ever we call them we have two different things- "is" things like individual preferences, and "ought" things like the quantificational domain and aggregation rules privileged by the analysts' SWF.

Now, chances are that most analysts are aware of at least this much, even if inchoately. But they seem-at least so far as I am able to tell in reading these "analyses"-always to forget one other thing: themselves. What do I mean here? Well, the apparatus of SWFs purports to judge worlds as, in the analysts' own jargon, "completely" described. ${ }^{268}$ That is to say, possible worlds are specified as complete descriptions of possible states of affairs, "completeness" in turn unpacked as to include every feature of worlds that will be taken as

267 Otherwise we are off on an infinite regress. One versus Two, then Three judges in favor of Two yielding Two and Three versus One, then Four judges in favor of One yielding One and Four versus Two and Three, and so on.

268 See, e.g., Bergson, supra note 249 ("the" value judgments); see also, e.g., Louis Kaplow \& Stephen Shavell, Any Non-welfarist Method of Policy Assessment Violates the Pareto Principle, 109 J. POL. ECON. 281 (2001) ("complete" description). 
normatively salient by the particular ethical position- "mode of evaluation" is the preferred phrase of art in this practice-held by the analyst. But now, ask yourself, isn't what the analyst herself is doing itself a normatively salient feature of possible worlds? Isn't she committed, by her very activity, to the judgment that it is-and that it is indeed world-bettering?

For consider, if the analyst did not think her analysis a good thing to be done, would she be doing it? Isn't this (second-order) "preference," to recur to her own idiom, "revealed" in her very activity? And if the answer is "yes" and she thinks welfare analysis a good thing to do, hence goes ahead and does it in the world, while possible worlds in turn are meant to be completely described such that every normatively relevant feature of each is taken into account and figures into the descriptions, then aren't worlds indeed "better" in her own judgment, ceteris paribus, precisely insofar as they feature her engaging in her analyses in them? I don't see how this can be denied. And then, finally, note once again that the analyst also privileges her principlesagain we might call them her "second order preferences" (preferences as to how preferences are to be adjudicated)-over all preferences that her SWF takes into account. No preference over which her SWF quantifies, that is to say, will trump her SWF itself once it is formulated. This is simply a trivial restatement of the observation made earlier, to the effect that the SWF itself is the measure of what preference-satisfactions and satisfaction-increments are cognizable as veritable, normatively compelling "welfare."

Now, these three observations bear a couple of very important consequences, which analysts might have noticed by now had they not forgotten themselves and their activity itself in the course of their analyses. For this valuing of the analyst's own activity that I mentioned can be named. I call it valuing the "incumbency" of the principles pursuant to which the analyst constructs her SWF and engages in her analysis, such that those principles now in effect receive names and are accordingly transparently acknowledgeable in the formalism just as are the named preference functions figuring into the SWF's argument domain.

The "privileging" of the analyst's principles—or, if you prefer, "second order preferences"- that I mention, in turn, takes the form of valuing worlds more highly, at least ceteris paribus, when these principles are incumbent in them, i.e., when the analyst is indeed engaging in analysis in them. But now go back up above to the general form of the "individualist" SWF as we laid it out. Incumbency, I trust you'll see, is simply one possible " $\bullet$ " in such a function. It is a minimal one, in fact-one that cannot not be included in the analyst's SWF on pain of normative self-contradiction. For if the analyst deems the 
upshot of her analysis worthwhile and worth believing or acting upon or judging in conformity with, then she affords at least some weight to one "•" in her SWF-the "๑" that is her own welfare analysis's incumbency. And that " $\bullet$ " is not merely one of the preferences over which she quantifies. It is something additional to those. ${ }^{269}$

Now, you might wonder why I am belaboring this, and what it has to do with self-reference's aiding us in avoiding the error of normativizing arbitrary preferences and arbitrary distributions. Well, there are two answers. First, as we discussed above, to include a " $\bullet$ " in your SWF is just to refrain from being a strict welfarist. It is to be humbler about your welfarism. It is to content yourself with being individualist alone, the only coherent way in which both to prescribe and to count preferences. And so, one upshot of the analyst's having to weight the incumbency of her principles is that she simply cannot be strictly welfarist. It is just analytically impossible. And one sees this as soon as one remembers oneself in conducting one's normative analysis. Giving incumbency a name assists with this act of remembrance.

Now of course, if the analyst were merely describing allocationsif her SWF were forthrightly ethically arbitrary, descriptive rather than prescriptive-there would need be no "•" in her function. There would be no need to register the value attaching to the analyst's incumbency. But in that case it also would not be a welfare function. It would effectively admit to having nothing to do with faring well, with wellbeing, at all. It would have only to do with "being" minus the "well"with de facto allocations left normatively unjudged-like the fanciful "Dirichlet welfare functions" countenanced just above in Part 4.3.3. But as soon as the adverb-particle "well" enters the act, we are speaking of judgment, of normatively deeming "better" and "worse." And that, as we've seen, implicates the concept of incumbency, and in so doing jettisons "strict welfarism." The latter just is not compatible with prescriptive analysis—or with any "oughtness" type inquiry-at all. It is literally nonsensical to hold otherwise, precisely as nonsensical as it is to speak of "fairness versus welfare" or " $35 \mathrm{mph}$ versus tennis balls."

The second (albeit closely related) point of significance to note here is that it is easy to prove that, for a given profile of preference functions, an SWF's not being strictly welfarist further entails its not being capable of strict conformity to any of the three so-called "Pareto" criteria typically imposed upon would-be SWFs by social welfare analysts. Full discussion and proof of the matter is somewhat technical - though nonetheless strikingly simple - and so I shall simply refer you to another paper in which I draw out the proofs if you would like details. ${ }^{270}$ But the upshot is that no bona fide prescriptive SWF-

269 That is one, minimal, sense in which her principles are transparently "privileged."

270 See Robert Hockett, The Impossibility of a Prescriptive Paretian, supra note 261. 
which is to say, no normative social welfare as distinguished from mere positive (and in this sense ethically arbitrary) social allocation function-can avoid coming into conflict with Pareto Indifference, Weak Pareto, and thus Strong Pareto. ${ }^{271}$ And, on reflection, this really should not be in any way surprising. 272 For Pareto is effectively the ultimate in "rationalizing" distributions that already are there. That's why it's sometimes described as a "veto."273 It is all about not rocking the boat, so to speak. And that, as we saw, is just ethically arbitrary-a matter of is rather than ought-quite as surely as was the Dirichlet-style post hoc "welfare" function countenanced a moment ago.

As I say, all of this seems very obvious, at least once the analyst notices herself and what she is doing. So this is the first sense in which attending to the matter of self-reference assists, yet again, in diffusing some puzzles that crop up in connection with criterial versus arbitrary choice, or intensionalism versus extensionalism, in the case of welfare economic foundations.

But I noted that there is a second. So let me now turn to that one. Here things again could grow a bit more complex than might be suitable, so let me just sketch the sort of problem that is apt to come up for would-be strict welfarism because of self-reference, such that attending again to self-reference can assist one in avoiding falling into the trap-the incoherence-of strict welfarism. I'll also refer you to yet another paper for more technical treatment.

271 Per Pareto Indifference, an SWF will deem possible worlds indifferent if all individuals' welfare functions so deem them. Per Strong Pareto, if all save one individual are indifferent as between two possible worlds, the SWF will follow the one non-indifferent individual's preference. Per Weak Pareto, if all individuals prefer one possible world to another, so will the SWF.

272 Nor, by the way, should "Arrow's Theorem" have been. The indeterminacy that is the "Arrow Impossibility Theorem" is an obvious forgone conclusion-a trivial conclusion-the moment that one eschews, as did Arrow and those who came after, all principles that might be incumbent upon, and thus enable us to adjudicate as between, individual preferences. Determinacy here just is incumbency - the incumbency of some principle by means of which we can adjudicate and, ultimately, prescribe, and of such principles as have dictated the choice of argument domain and aggregation rule constitutive of the chosen SWF itself. Arrow and subsequent "analysts" missed all of this simply by conflating the mere "is" of preference with the full "ought" of prescription, as described below. They ejected prescription when they ejected the "dictator," in Arrow's terminology, who they mistakenly thought had to be merely another (arbitrary) preferrer rather than an incumbent principle, or perhaps thought could exist only in "some Platonic realm of being" judged as "meaningless" by "the nominalist temperament of the modern era." ARROW supra note 261 , at 22. See Hockett, The Impossibility of a Prescriptive Paretian, supra note 261, for fuller diagnosis. And see supra, caption to this subsection: We are indeed speaking here of "the oldest conflation in the book."

273 Use of the "veto" locution in this context appears to originate with Sen. See SEN, COLLECTIVE CHOICE AND SOCIAL WELFARE, supra note 153. 


\subsection{2 "Diagonal" and "Russellian" Social Welfare Functions}

So here is what I have in mind: Recall the Russell Set that we encountered in Part 2? And what I called the Russell Complement? Those were, you'll remember, the set of all non-self-membered sets, and the set of all self-membered sets, respectively. Now, the would-be strict welfarist, recall, purports to count only preference functions in constructing her SWF.274 And as we noted, the analyst will not "presume to judge," hence to filter or edit or otherwise bound the preferences over which she quantifies. All of them "count," all are "on a level" in determining what the SWF shall quantify over.

Now in thinking along these lines, the analyst seems inchoately to be thinking of preferences as what we might call "first order," or, perhaps in a more Tarskian idiom, "object preferences."275 She's got the micro-theorists preferences for what are called "normal goods" in mind-apples, oranges, candy, strong drink, pornography, etc. But preferences can be "higher order" too, of course. I might have preferences as to what you yourself prefer. (I hope that you won't consume pornography, which is bad for you. ${ }^{276}$ Or I might have preferences about what I myself shall in future prefer-or even about what I prefer now. (I might be a regretful addict of some sort, for example). Now suppose that I am more ambitious than all of this in forming higher order preferences: I prefer precisely that the SWF itself not be maximized. I'm a curmudgeon or misanthrope. I am Scrooge, say-a Scrooge who "diagonalizes" out of each SWF.

So now here is the question: What is the analyst to make of me? What is she to do with my preference? What is she to do with additional such preferences if there are many of us? You might say, "well, yours only count for as much as they count for, and you'll be outvoted by all the others she counts, so you're just a very weak drag on the maximizing project, not a serious problem." But not so fast. You haven't actually seen the problem if this is your response. Because the problem isn't that I might "drag down" the aggregate. The problem is that the analyst cannot count me at all if there's to be any meaning in "aggregate" at all. For if she counts me, the social welfare aggregate is added-to only when it is subtracted-from (in my case), and it is subtracted-from precisely when it is added-to.

274 These functions, by the way, are themselves treated as sets-as extensions. They are sets of ordered $n$-tuples of possible worlds, one such $n$-tuple for each person over whose preferences the SWF quantifies.

275 By analogy with Tarski's terminology_-object language" and "metalanguage"-in his celebrated Concept of Truth in Formalized Languages, reprinted in ALFRED TARSKI, LOGIC, SEMANTICS, META-MATHEMATICS 152 (J. H. Woodger ed. \& trans., 1953).

276 Like Sen's "Prude," in A. K. Sen, The Impossibility of a Paretian Liberal, 78 J. POL. ECON. 152 (1970). 
See? My preferences cramp the analyst's very style, you might say. They cognitively cramp her, just as the set-theoretic and cognate paradoxes cramp more abstract theoretical cognition. She can do quite literally nothing with me in her analysis. So she either has to go back on her decision to count everyone's preferences, or she has at the very least to screen out some portion of my preferences-those concerning the SWF itself. Indeed she will have to impose something very like ad hoc Russellian "type" theory, a stratification rule, in my case, allowing only my "first order" or "object" preferences to count. Not also, in this connection, that our analyst cannot worm out in some intuitionist or paraconsistent way, as we found possible in set theoretic contexts. For here we are asking about what actually to do, not simply about how we should tag, register, and quarantine contradictions and indeterminacies that crop up quite inevitably at the outer limits of extensionalist cognition itself.

Now, lest you think this simply a quirk case, note that there actually are countless additional sorts of "higher order" preference problems like this one that will yield similarly pathological effects, even if somewhat less dramatic ones. I have simply chosen the heuristically easiest one. So, for example, I might be the opposite of the curmudgeon-I might have what we might call Russell Complement preferences. My preference is simply that the SWF be maximized. What is the analyst to do with that? Or, I might prefer simply that your preferences be maximized, adding my vote to yours. Or I might prefer that whatever you prefer not be the case-I am a sort of parasitic negator, the "you-diagonalizer" or "anti-you." And of course I can extend the "pro-you" case to my family or loved-ones more generally, and the "anti-you" case to your family (if you are a Hatfield and I a McCoy) or your ethnic group (if I am a loathsome damn racist).

Now it happens that preferences of these sorts can render constrained optimization problems of the kind SWFs are employed in formulating and solving quite incapable of determinate solution. The only way to get around such problems is to impose certain assumptions upon the behavior of individual preference functions. Most such assumptions turn out to be quite implausible as an empirical matter. But for present purposes, empirical implausibility is the least of our problems. For the real point here is that "imposing" such assumptions is, once again, departing from the stated position of "welfarist" analysts, which is, again, that all preferences are to be taken as they are, how ever arbitrary or pathological these might be from an ethical or social policy point of view. And once again we find that the problems could readily have been foreseen, and the consequent incoherence avoided, had our analysts simply kept mindful of self-referential phenomena. We find here yet another instance, then, of how attending to one Cantorian 
decision-point assists in satisfactorily dealing with the other.

\subsection{Thin Intensionalism Again: Fair Welfare}

Let's pause for a moment to take stock. Where do the considerations we've run through in this Part now leave us? Well, consider: On the one hand, we noted that "pluralist" considerations rooted in liberal autonomy make at least some form of "individualist" welfarism attractive when it comes to construing the notion of "social welfare." We reasonably hold that what each of us prefers or desires, and in that sense values, must "count" in some way in characterizing the circumstances in which a "society" can be said to be faring well. To deny this is to deny a cardinal value of our political culture - a value we found also at work in constraining plausible answers to jurisprudential questions in Part 3. To deny it would be to accord somebody-some individual or some class falling short of the full class of citizens-some form of nondemocratic, "dictatorial" authority in determining what's "good" for other citizens. A "thick" form of normative intensionalism such as that would be is just not acceptable. Some form or degree of "extensionalism"-i.e., the recognition of some sphere within which individuals, each individual, may value things arbitrarily, simply according to taste-then must be deemed socially compelling at the first of our Cantorian decision points in welfare economic analysis.

By the same token, however, we have seen that no "full-bore" such extensionalism can be normatively coherent. It is impossible coherently to prescribe that no value other than individuals' arbitrary preferences shall determine the degree to which a society is faring well. For without some additional such value, there is no society to fare well or ill at all, nor is there any "Archimedian point" from which an "analyst" can coherently deem possible worlds "better" or "worse" simpliciter, rather than "better" or "worse" simply in one or another individual's subjective estimation. The analyst in order to pass judgments on worlds must in effect pass some judgment on preferences, even if only a "structuring" such judgment of the sort that determines here SWF's aggregation rule. In thus judging, moreover, the analyst privileges something like "meta-preferences"-normative principles, which adjudicate between individuals' preferences in aggregating-of her own. At the very least, she privileges such meta-preferences or principles in determining what sentient creatures' preferences will figure into her SWF's domain and thus "count," and in determining how to count-how to aggregate-those preference schedules she does count. So some residue of intensionalism must remain in any judgment of social welfare as distinguished from individual preference 
satisfaction. And this "first decision point" truth shows up with particular clarity, yet again, when the analyst reflects upon her own activity in normative analysis-i.e., when she thinks seriously at the second Cantorian decision point.

We've seen this before, have we not? Thick intensionalism is unacceptable, full-bore extensionalism is impossible. That was the case, as we saw, in foundational mathematics, and it was the case in foundational law. The upshot, in those cases, was that only a "thin" form of intensionalism is viable. And so it is here. What's "thin intensionalism" here? It is, I submit, what we might call "just welfarism"-i.e., distributively just satisfaction of preferences. What does that mean, and what does it mean for the practice of a normatively coherent welfare economics? I think it means this: Our SWFs, at least if we wish to continue formulating them as maximization formulae, must indeed quantify over individual preference functions. But they must also in effect quantify over one thing more-one " $\bullet, "$ in the idiom introduced above. The "•" in this case is the incumbency of a conception of just distribution, just distribution of welfare itself. This is the conceptually indispensible structuring or patterning value that must accompany what we might call the "named beneficiary" value in fashioning any normatively coherent SWF. The named beneficiaries are of course the persons whose preferences count in determining the social welfare aggregate. The patterning value is simply the value pursuant to which those plural preferences are adjudicated, structured, in a word "aggregated."

Now, strictly speaking, the patterning value need not be named. It can simply be manifest in the pattern-the "internal" aggregation structure of the SWF. But it seems that our leaving it un-named foments confusion, the sort of confusion that's starkly evident in the nonsense-locutions I referenced above-pseudo-phrases like "fairness versus welfare." Perhaps if we named patterning values in the SWF itself, or named their incumbency, they would be less apt to escape notice; or perhaps at any rate the analysts' own activity and de facto adjudicative role over individual preferences - and indeed, it is "over" them-would not escape notice. And when these things do escape notice, we've seen, prescriptive incoherence quite quickly ensues.

There is another reason we might wish to name patterning values or their incumbency in our SWFs: It is that, for a society indeed to endure stably through time as a cooperative structure of persons whose day to day preferences and indeed views of the good can conflict, it is quite salutary for all citizens to share at least one "thin" and minimal "meta-intention," as we saw above in Part 3. It is a structural intention-an intention concerning the sustainability of a stable sociopolitical structure within which individual pursuits of "the good" or of 
self-defined "welfare" can be carried on. It is, therefore, in a word, a collective intention to maintain a just order. The incumbency named by the "•" in this case would be that-the incumbency of this shared commitment to a just-i.e., a fair-order within which individual pursuits of autonomously defined welfare or "the good" are pursued.

I now hasten to add one more point: Recall that all that I just said I predicated on the antecedent, "if we wish still to formulate our SWFs as maximization formulae." I think we'd do better, both for what I'll call "operational" reasons and for reasons of perspicuity, to recast our SWFs from maximization into equalization formulae. Formulae of the one kind are readily reformulated into formulae of the other, no matter from which side of the divide we begin. But the equalization formulae are preferable precisely because they more transparently fix upon what is at stake.

Here is the idea in a nutshell:277 The ethical considerations that go into formulating an aggregation rule, and even into selecting an SWF's argument domain, for that matter, always seem to take individuals to be equals in one or another respect adjudged to be ethically relevant. The classical Utilitarian rule, for example, treats them as equals in respect of their utility functions and thus sums over the latter in unweighted form. ${ }^{278}$ Now any such summand implies a complement equalisand embracing all attributes of individuals considered not to be ethically relevant. An opportunity-egalitarian distribution rule, for example, deems factors beyond an individual's control to be ethically arbitrary, hence judges that such factors' effects should be equalized across individuals. Call the latter equalisand "ethically exogenous opportunity and risk," or if you prefer, simply "opportunity" for short. (The longer form is better because we "make" some of "our own" opportunities and risks; they're not all of them accidents, some are what we can call "ethically endogenous.") Now index such opportunity individual by individual and symbolize it thus: "Oi" (Please think of this, not as spelling out a familiar East End London ejaculation, but as standing for person $i$ 's opportunity.)

Now call that which the individual produces out of such opportunity-something which I think our earlier-mentioned commitments to autonomy commit us to allowing her to maximize untrammeled-"ethically cognizable welfare," and symbolize it thus: "WEi." (Please think of this as standing for person $i$ 's ethically $(E)$ cognizable welfare $(W)$.) Then an opportunity-egalitarian social welfare

277 See Hockett, Taking Distribution Seriously, supra note 254 , for fuller account.

278 Because I can't see the ethical relevance of utility functions for which persons are not responsible, utilitarianism seems to me fetishist for precisely this reason; it's like summing over randomly distributed endorphin counts, or even over foreheads. But we need not argue the point here. See $i d$. for more. 
function can be formulated either thus: $\forall i$ : Max $\sum W_{E i}$, or equivalently and operationally more helpfully, $\forall i$ : Eq Oi. The appropriately characterized-i.e., ethically contoured or "weighted"-summand in the first formula corresponds as full complement to the equalisand of the second formula. And because the most direct way, operationally speaking, to ensure that the first formula is satisfied is by acting on the second formula (maximization of the first will "take care of itself," i.e. will follow directly, upon our satisfying the second), formulae of the second type will prove ultimately more helpful to those who implement policy. Our attachment to maximization formulae even in the social and not just the individual context, I think, is simply a relic. It is a relic partly of the conflations we noted above-of positive preference with normative welfare - and is a relic partly as well of the mathematical methods that happened to be prevalent in the most admired natural sciences during a formative period of welfare economics. ${ }^{279} \mathrm{It}$ is, in any event, a relic that's now easily and best-advisedly dispensed with.

But that will do for now. I hope that in all events the point that I hoped to make here has been made: Once again careful reflection at a discipline's analogue to the second Cantorian decision point has enabled us more readily to spot the correct resolution of long stalemate at that discipline's analogue to the first such decision point. Once again we find that a form of "thin" intensionalism is, in contrast to "thick" such intensionalism or full-bore extensionalism, both friendly to freedomwhich thick intensionalism is not-and conceptually coherent-which full-bore extensionalism is not. In this, welfare economic case, the thin form of intensionalism seems to be what might well be called, "fair welfarism." It amounts to a conception of the just distribution of welfare itself.

\section{CONCLUDING THOUGHTS}

We have come a long way since beginning. And I fear that to say much more by way of summing things up would just try your patience at the end of what has already been a long trip. Let me conclude, then, by saying that I think what we've found here might well be more widely applicable. The requirement of meaning-of intension-I think is deeply and universally human. And the requirement of meaning is a requirement of a certain form of boundedness, the finiteness that comes with definiteness, with intelligibility. But the truth of infinitude, of ultimate freedom, of the capacity for arbitrariness, is also always with us, and generally cannot be banished save by trampling upon the value

279 See Hockett, The Impossibility of a Prescriptive Paretian, supra note 261, for more on this. 
of intelligibility and, generally, other normative commitments themselves. That is the "tragedy" found at the first of the Cantorian decision points.

The only way out of the impasse, it seems, is to insist upon a core minimum of meaning that all can share and that all must share in order that freedom itself remain sensical. That is what I have been calling a "thin" form of intensionalism. We find both the need and the possibility of such thin forms of intensionalism, I've argued, when we turn to that which turned up at the second Cantorian decision point-self-reference, reflectivity. And in a sense, this is not really surprising. For we best confront both our own finitude, and our infinitude, when we confront both ourselves and the fact that we're able to confront ourselves. Our need for meaning, and our meaning, and our sense of the meaningless, all coexist at their most poignant in that confrontation. It is scarce wonder that our two principal heroes, above, in laying out the terms of the confrontation-Cantor and Wittgenstein-each of them both at times struggled with madness. Let it be our fate to sweeten the confrontation. 